\title{
Apoptosis inducing 1,3,4-oxadiazole conjugates of Capsaicin: Their in vitro anti-proliferative and in silico studies
}

\author{
Fatima Naaz, ${ }^{\Uparrow}$ Faiz Ahmad, ${ }^{\dagger}$ Bilal Ahmad Lone, ${ }^{\dagger}$ Arif Khan,, \\ Kalicharan Sharma, ${ }^{\#}$ Intzar Ali, ${ }^{\mathrm{T}}$ M. ShaharYar, ${ }^{*}$ Yuba Raj Pokharel, ${ }^{* *}$ Syed Shafi. ${ }^{\text {I* }}$
}

IDepartment of Chemistry, School of Chemical and Life Science, Jamia Hamdard, New Delhi110062, India;

$\dagger$ Faculty of Life Sciences and Biology, South Asian University, New Delhi-110021;

\#Department of Pharmaceutical Chemistry, School of Pharmaceutical Education and Research, Jamia Hamdard, New Delhi-110062, India;

${ }^{\mathrm{F}}$ Department of Medical Microbiology Hamdard Institute of Medical Studies and Research, Jamia Hamdard, New Delhi-110062, India.

\section{Content}

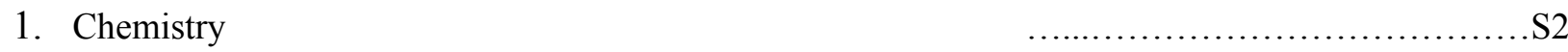

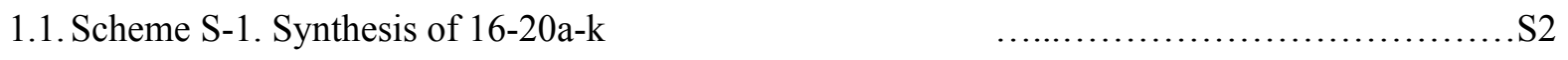

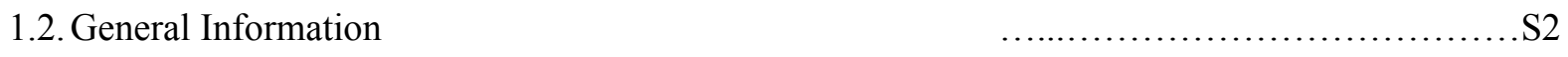

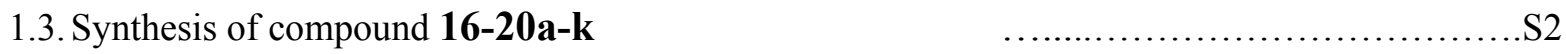

1.4. Scheme S-2. Synthesis of compound 21, 22a-b. $\quad$.............................

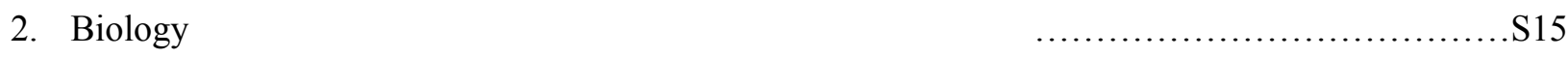

2.1 In vitro anti-proliferative assay $\quad$............................... 15

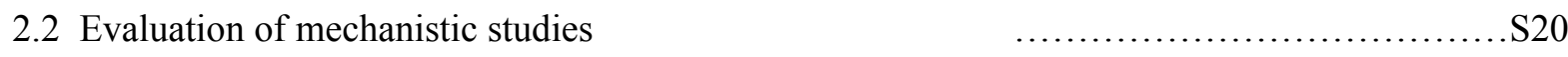

2.3. Molecular studies $\quad$................................ 22

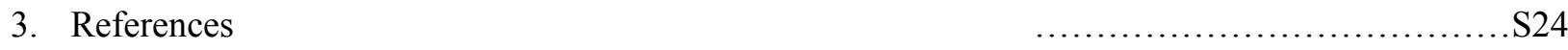

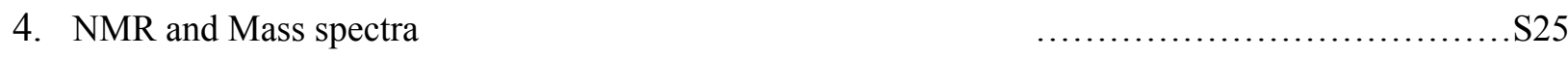




\section{Chemistry}

\subsection{Scheme S-1. Synthesis of compound $20 \mathrm{a}-\mathrm{k}$}

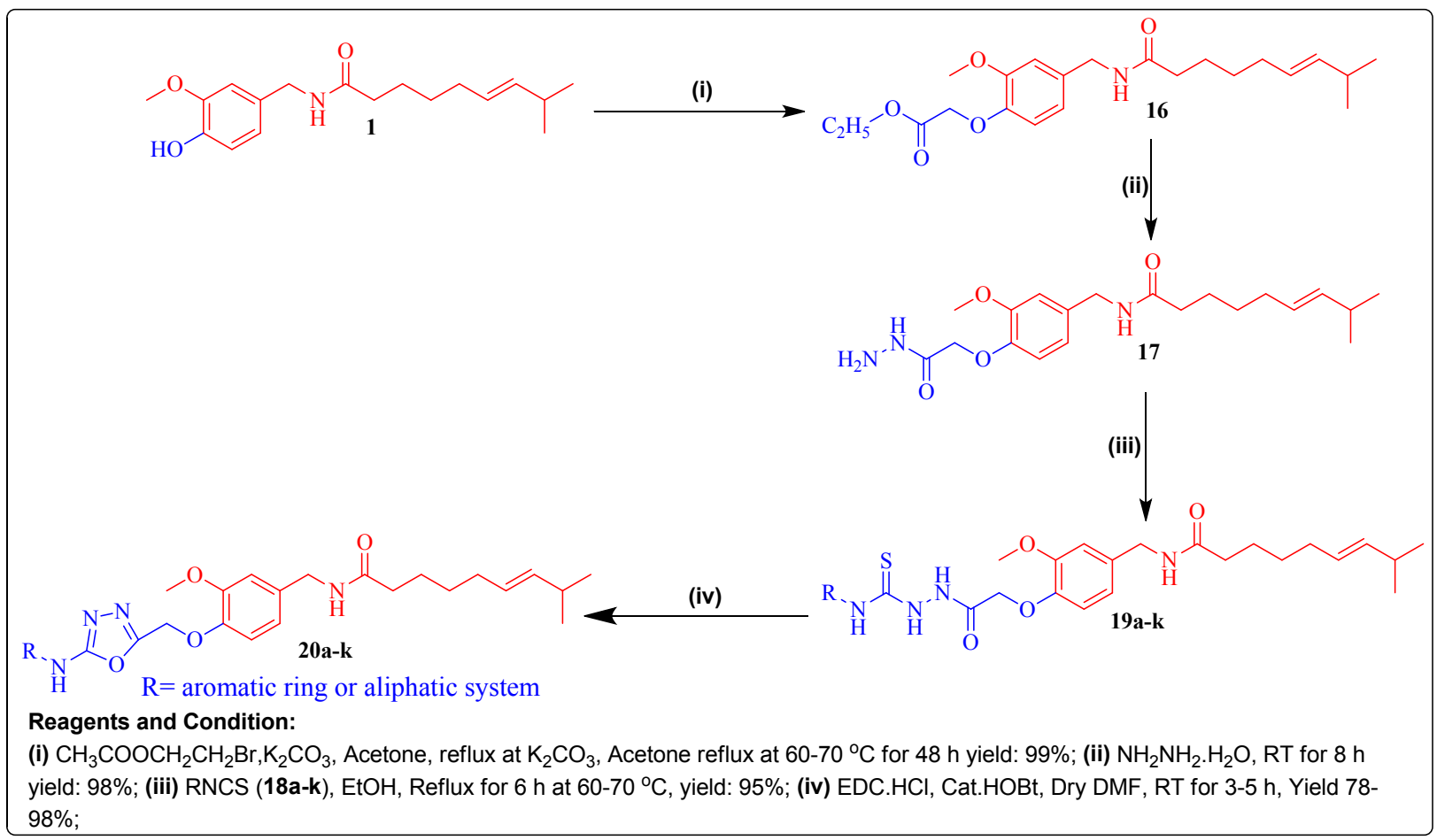

\section{Scheme S-1}

\subsection{General information}

All the chemicals and reagents used in the study were purchased from Merck (India), Spectrochem, and Sigma Aldrich which were of reagent grade. TLC was performed for indication of reaction completion on $0.25 \mathrm{~mm}$ silica gel $60-\mathrm{F} 254$ plates. UV light was used to visualize spots. Melting points of all the synthesized compounds were measured using Buchi labortechnik AG 9230 automated melting point apparatus (Switzerland); IR spectra were recorded on Bruker ALPHA FT-IR spectrometer (Germany), ${ }^{1} \mathrm{H}$ and ${ }^{13} \mathrm{C}$ NMR spectra were determined on a Bruker $(300 \mathrm{MHz}$ and $75 \mathrm{MHz})$ spectrometer and chemical shifts were expressed as ppm against TMS as internal reference. Solvent peak of $\mathrm{CDCl}_{3}$ in ${ }^{1} \mathrm{H} \mathrm{NMR}$ was observed at $7.26 \mathrm{ppm}$ and in ${ }^{13} \mathrm{C}$ observed at $77.28-76.77 \mathrm{ppm}$. A residual DMSO- $\mathrm{d}_{5}{ }^{1} \mathrm{H}$ NMR signal is observed at $2.52 \mathrm{ppm}$. Mass spectra's were recorded on ESI-MS. CHNS elemental analysis of synthesized compounds has been done on Vario EL III Elementar Equipment All compounds prepared in this paper are novel and confirmed with spectral data. All the synthesized compounds were recrystallized in methanol and were purified by column chromatography. 


\subsection{Synthesis of compound 16-20a-k.}

\subsubsection{Synthesis of (E)-ethyl 2-(2-methoxy-4-((8-methylnon-6- enamido)methyl)phenoxy)acetate (16)}

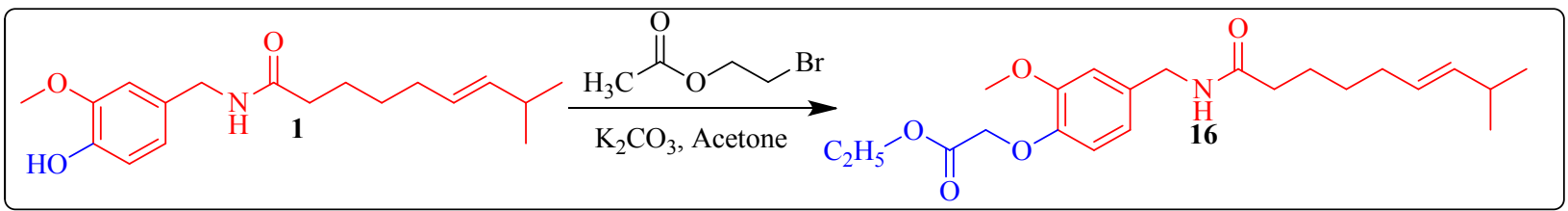

$1 \mathrm{~g}$ of capsaicin 1 was dissolved in $10 \mathrm{~mL}$ of dry acetone. Then $0.54 \mathrm{~g}$ of activated potassium carbonate was added to the reaction mixture and was allowed to stir for $10 \mathrm{~min}$. after $10 \mathrm{~min}, 0.5$ $\mathrm{mL}$ (1.2 equiv.) of bromoethyl acetate was added and refluxed at $60-70{ }^{\circ} \mathrm{C}$ for $48 \mathrm{~h}$. Completion of reaction was monitored by doing TLC (4:6 ratio of ethylacetate:hexane) and anisaldehyde was used as spraying agent for detection of TLC. After completion, reaction mixture was poured into ice and white colour solid was produced which was further filtered and dried under vacuum.

${ }^{1} \mathrm{H}$ NMR (400 MHz, DMSO- $\left.d_{6}\right) \delta(\mathrm{ppm}): 8.24(\mathrm{~s}, 1 \mathrm{H}), 6.87(\mathrm{~s}, 1 \mathrm{H}), 6.79(\mathrm{~d}, J=8 \mathrm{~Hz}, 1 \mathrm{H}), 6.71$ $(\mathrm{s}, J=8.4 \mathrm{~Hz}, 1 \mathrm{H}), 5.40-5.29(\mathrm{~m}, 2 \mathrm{H}), 4.71(\mathrm{~s}, 1 \mathrm{H}), 4.18-4.10(\mathrm{~m}, 4 \mathrm{H}), 3.75(\mathrm{~s}, 3 \mathrm{H}), 2.11(\mathrm{t}, J=$ 7.2 Hz, 2H), 1.96-1.91 (m, 2H), 1.55-1.48 (m, 2H), 1.33-1.19 (m, 6H), 0.93 (d, J=6.8 Hz, 4H), $0.85(\mathrm{~d}, J=6.4 \mathrm{~Hz}, 2 \mathrm{H})$.

MS (ESI) $m / z:[\mathrm{M}-1]^{+} 390.1$.

\subsubsection{Synthesis of (E)-N-(4-(2-hydrazinyl-2-oxoethoxy)-3-methoxybenzyl)-8-methylnon-6- enamide (17)}

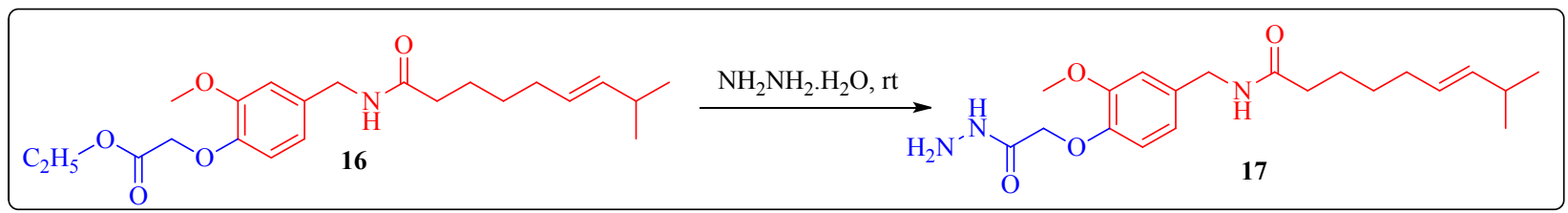

To $2 \mathrm{ml}$ of hydrazine hydrate, $1.4 \mathrm{~g}$ of compound $\mathbf{1 6}$ was added and reaction mixture was stirred for $8 \mathrm{~h}$ at room temperature. Completion of reaction was examined by TLC (6:4 ratio of ethylacetate:hexane). A white colour solid was produced within the reaction mixture which was further carried to filter off and dried under high vacuum pump. 
${ }^{1} \mathrm{H}$ NMR (400 MHz, DMSO-d $d_{6} \delta(\mathrm{ppm}): 9.14(\mathrm{~s}, 1 \mathrm{H}), 8.42(\mathrm{t}, J=5.6 \mathrm{~Hz}, 1 \mathrm{H}), 6.86(\mathrm{~d}, J=8.4$ $\mathrm{Hz}, 2 \mathrm{H}), 6.72(\mathrm{~d}, J=8 \mathrm{~Hz}, 1 \mathrm{H}), 4.42(\mathrm{~s}, 2 \mathrm{H}), 4.33(\mathrm{~s}, 2 \mathrm{H}), 4.18$ (d, J=6.0 Hz, 2H), 3.75 (s, 3H), $2.11(\mathrm{t}, J=7.2 \mathrm{~Hz}, 2 \mathrm{H}), 1.53-1.48(\mathrm{~m}, 3 \mathrm{H}), 1.23(\mathrm{~s}, 6 \mathrm{H}), 0.84(\mathrm{~d}, J=6.8 \mathrm{~Hz}, 6 \mathrm{H})$.

MS (ESI) $m / z:[\mathrm{M}+3]^{+} 380.4$.
1.3.3. Synthesis
of
(E)-N-(3-methoxy-4-(2-oxo-2-(2-

(phenylcarbamothioyl)hydrazinyl)ethoxy)benzyl)-8-methylnon-6-enamide (19a-k)

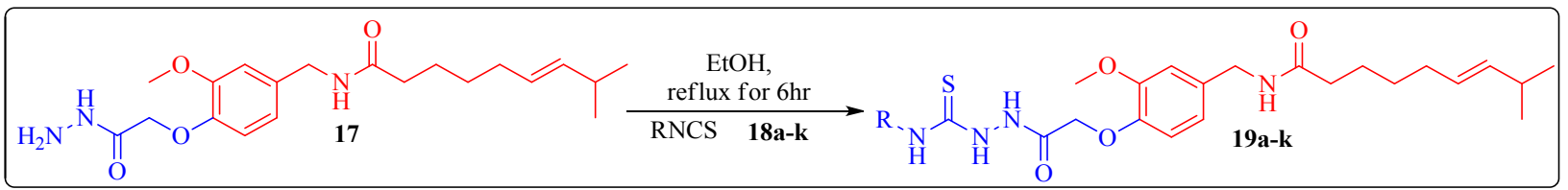

\section{General procedure A}

To ethanolic solution (absolute) of compound 17, different substituted aryl and alkyl isothiocyanates (18a-k) were added to it then the reaction mixture was refluxed for $6 \mathrm{~h}$ at $60-70$ ${ }^{\circ} \mathrm{C}$. Solid precipitate was formed in the reaction mixture was filtered of and washed with cold alcohol to yield compounds (19a-k). TLC was run in TEF 4:5:1 which indicate the completion of the reaction.

\subsubsection{Synthesis of (E)-N-(3-methoxy-4-(2-(2-((4-nitrophenyl)carbamothioyl)hydrazinyl)-} 2-oxoethoxy)benzyl)-8-methylnon-6-enamide (19a)

To $10 \mathrm{~mL}$ of absolute ethanol, $0.5 \mathrm{~g}$ of compound 17 was dissolved, followed by addition of $0.47 \mathrm{~g} \quad(1.2$

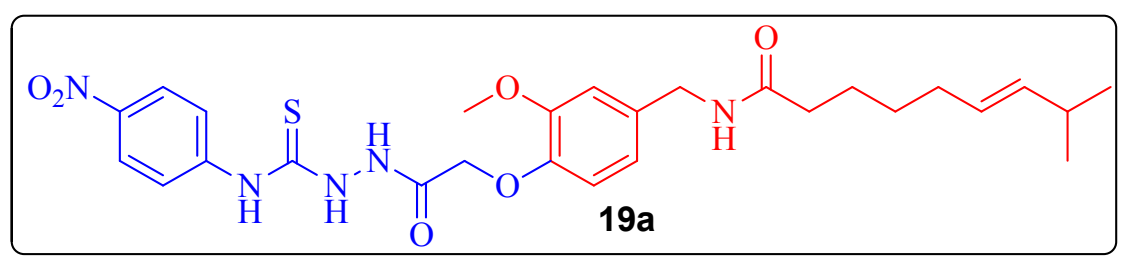
equivalents) of 1-isothiocyanato-4-nitrobenzene 18a. Reaction mixture was refluxed for $6 \mathrm{~h}$ at $60-70{ }^{\circ} \mathrm{C}$ and after completion of reaction; solid precipitate was formed in reaction mixture. These Solid precipitate was filtered off and dried to afford compound 19a.

${ }^{1} \mathrm{H}$ NMR (400 MHz, DMSO-d $)_{6} \delta(\mathrm{ppm}): 11.66(\mathrm{~s}, 1 \mathrm{H}), 10.24(\mathrm{~s}, 1 \mathrm{H}), 10.09$ (s , 1H), 9.93 (s, 1H), $8.23(\mathrm{~d}, J=8 \mathrm{~Hz}, 2 \mathrm{H}), 7.89(\mathrm{~d}, J=8 \mathrm{~Hz}, 2 \mathrm{H}), 6.89(\mathrm{~s}, 2 \mathrm{H}), 6.74(\mathrm{~d}, J=8 \mathrm{~Hz}, 1 \mathrm{H}), 4.61$ (s, 2H), 4.19 (d, $J=8 \mathrm{~Hz}, 2 \mathrm{H}), 3.71(\mathrm{~s}, 3 \mathrm{H}), 2.11(\mathrm{t}, J=8 \mathrm{~Hz}, 2 \mathrm{H}), 1.53-1.48$ (m, 3H), 1.39-1.36 (m, 1H), $1.24(\mathrm{~s}, 6 \mathrm{H}), 0.84(\mathrm{~d}, J=8 \mathrm{~Hz}, 6 \mathrm{H})$.

MS (ESI) $m / z:[\mathrm{M}+1]^{+} 558.5$. 


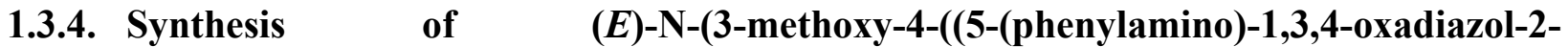

yl)methoxy)benzyl)-8-methylnon-6-enamide (20a-k)

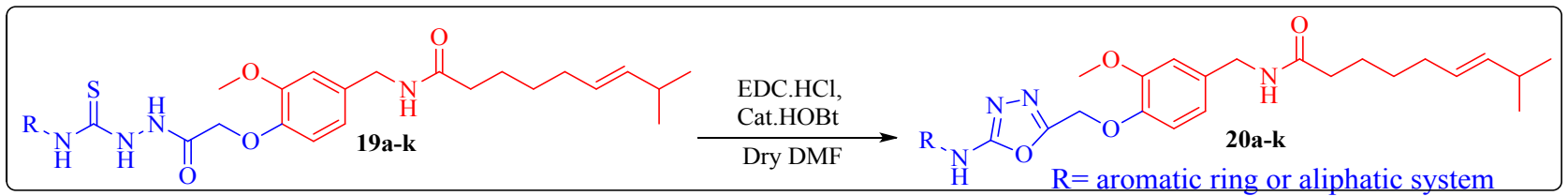

\section{General procedure B}

To $5 \mathrm{~mL}$ of dry dimethylformamide (DMF), $0.5 \mathrm{~g}$ of compound 19a-k and $0.52 \mathrm{~g}$ (3 equivalents) of $N$-(3-Dimethylaminopropyl)- $N$ '-ethylcarbodiimide hydrochloride (EDC.HCl) with catalytic amount of Hydroxybenzotriazole (HOBt) were added to it. Reaction mixture was stirred at room temperature for 3-5 h under inert atmosphere. After the completion of reaction monitored by TLC (TEF, 4:5:1), the reaction mixture was poured onto ice. The precipitate formed was filtered off, washed with excess of water, dried under high vacuum and recrystallized in ethanol to afford the title compound 20a-k in pure form.

\subsubsection{Synthesis of (E)-N-(3-methoxy-4-((5-((4-nitrophenyl)amino)-1,3,4-oxadiazol-2- yl)methoxy)benzyl)-8-methylnon-6-enamide (20a)}

According to general procedure A, To $5 \mathrm{~mL}$ of dry dimethylformamide (DMF), $0.5 \mathrm{~g}$ of compound 19a and $0.52 \mathrm{~g}(3$

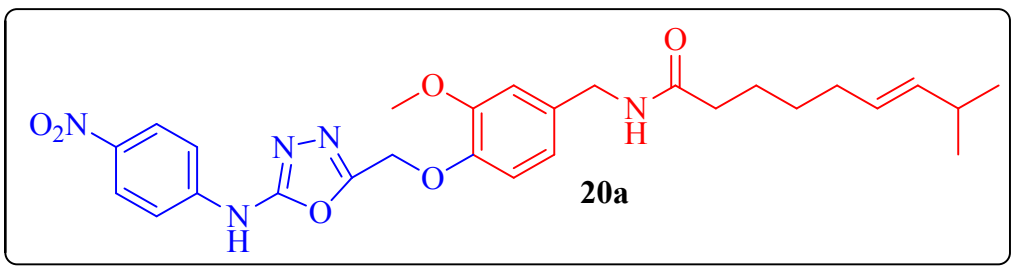
equivalents) of $N$-(3-Dimethylaminopropyl)- $N$ '-ethylcarbodiimide hydrochloride (EDC.HCl) with catalytic amount of Hydroxybenzotriazole (HOBt) were added to it. Reaction mixture was stirred at room temperature for 3-5 h under inert atmosphere. After the completion of reaction monitored by TLC (TEF, 4:5:1), the reaction mixture was poured onto ice. The precipitate formed was filtered off, washed with excess of water, dried under high vacuum and recrystallized in ethanol to afford the title compound $\mathbf{2 0 a - k}$ in pure form.

Creamish yellow; yield: $91 \%$.

Mp: $189.0{ }^{\circ} \mathrm{C}$.

IR cm$~^{-1}: 3487,3437,3384,3335,3285,3231,3200,3049,2990,2924,1668,1639,1590,1513$, $1459,1419,1325,1266,1230,1196,1142,1107,1014,955,846,770,738,679,619,546$.

${ }^{1} \mathrm{H}$ NMR (300 MHz, DMSO- $\left.d_{6}\right) \delta(\mathrm{ppm}): 10.97(\mathrm{~s}, 1 \mathrm{H}), 8.21$ (d, $\left.J=8.4 \mathrm{~Hz}, 2 \mathrm{H}\right), 7.76(\mathrm{~d}, J=8.4$ Hz, 2H), 7.09 (s, 1H), 6.99 (d, J=8.1 Hz, 1H), $6.88(\mathrm{~s}, 1 \mathrm{H}), 6.80(\mathrm{~d}, J=8.1 \mathrm{~Hz}, 1 \mathrm{H}), 5.22$ (s, 
2H), $4.34(\mathrm{~d}, J=5.1 \mathrm{~Hz}, 2 \mathrm{H}), 3.84(\mathrm{~s}, 3 \mathrm{H}), 2.21(\mathrm{t}, J=7.5 \mathrm{~Hz}, 2 \mathrm{H}), 1.64(\mathrm{t}, J=6 \mathrm{~Hz}, 2 \mathrm{H}), 1.54-$ $1.43(\mathrm{~m}, 1 \mathrm{H}), 1.28(\mathrm{~s}, 6 \mathrm{H}), 0.85(\mathrm{~d}, J=6.3 \mathrm{~Hz}, 6 \mathrm{H})$.

${ }^{13} \mathrm{C}$ NMR (75 MHz, DMSO- $d_{6}$ ) $\delta: 173.2,160.2,156.6,149.9,145.6,144.4,141.7,134.4,125.0$, 124.4, 120.6, 119.6, 116.6, 115.7, 111.7, 61.3, 55.6, 42.6, 36.3, 29.4, 29.2, 27.7, 27.0, 25.7, 22.5, 14.0.

HRMS (ESI) $m / z$ : $[\mathrm{M}+\mathrm{H}]^{+}$Calcd for $\mathrm{C}_{27} \mathrm{H}_{34} \mathrm{~N}_{5} \mathrm{O}_{6}$ 524.2509; Found 524.2513.

Anal. Calcd for $\mathrm{C}_{27} \mathrm{H}_{33} \mathrm{~N}_{5} \mathrm{O}_{6}$ : C, 61.94; H, 6.35; N, 13.38; O, 18.33\%, Found: C, 61.62; H, 6.24; $\mathrm{N}, 13.28 \%$.

\subsubsection{Synthesis of (E)-N-(4-((5-((3-chlorophenyl)amino)-1,3,4-oxadiazol-2-yl)methoxy)-3- methoxybenzyl)-8-methylnon-6-enamide (20b)}

According to general procedure A, Compound 19b was cyclized under coupling conditions with EDC.HCl and HOBt to yield desired compound

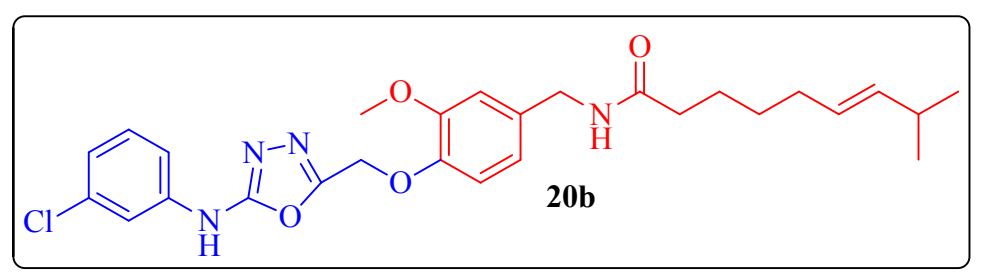
20b.

White solid, yield: $89 \%$.

Mp: $158.5^{\circ} \mathrm{C}$.

IR cm ${ }^{-1}: 3425,3387,3274,3228,3120,3093,3056,3006,2955,2922,1649,1596,1570,1544$, $1511,1475,1420,1262,1223,120,1082,1021,907,848,793,740,700,642,580$.

${ }^{1} \mathrm{H}$ NMR (300 MHz, $\left.\mathrm{CDCl}_{3}\right) \delta(\mathrm{ppm}):$ 7.60-7.57 (m, 1H), 7.43-7.36 (m, 2H), $7.04(\mathrm{~d}, J=7.8 \mathrm{~Hz}$, $1 \mathrm{H}), 6.96(\mathrm{~d}, J=8.4 \mathrm{~Hz}, 1 \mathrm{H}), 6.81(\mathrm{~s}, 1 \mathrm{H}), 6.74(\mathrm{~d}, J=6.3 \mathrm{~Hz}, 1 \mathrm{H}), 5.78(\mathrm{~s}, 1 \mathrm{H}), 5.20(\mathrm{~s}, 2 \mathrm{H})$, $4.36(\mathrm{~d}, J=5.7 \mathrm{~Hz}, 2 \mathrm{H}), 3.83$ (s, 3H), 2.21 (t, $J=7.5 \mathrm{~Hz}, 2 \mathrm{H}), 1.76(\mathrm{~s}, 2 \mathrm{H}), 1.28-1.22(\mathrm{~m}, 7 \mathrm{H})$, $0.85(\mathrm{~d}, J=6.6 \mathrm{~Hz}, 6 \mathrm{H})$.

HRMS (ESI) $m / z$ : $[\mathrm{M}+\mathrm{H}]^{+}$Calcd for $\mathrm{C}_{27} \mathrm{H}_{34} \mathrm{ClN}_{4} \mathrm{O}_{4}$ 513.2269; Found 513.2272.

Anal. Calcd for $\mathrm{C}_{27} \mathrm{H}_{33} \mathrm{ClN}_{4} \mathrm{O}_{4}: \mathrm{C}, 63.21 ; \mathrm{H}, 6.48 ; \mathrm{Cl}, 6.91 ; \mathrm{N}, 10.92 ; \mathrm{O}, 12.47 \%$, Found: $\mathrm{C}$, 63.17; H, 6.41; N, $10.83 \%$.

\subsubsection{Synthesis of (E)-N-(4-((5-((4-chlorophenyl)amino)-1,3,4-oxadiazol-2-yl)methoxy)-3- methoxybenzyl)-8-methylnon-6-enamide (20c)}

According to general procedure A, Compound 19c was cyclized under coupling conditions with EDC.HCl and HOBt to yield desired compound 20c. 
White solid, yield: $98 \%$.

Mp: $175.9{ }^{\circ} \mathrm{C}$.

IR cm ${ }^{-1}: 3457,3419,3387,3323,3223$,

3235, 3197, 3120, 3024, 2995, 2926,

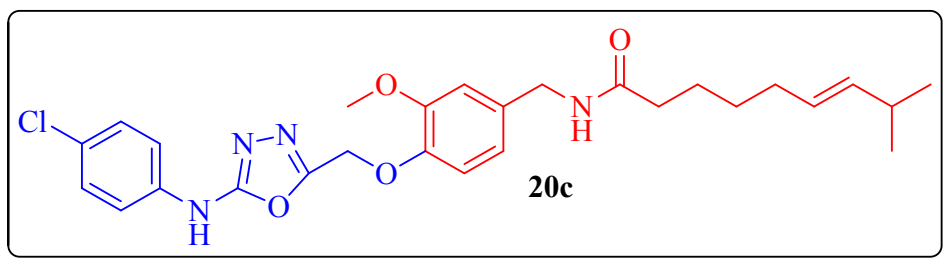

$1651,1621,1572,1515,1462,1416,1317,1267,1224,1139,1018,963,843,806,754,707$, $671,612$.

${ }^{1} \mathrm{H} \mathrm{NMR}\left(300 \mathrm{MHz}, \mathrm{CDCl}_{3}\right) \delta(\mathrm{ppm}): 8.31(\mathrm{~d}, J=7.5 \mathrm{~Hz}, 1 \mathrm{H}), 7.56(\mathrm{~d}, J=7.5 \mathrm{~Hz}, 1 \mathrm{H}), 7.47(\mathrm{~s}$, 1H), 7.40-7.35 (m, 1H), 7.02-6.94 (m, 1H), $6.86(\mathrm{~s}, 1 \mathrm{H}), 6.79(\mathrm{~d}, J=7.5 \mathrm{~Hz}, 1 \mathrm{H}), 5.70(\mathrm{~s}, 1 \mathrm{H})$, $5.23(\mathrm{~s}, 2 \mathrm{H}), 4.38(\mathrm{~d}, J=5.1 \mathrm{~Hz}, 2 \mathrm{H}), 3.86(\mathrm{~s}, 3 \mathrm{H}), 2.20(\mathrm{t}, J=6.6 \mathrm{~Hz}, 2 \mathrm{H}), 1.65$ (s, 2H), $1.53-$ $1.48(\mathrm{~m}, 1 \mathrm{H}), 1.28(\mathrm{~s}, 6 \mathrm{H}), 0.85(\mathrm{~d}, J=6.3 \mathrm{~Hz}, 6 \mathrm{H})$.

${ }^{13} \mathrm{C}$ NMR $\left(75 \mathrm{MHz}, \mathrm{CDCl}_{3}\right) \delta: 172.9,156.8,146.0,135.0,133.8,132.4,128.8,124.1,120.0$, 118.6, 115.7, 111.9, 111.4, 61.3, 55.9, 43.3, 38.9, 36.8, 29.6, 29.3, 27.9, 27.2, 25.7, 22.6.

HRMS (ESI) $m / z:[\mathrm{M}+\mathrm{H}]^{+}$Calcd for $\mathrm{C}_{27} \mathrm{H}_{34} \mathrm{ClN}_{4} \mathrm{O}_{4}$ 513.2269; Found 513.2270.

Anal. Calcd for $\mathrm{C}_{27} \mathrm{H}_{33} \mathrm{ClN}_{4} \mathrm{O}_{4}$ : C, 63.21; H, 6.48; Cl, 6.91; N, 10.92; O, 12.47\%, Found: $\mathrm{C}$, 63.17 ; H, 6.31; N, 10.83\%.

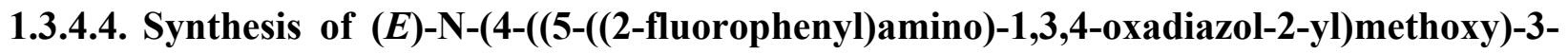 methoxybenzyl)-8-methylnon-6-enamide (20d)}

According to general procedure A, Compound 19d was cyclized under coupling conditions with EDC.HCl and HOBt to yield desired compound 20d.

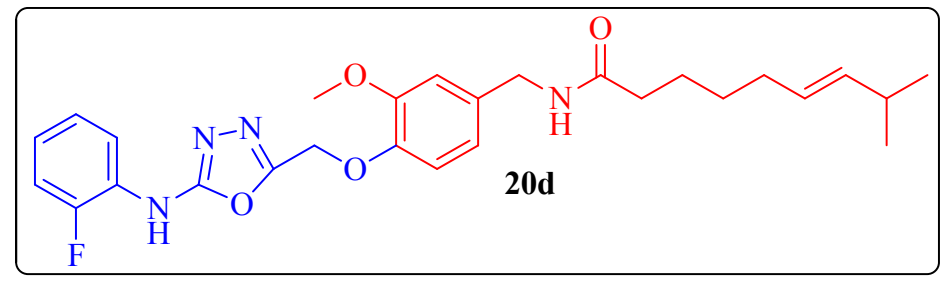

White solid, yield: $78 \%$.

Mp: $141.4{ }^{\circ} \mathrm{C}$.

IR cm ${ }^{-1}: 3473,3432,3375,3321,3260,3201,3122,3048,2922,1651,1639,1581,1557,1518$, $1460,1426,1389,1271,1221,1134,1029,851,814,730,690,645,618,560$.

${ }^{1} \mathrm{H}$ NMR (300 MHz, $\left.\mathrm{CDCl}_{3}\right) \delta(\mathrm{ppm}): 8.13(\mathrm{t}, J=8.1 \mathrm{~Hz}, 1 \mathrm{H}), 7.25(\mathrm{~s}, 1 \mathrm{H}), 7.13-7.05(\mathrm{~m}, 2 \mathrm{H})$, 7.02-6.90 (m, 2H), 6.77(s, 1H), 6.70 (d, $J=7.8 \mathrm{~Hz}, 1 \mathrm{H}), 5.67$ (s, 1H), 5.13 (s, 2H), 4.29 (d, $J=$ $5.7 \mathrm{~Hz}, 2 \mathrm{H}), 3.77(\mathrm{~s}, 1 \mathrm{H}), 2.13(\mathrm{t}, J=7.2 \mathrm{~Hz}, 2 \mathrm{H}), 1.91(\mathrm{q}, J=6.6 \mathrm{~Hz}, 1 \mathrm{H}), 1.61-1.56(\mathrm{~m}, 4 \mathrm{H})$, $1.04-1.31(\mathrm{~m}, 2 \mathrm{H}), 1.31-1.21(\mathrm{~m}, 2 \mathrm{H}), 0.87(\mathrm{~d}, J=6.6 \mathrm{~Hz}, 3 \mathrm{H}), 0.78(\mathrm{~d}, J=6.6 \mathrm{~Hz}, 3 \mathrm{H})$. 
${ }^{13} \mathrm{C}$ NMR $\left(75 \mathrm{MHz}, \mathrm{CDCl}_{3}\right) \delta: 173.3,160.9,159.7,156.3,150.0,145.9,133.7,119.8,119.4$, 119.3, 116.0, 115.8, 115.6, 111.8, 61.25, 55.8, 43.2, 38.9, 36.8, 29.6, 29.3, 27.9, 27.2 25.8, 22.6; HRMS (ESI) $m / z:[\mathrm{M}+\mathrm{H}]^{+}$Calcd for $\mathrm{C}_{27} \mathrm{H}_{34} \mathrm{FN}_{4} \mathrm{O}_{4}$ 497.2564; Found 497.2565.

Anal. Calcd for $\mathrm{C}_{27} \mathrm{H}_{33} \mathrm{FN}_{4} \mathrm{O}_{4}$ : C, 65.31; H, 6.70; F, 3.83; N, 11.28; O, 12.89\%, Found: C, 65.28; H, 6.63; N, 11.19\%.

\subsubsection{Synthesis of $(E)-\mathrm{N}-(4-((5-((4-f l u o r o p h e n y l) a m i n o)-1,3,4-0 x a d i a z o l-2-y l) m e t h o x y)-3-$ methoxybenzyl)-8-methylnon-6-enamide (20e)}

According to general procedure A, Compound 19e was cyclized under coupling conditions with EDC.HCl and HOBt to yield desired compound 20e.

White solid; yield: $98 \%$.

Mp: $154.3^{\circ} \mathrm{C}$.

IR $\mathrm{cm}^{-1}: 3472,3438,3385,3322$, $3263,3205,3123,3050,2928$,

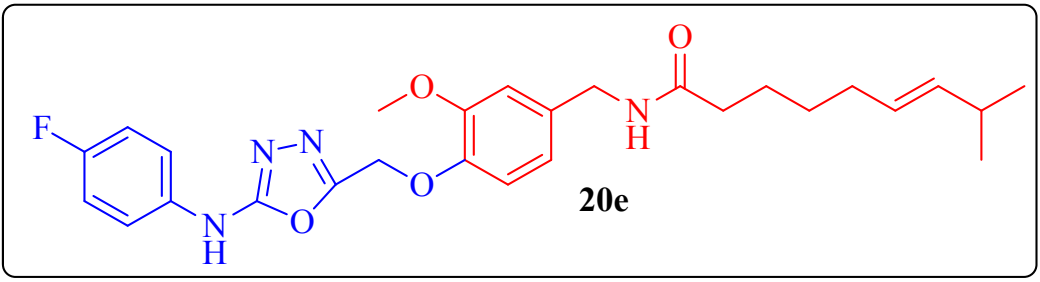
$1649,1626,1579,1549,1511,1455,1420,1388,1266,1218,1137,1020,843,808,722,683$, $634,610,552$.

${ }^{1} \mathrm{H}$ NMR (300 MHz, $\left.\mathrm{CDCl}_{3}\right) \delta(\mathrm{ppm}): 8.26(\mathrm{~s}, 1 \mathrm{H}), 7.46(\mathrm{q}, J=4.2 \mathrm{~Hz}, 2 \mathrm{H}), 7.02$ (t, $J=8.4 \mathrm{~Hz}$, 2H), $6.90(\mathrm{~d}, J=8.1 \mathrm{~Hz}, 1 \mathrm{H}), 6.78(\mathrm{~s}, 1 \mathrm{H}), 6.70(\mathrm{~d}, J=8.4 \mathrm{~Hz}, 1 \mathrm{H}), 5.93(\mathrm{~s}, 1 \mathrm{H}), 5.15(\mathrm{~s}, 1 \mathrm{H})$, $4.34(\mathrm{~d}, J=5.4 \mathrm{~Hz}, 1 \mathrm{H}), 3.78(\mathrm{~s}, 3 \mathrm{H}), 2.21(\mathrm{t}, J=7.2 \mathrm{~Hz}, 2 \mathrm{H}), 1.65(\mathrm{t}, J=6.6 \mathrm{~Hz}, 2 \mathrm{H}), 1.53-1.41$ (m, 1H), $1.26(\mathrm{~s}, 1 \mathrm{H}), 0.84(\mathrm{~d}, J=6.6 \mathrm{~Hz}, 6 \mathrm{H})$.

${ }^{13} \mathrm{C}$ NMR (75 MHz, $\left.\mathrm{CDCl}_{3}\right) \delta: 173.3,160.9,159.7,156.3,150.0,145.9,133.7,119.8,119.4$, 119.3, 116.0, 115.8, 115.6, 111.8, 61.25, 55.8, 43.2, 38.9, 36.8, 29.6, 29.3, 27.9, 27.2, 25.8, 22.6; HRMS (ESI) $m / z:[\mathrm{M}+\mathrm{H}]^{+}$Calcd for $\mathrm{C}_{27} \mathrm{H}_{34} \mathrm{FN}_{4} \mathrm{O}_{4}$ 497.2564; Found 497.2568.

Anal. Calcd for $\mathrm{C}_{27} \mathrm{H}_{33} \mathrm{FN}_{4} \mathrm{O}_{4}$ : C, 65.31; H, 6.70; F, 3.83; N, 11.28; O, 12.89\%, Found: C, 65.27; $\mathrm{H}, 6.64 ; \mathrm{N}, 11.21 \%$.

\subsubsection{Synthesis of (E)-N-(3-methoxy-4-((5-((2-methoxyphenyl)amino)-1,3,4-oxadiazol-2- yl)methoxy)benzyl)-8-methylnon-6-enamide (20f)}

According to general procedure A, Compound 19f was cyclized under coupling conditions with EDC. $\mathrm{HCl}$

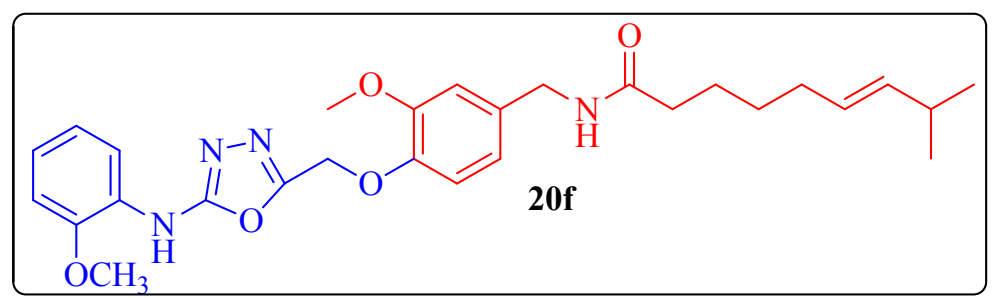


and HOBt to yield desired compound $20 f$.

White solid; Yield 95\%.

Mp: $104.7^{\circ} \mathrm{C}$.

IR cm ${ }^{-1}$ : 3491, 3413, 3390, 3353, 3307, 3223, 3194, 3108, 3054, 2998, 2923, 1629, 1577, 1520 , $1460,1421,1391,1250,1217,1137,1018,976,918,849,805,736,670,642,581$.

${ }^{1} \mathrm{H}$ NMR $\left(300 \mathrm{MHz}, \mathrm{CDCl}_{3}\right) \delta(\mathrm{ppm}): 8.12(\mathrm{~d}, J=3.3 \mathrm{~Hz}, 1 \mathrm{H}), 7.55(\mathrm{~s}, 1 \mathrm{H}), 7.01(\mathrm{~d}, J=6.9 \mathrm{~Hz}$, 3H), 6.91-6.88 (m, 1H), $6.84(\mathrm{~s}, 1 \mathrm{H}), 6.78(\mathrm{~d}, J=7.8 \mathrm{~Hz}, 1 \mathrm{H}), 5.70(\mathrm{~s}, 1 \mathrm{H}), 5.21(\mathrm{~s}, 2 \mathrm{H}), 4.37$ (d, $J=5.4 \mathrm{~Hz}, 2 \mathrm{H}), 3.87$ (d, $J=16.8 \mathrm{~Hz}, 6 \mathrm{H}), 2.20$ (t, $J=7.8 \mathrm{~Hz}, 2 \mathrm{H}), 1.67-1.62(\mathrm{t}, J=6.3 \mathrm{~Hz}, 2 \mathrm{H})$, $1.54-1.43(\mathrm{~m}, 1 \mathrm{H}), 1.28(\mathrm{~s}, 6 \mathrm{H}), 0.84(\mathrm{~d}, J=6.6 \mathrm{~Hz}, 6 \mathrm{H})$.

${ }^{13} \mathrm{C}$ NMR $\left(75 \mathrm{MHz}, \mathrm{CDCl}_{3}\right) \delta: 172.97,160.5,156.4,150.2,147.0,146.1,133.6,126.9,122.8$, 121.3, 120.1, 117.1, 115.7, 111.9, 110.0, 61.4, 55.9, 55.8, 43.3, 38.9, 36.8, 29.6, 29.3, 27.9, 27.2, 25.8, 22.6.

HRMS (ESI) $m / z$ : [M + H] $]^{+}$Calcd for $\mathrm{C}_{28} \mathrm{H}_{37} \mathrm{~N}_{4} \mathrm{O}_{5}$ 509.2764; Found 509.2766.

Anal. Calcd for $\mathrm{C}_{28} \mathrm{H}_{36} \mathrm{~N}_{4} \mathrm{O}_{5}$ : C, 66.12; H, 7.13; N, 11.02; O, 15.73\%, Found: C, 66.06; H, 7.08; $\mathrm{N}, 10.98 \%$.

\subsubsection{Synthesis of (E)-N-(3-methoxy-4-((5-((4-methoxyphenyl)amino)-1,3,4-0xadiazol-2- yl)methoxy)benzyl)-8-methylnon-6-enamide (20g)}

According to general procedure A, Compound $19 \mathrm{~g}$ was cyclized under coupling conditions with EDC.HCl and HOBt to yield desired compound $\mathbf{2 0 g}$.

White solid, yield: $94 \%$.

Mp: $154.9^{\circ} \mathrm{C}$.

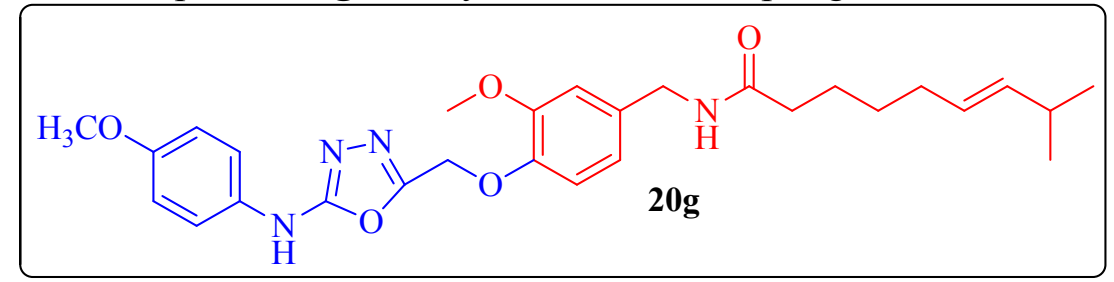

IR cm ${ }^{-1}: 3463,3424,3380,3273,3192,3138,3063,3007,2924,1650,1621,1576,1510,1451$, $1420,1383,1312,1239,1175,1015,965,836,691,634,581,557,535$.

${ }^{1} \mathrm{H}$ NMR (300 MHz, $\left.\mathrm{CDCl}_{3}\right) \delta(\mathrm{ppm}): 7.37(\mathrm{~d}, J=8.7 \mathrm{~Hz}, 2 \mathrm{H}), 7.05-6.98(\mathrm{~m}, 2 \mathrm{H}), 6.88(\mathrm{~d}, J=$ $9.0 \mathrm{~Hz}, 1 \mathrm{H}), 6.83(\mathrm{~s}, 1 \mathrm{H}), 6.76(\mathrm{~d}, J=8.4 \mathrm{~Hz}, 1 \mathrm{H}), 5.71(\mathrm{~s}, 1 \mathrm{H}), 5.18(\mathrm{~s}, 2 \mathrm{H}), 4.37$ (d, $J=5.7 \mathrm{~Hz}$, 2H), $3.82(\mathrm{~d}, J=6 \mathrm{~Hz}, 6 \mathrm{H}), 2.20(\mathrm{t}, J=7.2 \mathrm{~Hz}, 2 \mathrm{H}), 1.65-1.60(\mathrm{~m}, 2 \mathrm{H}), 1.52-1.48(\mathrm{~m}, 1 \mathrm{H}), 1.25$ (s, 6H), $0.85(\mathrm{~d}, J=6.6 \mathrm{~Hz}, 6 \mathrm{H})$.

MS (ESI) $m / z:[\mathrm{M}+1]^{+} 509$.

Anal. Calcd for $\mathrm{C}_{28} \mathrm{H}_{36} \mathrm{~N}_{4} \mathrm{O}_{5}$ : C, 66.12; H, 7.13; N, 11.02; O, 15.73\%, Found: C, 66.07; H, 7.06; $\mathrm{N}, 10.99 \%$. 


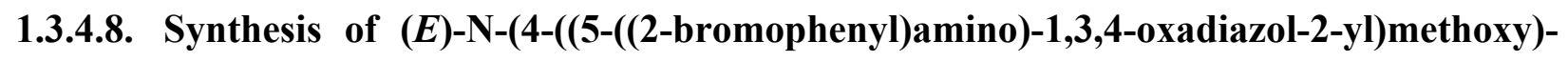
3-methoxybenzyl)-8-methylnon-6-enamide (20h)

According to general procedure A, Compound 19h was cyclized under coupling conditions with EDC.HCl and HOBt to yield desired compound $\mathbf{2 0 h}$.

White solid, yield: $83 \%$.

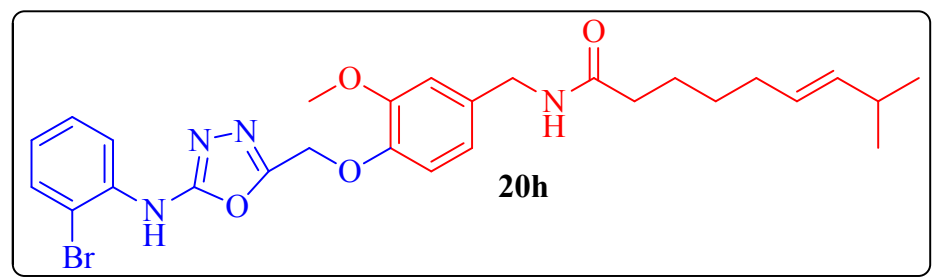
Mp: $145.5^{\circ} \mathrm{C}$.

IR cm$~^{-1}: 3450,3410,3371,3320,3239,3194,3133,3089,3055,2918,1628,1592,1514,1451$, 1384, 1263, 1222, 1141, 1025, 846, 808, 749, 683, 593, 565.

${ }^{1} \mathrm{H}$ NMR (300 MHz,CDCl$) \delta(\mathrm{ppm}): 7.71(\mathrm{~d}, J=1.2 \mathrm{~Hz}, 1 \mathrm{H}), 7.22-7.19(\mathrm{~m}, 3 \mathrm{H}), 6.94(\mathrm{~d}, J=$ $7.8 \mathrm{~Hz}, 1 \mathrm{H}), 6.81(\mathrm{~s}, 1 \mathrm{H}), 6.73(\mathrm{~d}, J=8.1 \mathrm{~Hz}, 1 \mathrm{H}), 5.82(\mathrm{~s}, 1 \mathrm{H}), 5.19$ (s, 2H), 4.36 (d, J=5.4 Hz, 2H), $3.82(\mathrm{~s}, 3 \mathrm{H}), 2.20(\mathrm{t}, J=7.2 \mathrm{~Hz}, 2 \mathrm{H}), 1.43(\mathrm{t}, J=6.9 \mathrm{~Hz}, 2 \mathrm{H}), 1.28-1.25(\mathrm{~m}, 7 \mathrm{H}), 0.85(\mathrm{~d}, J$ $=6.3 \mathrm{~Hz}, 6 \mathrm{H})$.

${ }^{13} \mathrm{C}$ NMR $\left(75 \mathrm{MHz}, \mathrm{CDCl}_{3}\right) \delta: 173.3,160.3,156.6,150.1,145.9,138.7,133.7,130.6,128.3$, $126.1,123.0,122.5,120.4,119.8,116.1,115.7,111.8,61.2,55.8,43.2,38.9,36.8,29.6,27.9$, $27.2,25.8,22.6,14.0$.

HRMS (ESI) m/z: [M] Calcd for $\mathrm{C}_{27} \mathrm{H}_{33} \mathrm{BrN}_{4} \mathrm{O}_{4}$ 556.1685; Found 556.1688.

Anal. Calcd for $\mathrm{C}_{27} \mathrm{H}_{33} \mathrm{BrN}_{4} \mathrm{O}_{4}$ : C, 58.17; H, 5.97; Br, 14.33, N, 10.05; O, 11.48 \%, Found: C, 58.07; H, 5.90; N, 10.01\%.

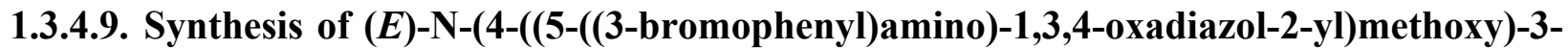
methoxybenzyl)-8-methylnon-6-enamide (20i)

According to general procedure A, Compound 19i was cyclized under coupling conditions with EDC.HCl and HOBt to yield desired compound 20i.

White solid, Yield 93\%.

Mp: $145.7{ }^{\circ} \mathrm{C}$.

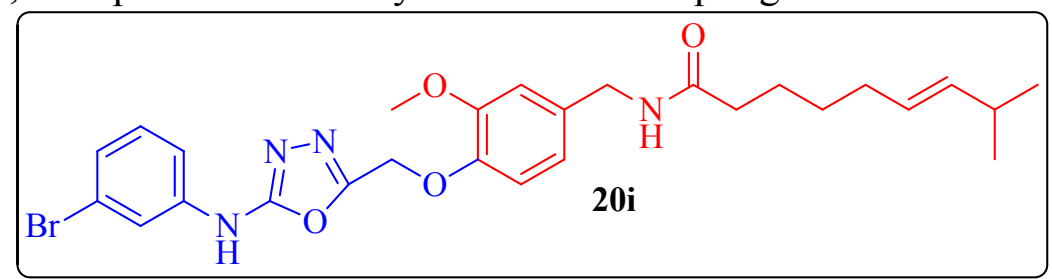

IR cm ${ }^{-1}: 3482,3453,3416,3379,3332,3275,3275,3237,3169,3072,3039,2925,1644,1621$, $1571,1543,1471,1418,1387,1333,1266,1221,1137,1096,1026,849,805,772,716,657,615$, 555. 
${ }^{1} \mathrm{H}$ NMR (300 MHz, $\left.\mathrm{CDCl}_{3}\right) \delta(\mathrm{ppm}): 7.71(\mathrm{~s}, 1 \mathrm{H}), 7.44-7.42(\mathrm{~m}, 1 \mathrm{H}), 7.20(\mathrm{~d}, J=4.5 \mathrm{~Hz}, 2 \mathrm{H})$, $6.94(\mathrm{~d}, J=8.1 \mathrm{~Hz}, 1 \mathrm{H}), 6.80(\mathrm{~s}, 1 \mathrm{H}), 6.72(\mathrm{~d}, J=9.0 \mathrm{~Hz}, 1 \mathrm{H}), 5.85(\mathrm{~s}, 1 \mathrm{H}), 5.19(\mathrm{~s}, 2 \mathrm{H}), 4.36$ $(\mathrm{d}, J=5.1 \mathrm{~Hz}, 2 \mathrm{H}), 3.82(\mathrm{~s}, 3 \mathrm{H}), 2.21(\mathrm{t}, J=7.5 \mathrm{~Hz}, 2 \mathrm{H}), 1.67-1.60(\mathrm{~m}, 2 \mathrm{H}), 1.52-1.43(\mathrm{~m}, 1 \mathrm{H})$, $1.25(\mathrm{~s}, 6 \mathrm{H}), 0.85(\mathrm{~d}, J=6.3 \mathrm{~Hz}, 6 \mathrm{H})$.

${ }^{13} \mathrm{C}$ NMR $\left(75 \mathrm{MHz}, \mathrm{CDCl}_{3}\right) \delta: 173.3,160.3,156.6,150.1,145.9,138.7,133.7,130.6,128.3$, $126.1,123.0,122.5,120.4,119.8,116.1,115.7,111.8,61.2,55.8,43.2,38.9,36.8,29.6,27.9$, $27.2,25.8,22.6,14.0$.

MS (ESI) $m / z:[\mathrm{M}]^{+} 557.3,[\mathrm{M}+1]^{+} 558,[\mathrm{M}+2]^{+} 559.1$.

Anal. Calcd for $\mathrm{C}_{27} \mathrm{H}_{33} \mathrm{BrN}_{4} \mathrm{O}_{4}$ : C, 58.17; H, 5.97; Br, 14.33, N, 10.05; O, 11.48 \%, Found: $\mathrm{C}$, 58.11; H, 5.94; N, 9.98\%.

\subsubsection{Synthesis of $\quad(E)-N-(4-((5-($ ethylamino)-1,3,4-oxadiazol-2-yl)methoxy)-3- methoxybenzyl)-8-methylnon-6-enamide (20j)}

According to general procedure A, Compound

19j was cyclized under coupling conditions with

EDC.HCl and HOBt to yield desired compound

$20 j$.

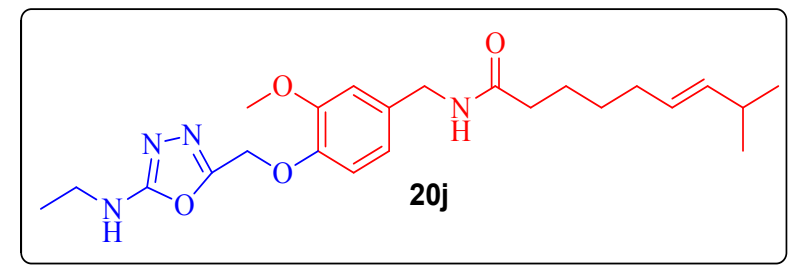

White solid, yield: $87 \%$.

$\mathrm{Mp}: 106^{\circ} \mathrm{C}$.

IR cm$~^{-1}: 3483,3458,3413,3379,3343,3307,3259,3212,3143,3107,2924,1631,1557,1516$, 1462, 201, 1260, 1221, 1145, 1090, 1026, 855, 798, 721, 689, 649, 554.

${ }^{1} \mathrm{H}$ NMR (300 MHz, $\left.\mathrm{CDCl}_{3}\right) \delta(\mathrm{ppm}): 6.94(\mathrm{~d}, J=7.8 \mathrm{~Hz}, 1 \mathrm{H}), 6.85(\mathrm{~s}, 1 \mathrm{H}), 6.78(\mathrm{~d}, J=7.2 \mathrm{~Hz}$, $1 \mathrm{H}), 5.80(\mathrm{~s}, 1 \mathrm{H}), 5.33(\mathrm{~s}, 1 \mathrm{H}), 4.38(\mathrm{~d}, J=5.4 \mathrm{~Hz}, 2 \mathrm{H}), 4.27-4.20(\mathrm{~m}, 2 \mathrm{H}), 3.83(\mathrm{~s}, 3 \mathrm{H}), 2.20(\mathrm{t}$, $J=7.2 \mathrm{~Hz}, 2 \mathrm{H}), 1.65(\mathrm{t}, J=5.4 \mathrm{~Hz}, 2 \mathrm{H}), 1.54-1.48(\mathrm{~m}, 1 \mathrm{H}), 1.42(\mathrm{t}, J=7.2 \mathrm{~Hz}, 3 \mathrm{H}), 1.27(\mathrm{~s}, 6 \mathrm{H})$, $0.85(\mathrm{~d}, J=6.6 \mathrm{~Hz}, 6 \mathrm{H})$.

${ }^{13} \mathrm{C}$ NMR (75 MHz, $\left.\mathrm{CDCl}_{3}\right) \delta: 173.1,168.2,150.3,148.0,145.6,134.0,120.0,115.9,111.9$, $62.0,55.7,43.3,39.9,38.9,36.8,29.6,29.3,27.9,27.2,25.8,22.6,13.5$.

MS (ESI) $m / z:[\mathrm{M}+1]^{+} 431.2$.

Anal. Calcd for $\mathrm{C}_{23} \mathrm{H}_{34} \mathrm{~N}_{4} \mathrm{O}_{4}$ : C, 64.16; H, 7.96; N, 13.01; O, 14.86 \%, Found: C, 64.08; H, 7.91, $\mathrm{N}, 12.99 \%$. 


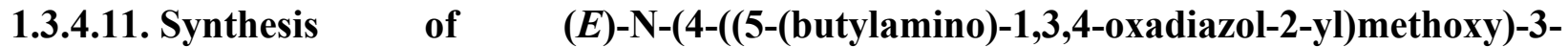

\section{methoxybenzyl)-8-methylnon-6-enamide (20k)}

According to general procedure A, Compound 19k was cyclized under coupling conditions with EDC.HCl and HOBt to yield desired compound 20k.

Light grey; solid, yield: $91 \%$.

Mp: $145.6{ }^{\circ} \mathrm{C}$.

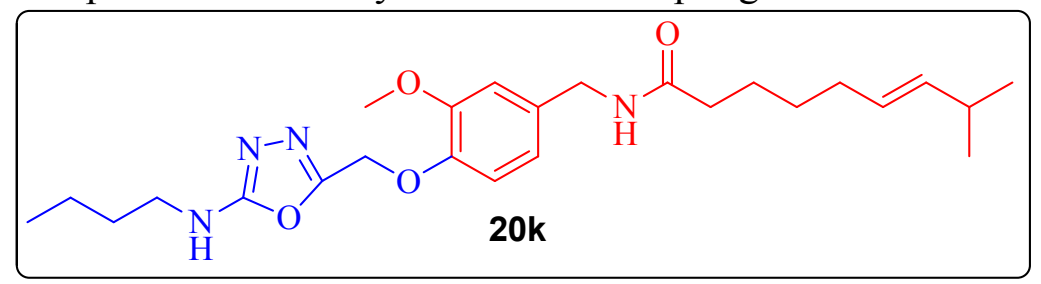

IR cm$~^{-1}: 3449,3341,3281,3161,3108,3077,3003,29212848,1636,1558,1502,1460,1355$, $1262,1213,1147,1113,1029,997,860,791,747,656,599,546$.

${ }^{1} \mathrm{H}$ NMR $\left(300 \mathrm{MHz}, \mathrm{CDCl}_{3}\right) \delta(\mathrm{ppm}): 6.93(\mathrm{~d}, J=8.1 \mathrm{~Hz}, 1 \mathrm{H}), 6.85(\mathrm{~s}, 1 \mathrm{H}), 6.77(\mathrm{~d}, J=7.2 \mathrm{~Hz}$, 1H), $5.81(\mathrm{~s}, 1 \mathrm{H}), 5.09(\mathrm{~s}, 2 \mathrm{H}), 4.38(\mathrm{~d}, J=5.1 \mathrm{~Hz}, 2 \mathrm{H}), 4.15(\mathrm{t}, J=7.5 \mathrm{~Hz}, 2 \mathrm{H}), 3.83(\mathrm{~s}, 3 \mathrm{H})$, $2.22(\mathrm{t}, J=7.2 \mathrm{~Hz}, 2 \mathrm{H}), 1.82(\mathrm{t}, J=6.3 \mathrm{~Hz}, 2 \mathrm{H}), 1.65(\mathrm{t}, J=5.7 \mathrm{~Hz}, 2 \mathrm{H}), 1.54-1.37(\mathrm{~m}, 3 \mathrm{H})$, $1.28(\mathrm{~s}, 6 \mathrm{H}), 0.85(\mathrm{~d}, J=6.6 \mathrm{~Hz})$.

${ }^{13} \mathrm{C} \mathrm{NMR}\left(75 \mathrm{MHz}, \mathrm{CDCl}_{3}\right) \delta: 173.1,168.4,150.3,148.1,145.6,134.0,120.0,116.0,111.9$, $62.0,55.7,44.5,43.3,39.9,38.9,36.8,30.2$, 29.6, 29.3, 27.9, 27.2, 25.8, 22.6, 20.0, 13.6.

$\mathrm{MS}(\mathrm{ESI}) \mathrm{m} / z:[\mathrm{M}+3]^{+} 461.1$.

Anal. Calcd for $\mathrm{C}_{23} \mathrm{H}_{34} \mathrm{~N}_{4} \mathrm{O}_{4}$ : C, 65.48; H, 8.35; N, 12.22; O, 13.96 \%, Found: C, 65.41; H, 8.29; N, $12.18 \%$.

\subsection{Scheme S-2. Synthesis of compound 21, 22a-b.}

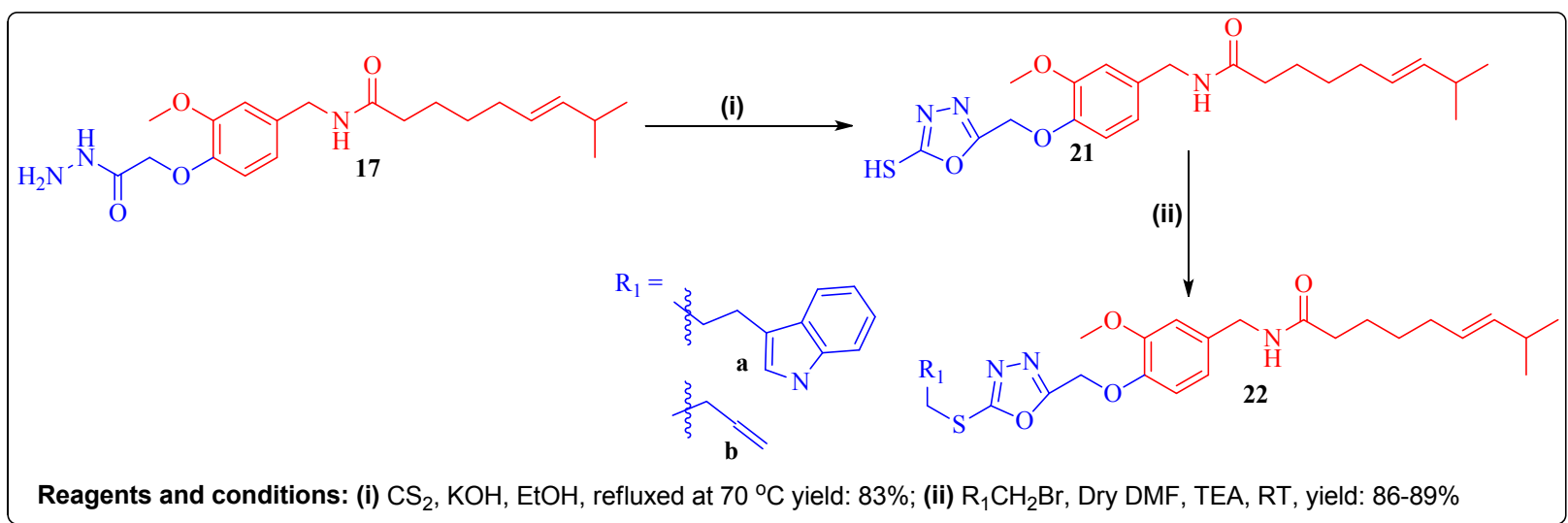

\section{Scheme S-2}




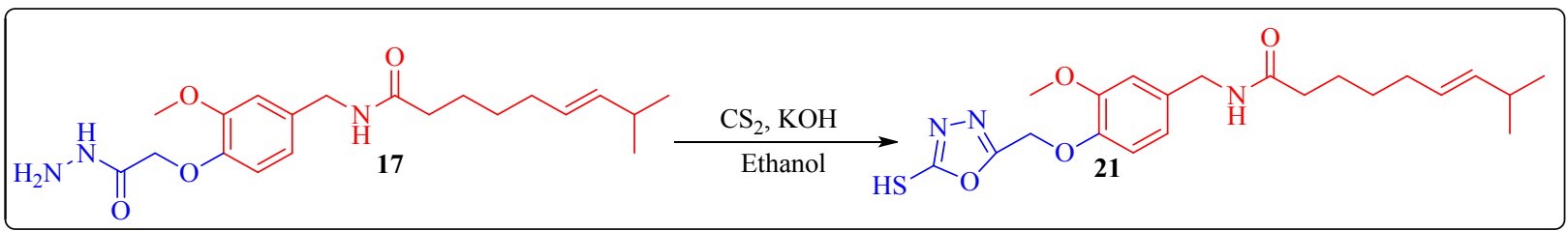

To ethanolic solution of carbon disulphide $(0.21 \mathrm{~g}), 0.16 \mathrm{~g}$ of potassium hydroxide was added and the reaction mixture was stirred at room temperature for $30 \mathrm{~min}$. After $30 \mathrm{~min}, 0.5 \mathrm{~g}$ of capsaicin hydrazide 17 was added to the reaction mixture and was refluxed at $70^{\circ} \mathrm{C}$. The completion of reaction was monitored by TLC (9:1 ratio of ethyl acetate:methanol). Reaction mixture was concentrated under rota-evaporator and the concentrated reaction mixture was poured into ice. White solid precipitates were formed and filtered under vacuum pump and dried.

White solid, yield: $83 \%$.

Mp: $160.3{ }^{\circ} \mathrm{C}$.

IR cm-1: 3459, 3395, 3311, 3281, 3224, 3189, 3093, 2955, 2927, 1681, 1638, 1514, 1481, 1377, $1265,1232,1143,1025,911,800,707,682,637,602,540$.

${ }^{1} \mathrm{H}$ NMR (300 MHz, $\left.\mathrm{CDCl}_{3}\right) \delta(\mathrm{ppm}): 9.51(\mathrm{~s}, 1 \mathrm{H}), 6.89-6.76(\mathrm{~m}, 3 \mathrm{H}), 5.60(\mathrm{~s}, 1 \mathrm{H}), 5.33-5.18(\mathrm{~m}$, 2H), 4.60 (s, 2H), $4.31(\mathrm{~s}, 2 \mathrm{H}), 3.82(\mathrm{~s}, 3 \mathrm{H}), 2.14(\mathrm{t}, J=6.9 \mathrm{~Hz}, 2 \mathrm{H}), 1.93-1.88(\mathrm{~m}, 1 \mathrm{H}), 1.59-$ 1.47 (m, 6H), 0.87 (d, $J=6.3 \mathrm{~Hz}, 3 \mathrm{H}), 0.63(\mathrm{~d}, J=6 \mathrm{~Hz}, 3 \mathrm{H})$.

MS (ESI) $m / z:[\mathrm{M}-1]^{+} 418.4$.

1.4.2. Synthesis of (E)-N-(4-((5-((2-(1H-indole-3-yl)ethyl)thio)-1,3,4-oxadiazol-2yl)methoxy)-3-methoxybenzyl)-8-methylnon-6-enamide (22a)

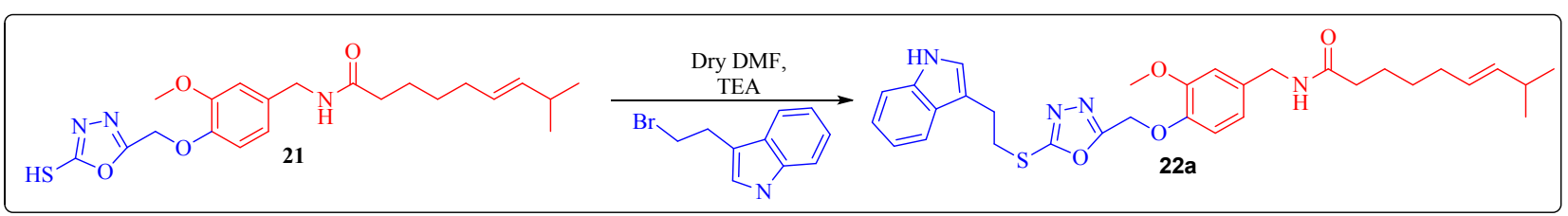

$0.2 \mathrm{~g}$ of compound 21 was added to dry DMF, $0.12 \mathrm{~g}$ of 3-(2-bromoethyl)indole and $9.4 \mu \mathrm{L}$ of triethylamine were added to the reaction mixture and was stirred at room temperature until the reaction get complete. Completion of reaction was monitored by TLC (7:3 ratio of ethyl 
acetate:hexane). Reaction mixture was poured into ice. A white solid precipitates were formed and filtered and dried under vacuum.

White solid, yield: $86 \%$.

Mp: $109.4{ }^{\circ} \mathrm{C}$.

IR cm ${ }^{-1}: 3470,3431,3385,3323,3171,3122,3086,3057,2932,1643,1544,1513,1456,1420$, $1318,1252,1216,1143,1026,964,923,843,808,765,736,656,600,558$.

${ }^{1} \mathrm{H}$ NMR (300 MHz,CDCl $\left.{ }_{3}\right) \delta(\mathrm{ppm}): 8.27(\mathrm{~s}, 1 \mathrm{H}), 7.63(\mathrm{~d}, J=7.8 \mathrm{~Hz}, 1 \mathrm{H}), 7.35(\mathrm{~d}, J=7.8 \mathrm{~Hz}$, 1H), 7.21-7.12 (m, 2H), $7.02(\mathrm{~s}, 1 \mathrm{H}), 6.95(\mathrm{~d}, J=8.1 \mathrm{~Hz}, 1 \mathrm{H}), 6.83(\mathrm{~s}, 1 \mathrm{H}), 6.76(\mathrm{~d}, J=8.4 \mathrm{~Hz}$, 1H), $5.72(\mathrm{~s}, 1 \mathrm{H}), 5.41-5.18(\mathrm{~m}, 3 \mathrm{H}), 4.36(\mathrm{~d}, J=5.7 \mathrm{~Hz}, 2 \mathrm{H}), 3.82(\mathrm{~s}, 3 \mathrm{H}), 3.54$ (t, $J=6.9 \mathrm{~Hz}$, 2H), 3.26 (t, $J=7.2 \mathrm{~Hz}, 2 \mathrm{H}), 2.20$ (t, $J=7.2 \mathrm{~Hz}, 2 \mathrm{H}), 2.01-1.95$ (m, 1H), 1.70-1.60 (m, 3H), $1.43-1.25(\mathrm{~m}, 4 \mathrm{H}), 0.94(\mathrm{~d}, J=6.6 \mathrm{~Hz}, 4 \mathrm{H}), 0.85(\mathrm{~d}, J=6.6 \mathrm{~Hz}, 2 \mathrm{H})$.

${ }^{13} \mathrm{C}$ NMR $\left(75 \mathrm{MHz}, \mathrm{CDCl}_{3}\right) \delta: 172.9,166.1,163.3,150.2,146.0,138.1,136.2,133.8,126.9$, 126.4, 122.1, 119.9, 119.5, 118.6, 115.9, 113.1, 111.8, 111.3, 61.3, 55.8, 43.2, 38.9, 36.6, 33.2, $32.2,30.9,29.6,29.2,27.9,27.2,25.5,25.2,22.6$.

HRMS (ESI) $m / z$ : $[\mathrm{M}+\mathrm{H}]^{+}$Calcd for $\mathrm{C}_{31} \mathrm{H}_{39} \mathrm{~N}_{4} \mathrm{O}_{4} \mathrm{~S}$ 563.2692; Found 563.2692.

Anal. Calcd for $\mathrm{C}_{31} \mathrm{H}_{38} \mathrm{~N}_{4} \mathrm{O}_{4} \mathrm{~S}: \mathrm{C}, 66.17 ; \mathrm{H}, 6.81 ; \mathrm{N}, 9.96 ; \mathrm{O}, 11.37$; S, 5.70 \%, Found: C, 66.10; H, 6.76; N, 9.91; S, 5.67\%.

\subsubsection{Synthesis of $\quad(E)-N-(4-((5-($ allylthio)-1,3,4-oxadiazol-2-yl)methoxy)-3- methoxybenzyl)-8-methylnon-6-enamide (22b)}

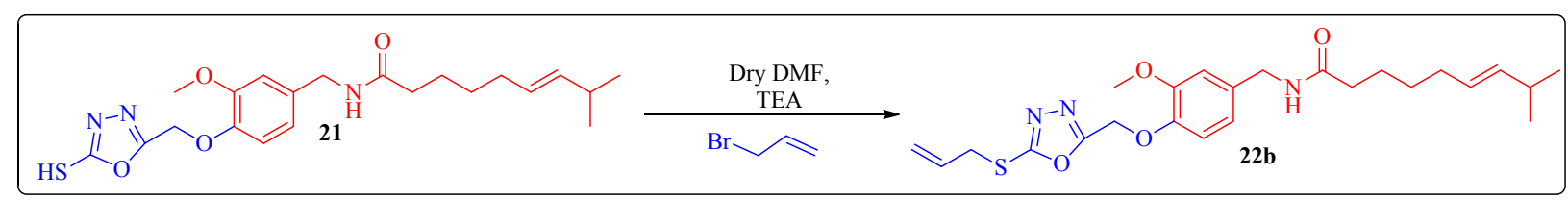

$0.2 \mathrm{~g}$ of compound 21 was added to dry DMF, $0.07 \mathrm{~g}$ of allylbromide and $9.4 \mu \mathrm{L}$ of triethylamine was added to the reaction mixture and was stirred at room temperature until the reaction get complete. Completion of reaction was monitored by TLC (7:3 ratio of ethyl acetate:hexane). Reaction mixture was poured into ice. A white solid precipitates were formed and filtered and dried under vacuum.

White solid, yield: $89 \%$.

Mp: $84.7^{\circ} \mathrm{C}$.

IR cm ${ }^{-1}: 3478,3407,3364,3292,3124,3085,3005,2960,2925,1633,1519,1469,1419,1384$, $1269,1221,1169,1140,1026,979,918,849,796,730,700,667,632,585,532$. 
${ }^{1} \mathrm{H}$ NMR $\left(300 \mathrm{MHz}, \mathrm{CDCl}_{3}\right) \delta(\mathrm{ppm}): 6.97(\mathrm{~d}, J=8.1 \mathrm{~Hz}, 1 \mathrm{H}), 6.84(\mathrm{~s}, 1 \mathrm{H}), 6.77(\mathrm{~d}, J=8.1 \mathrm{~Hz}$, $1 \mathrm{H}), 6.03-5.90(\mathrm{~m}, 1 \mathrm{H}), 5.67(\mathrm{~s}, 1 \mathrm{H}), 5.41-5.31(\mathrm{~m}, 2 \mathrm{H}), 5.24(\mathrm{~s}, 2 \mathrm{H}), 4.37(\mathrm{~d}, J=5.7 \mathrm{~Hz}, 2 \mathrm{H})$, $3.85(\mathrm{~m}, 4 \mathrm{H}), 2.21(\mathrm{t}, J=7.5 \mathrm{~Hz}, 2 \mathrm{H}), 1.99$ (q, $J=7.2 \mathrm{~Hz}, 1 \mathrm{H}), 1.71-1.59(\mathrm{~m}, 4 \mathrm{H}), 1.28-1.25(\mathrm{~m}$, $5 \mathrm{H}), 0.95(\mathrm{~d}, J=6.9 \mathrm{~Hz}, 3 \mathrm{H}), 0.85(\mathrm{~d}, J=6.6 \mathrm{~Hz}, 3 \mathrm{H})$.

HRMS (ESI) $m / z:[\mathrm{M}+\mathrm{H}]^{+}$Calcd for $\mathrm{C}_{24} \mathrm{H}_{35} \mathrm{~N}_{3} \mathrm{O}_{4} \mathrm{~S} 460.2270$; Found 460.2279.

Anal. Calcd for $\mathrm{C}_{24} \mathrm{H}_{33} \mathrm{~N}_{3} \mathrm{O}_{4} \mathrm{~S}$ : C, 62.72; H, 7.24; N, 9.14; O, 13.92; S, 6.98 \%, Found: C, 62.69; H, 7.19; N, 9.09; S, 6.94\%.

\section{Biology}

\subsection{In vitro anti-proliferative assay}

\subsubsection{In vitro anti-proliferative activity at single dose}

All the synthesized compounds were screened for their anti-proliferative activity against a panel of 60 cancer cell line at National Cancer Institute, Bethesda, MD, USA as per the standard procedure given at http://www.dtp.nci.nih.gov ${ }^{1}$. RPMI 1640 medium (5\% fetal bovine serum and $2 \mathrm{mM}$ L-glutamine) was used to grow the human tumor cell lines. All the tumor cells were incubated into 96-well microtiter plate. Then this plated was placed for incubation at $37{ }^{\circ} \mathrm{C}$ for 24 hour. After that two plates of each cell line were fixed with TCA in situ and optical density was measured at this point which represented the cell population of each cell line at the time of compound addition (ODtzero). On the other hand, all the tested compounds were dissolved in DMSO to yield 400 -fold desired final concentration and stored at $-80^{\circ} \mathrm{C}$. These frozen compounds were thawed and their aliquot part was diluted to $10^{-4} \mathrm{M}$ concentration with the medium containing $50 \mu \mathrm{g} / \mathrm{mL}$ of gentamicin at the time of compound addition. Control sample was made with DMSO only. $100 \mu 1$ of the tested compounds from the aliquot parts were added to appropriate 96-well microtiter plate containing $100 \mu \mathrm{l}$ of medium ensuing in the required final drug concentrations of $10^{-5} \mathrm{M}$ and $0 \mathrm{M}$ (control). After addition of tested compounds, 96-well microtiter plate was incubated for $48 \mathrm{~h}$ at $100 \%, 5 \% \mathrm{CO}_{2}, 95 \%$ air, $100 \%$ relative humidity. Cold TCA was used to stop the assay for adherent cells. Further on $50 \mathrm{~mL}$ of $50 \%(\mathrm{w} / \mathrm{v})$ TCA was used to fix the cell and incubated for $1 \mathrm{~h}$ at $4{ }^{\circ} \mathrm{C}$. The supernatant was removed, and the 96-well microtiter plates were rinsed five times with water and air dried. $100 \mathrm{~mL}$ solution of protein binding dye, Sulforhodamine B (SRB) was made at $0.4 \%(\mathrm{w} / \mathrm{v})$ in $1 \%$ acetic acid and was added to each well of the plates. These Plates were placed at room temperature for incubation for 10 
minutes then were washed with $1 \%$ acetic acid five times to remove unbound dye. Then the plates were treated with $10 \mathrm{Mm}$ trizma base, so that unbound dye was solubilized with trizma base. The absorbance was measured at a wavelength of $515 \mathrm{~nm}$ on an automated plate reader and results for each tested compounds were calculated as the percent of tumor growth of the treated cells in comparison with the untreated control cells. Optical density (OD) was recored for SRBderived color just before exposing the cells to the test compound (ODtzero) and after $48 \mathrm{~h}$ exposure to the test compound (OD test) or the control vehicle (OD ctrl). 
Table S1: Growth percentage against NCI panel of 60 human cancer cell lines at $10 \mu \mathrm{M}$ of all the synthesized compounds

\begin{tabular}{|c|c|c|c|c|c|c|c|c|c|c|c|c|c|c|}
\hline \multirow{2}{*}{$\begin{array}{l}\text { Sub panel } \\
\text { cancer cell line }\end{array}$} & \multicolumn{14}{|c|}{ Growth percentage } \\
\hline & $20 a$ & $20 \mathrm{~b}$ & $20 c$ & 20d & $20 \mathrm{e}$ & $20 f$ & $20 \mathrm{~g}$ & $20 \mathrm{~h}$ & $20 i$ & $20 j$ & $20 \mathrm{k}$ & 21 & $22 a$ & $22 b$ \\
\hline \multicolumn{15}{|l|}{ Leukemia } \\
\hline CCRF-CEM & 78.85 & 83.38 & 91.92 & 82.95 & 92.76 & 91.99 & $\mathrm{nt}$ & 97.26 & 81.76 & 97.54 & 91.34 & 99.62 & 34.67 & 90.64 \\
\hline HL-60(TB) & 101.03 & 89.41 & 89.08 & 89.70 & 99.69 & 81.09 & 98.57 & 89.55 & 79.77 & 98.36 & 86.64 & 103.37 & 50.23 & 98.26 \\
\hline K-562 & 59.62 & 70.62 & 87.28 & 60.36 & 70.24 & 67.95 & 84.49 & 81.01 & 65.02 & 91.59 & 85.73 & 93.12 & 40.71 & 70.34 \\
\hline MOLT-4 & 84.22 & 88.02 & 89.91 & 82.05 & 103.71 & 76.74 & 98.19 & 86.25 & 83.54 & 103.67 & 86.36 & $\mathrm{Nt}$ & 29.16 & 83.83 \\
\hline RPMI-8226 & 52.34 & 74.91 & 84.57 & 64.91 & 84.21 & 70.71 & 93.01 & 88.54 & 70.31 & 95.52 & 76.77 & 99.31 & $\mathrm{Nt}$ & $\mathrm{Nt}$ \\
\hline SR & 64.20 & 74.53 & 84.76 & 67.28 & 89.46 & 76.06 & 95.22 & 80.43 & 67.67 & 89.02 & 71.54 & 95.22 & 49.30 & 80.53 \\
\hline \multicolumn{15}{|l|}{$\begin{array}{l}\text { Non-small cell } \\
\text { lung cancer }\end{array}$} \\
\hline A549/ATCC & 49.02 & 87.33 & 102.17 & 105.30 & 97.53 & 99.28 & 99.76 & 100.52 & 95.38 & 97.00 & 100.32 & 101.17 & 79.42 & 98.75 \\
\hline EKVX & 74.70 & 88.18 & 101.13 & 77.14 & 93.21 & 85.03 & 91.18 & 90.94 & 78.09 & 96.74 & 98.76 & 96.09 & 57.36 & 94.12 \\
\hline HOP-62 & $\mathbf{0}$ & 90.21 & 88.26 & 56.40 & 87.34 & 79.11 & 106.83 & 99.73 & 75.58 & 98.27 & 78.66 & 110.73 & 92.77 & 82.37 \\
\hline NCI-H226 & 62.14 & 66.28 & 85.01 & 64.53 & 66.49 & 79.74 & 85.73 & 83.50 & 50.41 & 101.46 & 84.32 & 100.61 & 67.25 & 91.66 \\
\hline NCI-H23 & 62.14 & 77.86 & 90.57 & 63.80 & 82.89 & 92.25 & 92.09 & 87.06 & 66.01 & 93.67 & 93.14 & 100.87 & 66.57 & 96.56 \\
\hline NCI-H322M & 54.87 & 101.74 & 82.91 & 86.07 & 83.98 & 97.37 & 85.45 & 94.14 & 98.04 & 107.20 & 90.56 & 104.13 & 88.69 & 105.55 \\
\hline NCI-H460 & 33.48 & 97.70 & 103.15 & 80.34 & 97.70 & 104.67 & 105.96 & 93.22 & 97.55 & 102.79 & 102.28 & 106.50 & 89.80 & 105.48 \\
\hline NCI-H522 & 72.97 & 73.96 & 85.69 & 60.29 & 78.59 & 80.95 & 84.61 & 76.81 & 68.60 & 83.70 & 83.69 & 99.00 & 59.35 & 89.50 \\
\hline \multicolumn{15}{|l|}{ Colon cancer } \\
\hline COLO 205 & 70.91 & 113.34 & 105.02 & 104.24 & 98.70 & 125.25 & 123.61 & 113.16 & 109.93 & 110.12 & 112.79 & 103.84 & 71.22 & 110.75 \\
\hline HCC-2998 & 83.57 & 100.28 & 102.82 & 90.82 & 94.58 & 105.27 & 103.51 & 99.78 & 100.83 & 102.90 & 100.87 & 107.49 & 97.97 & 112.22 \\
\hline НCТ-116 & 24.55 & 78.21 & 95.48 & 53.45 & 84.11 & 86.76 & 98.15 & 64.86 & 67.59 & 87.16 & 95.61 & 102.79 & 69.99 & 98.01 \\
\hline НCТ-15 & 81.17 & 95.64 & 103.31 & 90.10 & 92.38 & 88.33 & 94.13 & 98.87 & 90.22 & 96.85 & 96.64 & 97.59 & 68.56 & 95.32 \\
\hline HT29 & 71.71 & 98.66 & 99.81 & 89.95 & 93.76 & 102.87 & 109.88 & 97.63 & 97.66 & 104.84 & 109.45 & 113.25 & 69.68 & 109.65 \\
\hline KM12 & 71.65 & 95.09 & 98.42 & 78.80 & 96.75 & 95.47 & 92.43 & 82.88 & 90.31 & 98.25 & 100.69 & 101.75 & 73.28 & 103.88 \\
\hline SW-620 & 67.32 & 105.60 & 103.77 & 98.94 & 97.91 & 105.15 & 103.10 & 94.64 & 95.44 & 109.92 & 101.45 & 100.81 & 84.70 & 96.35 \\
\hline \multicolumn{15}{|l|}{ CNS cancer } \\
\hline SF-268 & 79.65 & 88.42 & 98.18 & 45.48 & 87.38 & 90.77 & 89.30 & 90.35 & 92.63 & 97.15 & 102.42 & 100.57 & 78.89 & 97.08 \\
\hline SF-295 & 64.90 & 89.63 & 98.07 & 48.03 & 88.34 & 88.79 & 89.97 & 93.76 & 84.25 & 97.13 & 102.61 & 100.13 & 68.78 & 101.54 \\
\hline SF-539 & 70.24 & 103.25 & 94.45 & 48.16 & 86.63 & 93.38 & 98.35 & 90.97 & 88.44 & 103.92 & 99.53 & 101.54 & 80.83 & 101.59 \\
\hline SNB-19 & 54.05 & 99.28 & 96.48 & 58.55 & 86.86 & 94.57 & 96.21 & 90.61 & 99.55 & 103.83 & 94.52 & 97.90 & 77.05 & 95.53 \\
\hline SNB-75 & 48.71 & 80.51 & 81.58 & 57.78 & 68.43 & 94.51 & 80.03 & 95.25 & 83.48 & 86.23 & 88.42 & 83.81 & 83.14 & 83.94 \\
\hline U251 & 48.58 & 93.59 & 103.48 & 83.96 & 99.62 & 101.74 & 101.89 & 88.97 & 101.81 & 98.29 & 101.12 & 102.68 & 80.52 & 100.05 \\
\hline \multicolumn{15}{|l|}{ Melanoma } \\
\hline LOX IMVI & 55.24 & 92.37 & 92.05 & 83.41 & 90.96 & 95.63 & 92.06 & 94.00 & 88.92 & 93.19 & 92.01 & 100.41 & 55.24 & 95.91 \\
\hline M14 & 69.64 & 98.83 & 98.52 & 99.73 & 90.34 & 95.41 & 98.88 & 101.43 & 93.30 & 101.59 & 94.96 & 92.91 & $\mathrm{Nt}$ & $\mathrm{Nt}$ \\
\hline MDA-MB-435 & 66.39 & 104.85 & 103.53 & 100.01 & 99.57 & 103.20 & 102.02 & 105.39 & 101.19 & 104.46 & 100.39 & 100.51 & 90.22 & 98.38 \\
\hline SK-MEL-2 & 71.89 & 103.66 & 106.15 & 111.03 & 94.60 & 101.56 & 104.40 & 101.46 & 104.61 & 103.70 & 104.03 & 108.93 & 86.68 & 94.98 \\
\hline SK-MEL-28 & 78.87 & 98.50 & 94.43 & 85.18 & 90.32 & 98.06 & 99.09 & 99.16 & 107.28 & 103.96 & 97.23 & 110.77 & 104.42 & 106.07 \\
\hline SK-MEL-5 & 46.26 & 97.12 & 99.88 & 86.57 & 96.15 & 98.00 & 101.19 & 100.83 & 89.84 & 102.38 & 99.66 & $\mathrm{Nt}$ & 105.37 & 108.83 \\
\hline UACC-257 & 77.56 & 98.76 & 105.06 & 98.18 & 99.66 & 96.70 & 102.09 & 106.47 & 105.03 & 105.33 & 99.62 & 105.61 & 100.67 & 103.40 \\
\hline UACC-62 & 39.61 & 76.93 & 76.09 & 65.48 & 73.92 & 81.95 & 78.65 & 83.60 & 67.54 & 94.98 & 84.54 & 97.76 & 67.51 & 81.27 \\
\hline Ovarian ca & & & & & & & & & & & & & & \\
\hline IGROV1 & 53.49 & 99.02 & 89.70 & 58.44 & 88.25 & 97.77 & 86.79 & 91.27 & 92.89 & 102.86 & 103.25 & 97.96 & 73.71 & 95.03 \\
\hline OVCAR-3 & 77.31 & 97.45 & 103.80 & 68.29 & 94.73 & 89.64 & 97.64 & 104.92 & 87.99 & 105.82 & 98.26 & 110.88 & 88.32 & 106.81 \\
\hline OVCAR-4 & 11.25 & 85.83 & 96.58 & 0.69 & 84.23 & 101.24 & 95.28 & 97.29 & 85.10 & 103.05 & 94.12 & 99.42 & 71.67 & 99.46 \\
\hline OVCAR-5 & 100.97 & 93.32 & 94.10 & 77.67 & 90.36 & 89.67 & 94.23 & 92.26 & 91.08 & 103.14 & 93.11 & 105.20 & 101.99 & 102.84 \\
\hline OVCAR-8 & 24.96 & 99.66 & 100.55 & 45.17 & 100.44 & 100.61 & 97.55 & 98.66 & 98.03 & 105.88 & 99.16 & 101.33 & 71.26 & 96.48 \\
\hline NCI/ADR-RES & 79.62 & 96.09 & 100.02 & 43.35 & 93.66 & 89.81 & 95.71 & 90.56 & 87.04 & 102.01 & 94.80 & 103.36 & 56.51 & 90.53 \\
\hline SK-OV-3 & 11.82 & 88.19 & 78.61 & 48.61 & 85.35 & 107.43 & 86.46 & 97.96 & 82.58 & 91.51 & 94.35 & 103.46 & 85.74 & 107.07 \\
\hline Renal cancer & & & & & & & & & & & & & & \\
\hline $786-0$ & 22.25 & 89.17 & 97.65 & 11.98 & 85.60 & 96.22 & 94.33 & 95.33 & 95.60 & 95.46 & 103.39 & 104.31 & 89.26 & 98.36 \\
\hline A498 & 56.81 & 77.11 & 114.46 & 92.53 & 97.63 & 102.89 & 111.00 & 101.93 & 77.79 & 108.94 & 110.55 & 105.56 & 73.28 & 93.70 \\
\hline $\mathrm{ACHN}$ & 41.17 & 92.42 & 91.36 & 56.05 & 88.30 & 95.65 & 90.34 & 95.45 & 85.14 & 101.38 & 100.13 & 100.49 & 76.55 & 97.61 \\
\hline CAKI-1 & 33.60 & $\mathrm{Nt}$ & $\mathrm{Nt}$ & $\mathrm{Nt}$ & $\mathrm{Nt}$ & $\mathrm{Nt}$ & $\mathrm{Nt}$ & $\mathrm{Nt}$ & $\mathrm{Nt}$ & $\mathrm{Nt}$ & $\mathrm{Nt}$ & $\mathrm{Nt}$ & $\mathrm{Nt}$ & $\mathrm{Nt}$ \\
\hline RXF 393 & 54.11 & 109.40 & 119.47 & 68.76 & 105.35 & 102.60 & 101.82 & 96.06 & 70.61 & 120.40 & 117.01 & 85.08 & 54.00 & $\mathrm{Nt}$ \\
\hline SN 12C & 49.04 & 102.91 & 89.04 & 70.47 & 86.50 & 105.33 & 97.41 & 97.94 & 95.72 & 104.29 & 95.08 & 97.66 & 83.06 & 95.06 \\
\hline TK-10 & 84.10 & 102.60 & 146.30 & 97.67 & 100.39 & 103.22 & 129.89 & 118.10 & 104.24 & 106.57 & 111.63 & 106.13 & 91.69 & 107.78 \\
\hline UO-31 & 58.74 & 77.39 & 68.08 & 52.79 & 68.66 & 75.24 & 64.27 & 74.38 & 64.01 & 84.23 & 79.13 & 76.93 & 45.03 & 77.23 \\
\hline Prostate & & & & & & & & & & & & & & \\
\hline PC-3 & 37.64 & 93.71 & 93.53 & 72.50 & 92.51 & 84.37 & 103.14 & 103.24 & 87.90 & 103.73 & 96.62 & 98.96 & 56.85 & 93.63 \\
\hline DU-145 & 62.03 & 101.73 & 103.12 & 88.70 & 98.76 & 98.97 & 100.78 & 101.15 & 89.79 & 109.00 & 103.03 & 105.86 & 94.93 & 103.35 \\
\hline Breast cancer & & & & & & & & & & & & & & \\
\hline MCF7 & 55.23 & 93.28 & 95.59 & 66.88 & 90.88 & 87.12 & 88.37 & 82.71 & 83.70 & 95.22 & 90.76 & 95.31 & 58.79 & 98.26 \\
\hline $\begin{array}{l}\text { MDA-MB- } \\
\text { 231/ATCC }\end{array}$ & 67.10 & 88.44 & 84.33 & 63.87 & 81.41 & 99.24 & 81.96 & 92.54 & 78.30 & 103.58 & 92.62 & 102.36 & 70.64 & 97.59 \\
\hline HS 578T & 63.17 & 92.30 & 100.61 & 83.68 & 91.01 & 98.03 & 93.97 & 96.68 & 93.67 & 98.58 & 95.40 & 94.96 & 81.05 & 89.11 \\
\hline BT-549 & 108.01 & 95.78 & 96.92 & 76.95 & 80.99 & 85.59 & 88.24 & 100.93 & 76.43 & 102.29 & 93.67 & 113.07 & 75.03 & 103.85 \\
\hline $\mathrm{T}-47 \mathrm{D}$ & 48.58 & 66.28 & 79.31 & 65.02 & 69.56 & 76.11 & 92.81 & 85.60 & 58.86 & 81.04 & 88.82 & 97.17 & 42.98 & 93.68 \\
\hline MDA-MB-468 & 53.75 & 78.84 & 105.40 & 58.92 & 88.47 & 99.71 & 105.45 & 96.37 & 48.07 & 104.24 & 87.42 & 111.40 & 51.81 & 98.31 \\
\hline Mean GP & 59.69 & 91.19 & 95.99 & 71.72 & 89.51 & 93.21 & 96.03 & 93.94 & 85.48 & 99.24 & 95.63 & 101.05 & 72.88 & 96.78 \\
\hline
\end{tabular}

nt $=$ not tested; GP $=$ Growth Percentage 


\subsubsection{Crystal violet assay}

The cell viability of compound 20a against HCT-116 cancer cell line, NCI-H460 cancer cells, SKOV3 cancer cell line and normal PNT2 cells (normal prostatic epithelial cells) was measured by crystal violet assay. Appox. $4 \times 10^{3}$ were seeded in each well of 96 well plates. After $24 \mathrm{~h}$, the cells were treated with different concentrations of compound 20a and further incubated for $72 \mathrm{~h}$. Following this, the media was removed and cells were stained with $0.4 \%$ crystal violet solution (prepared in 50\% methanol) and the cells were stained for 30 minutes at room temperature. Plates were then washed gently with tape water and air dried at room temperature without lid for $24 \mathrm{~h}$. Next, $100 \mu \mathrm{l}$ of methanol was added and incubated at room temperature for 15 minutes on bench rocker, followed by measuring the absorbance of dissolved dye at $570 \mathrm{~nm}$. Cell viability was calculated as fold change in absorbance values of compound 20a treated cells with respect to control $^{2}$.

\section{Dose response curves for compound 20a}

HCT-116

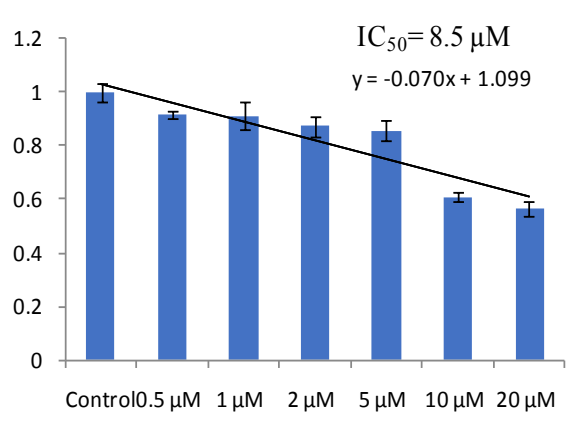

NCI-H460

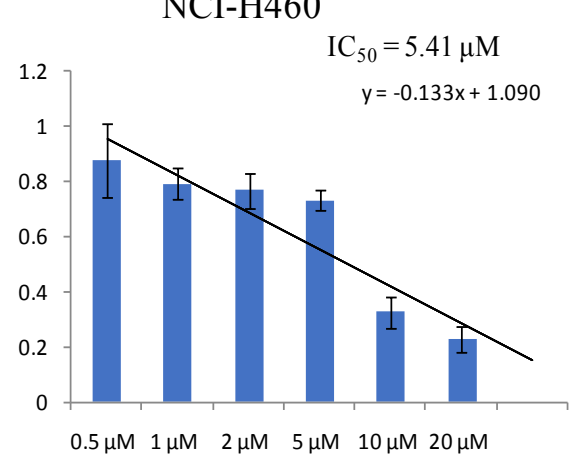

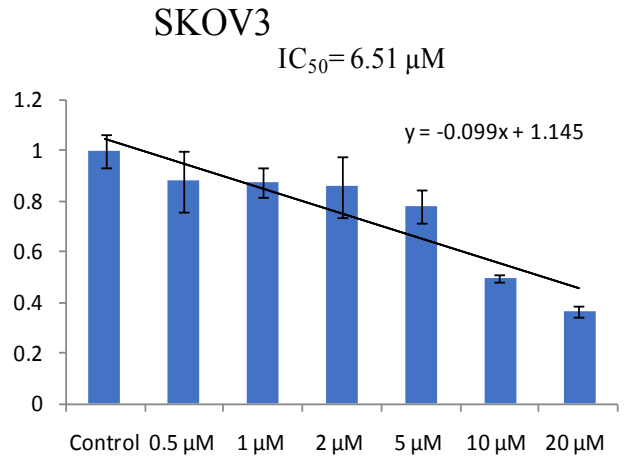

Dose response curves for compound 20d

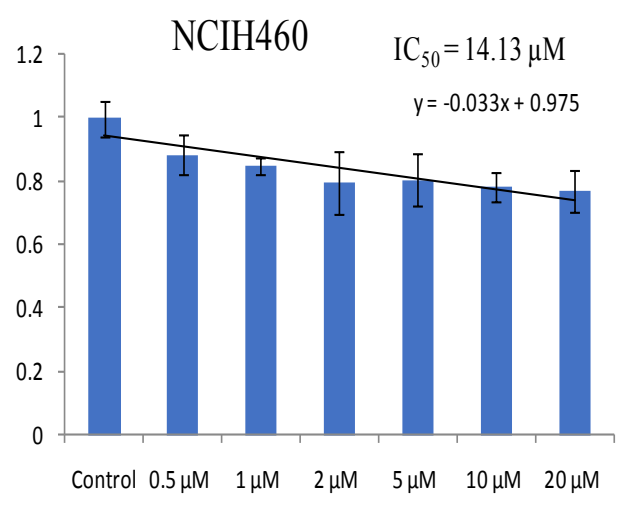

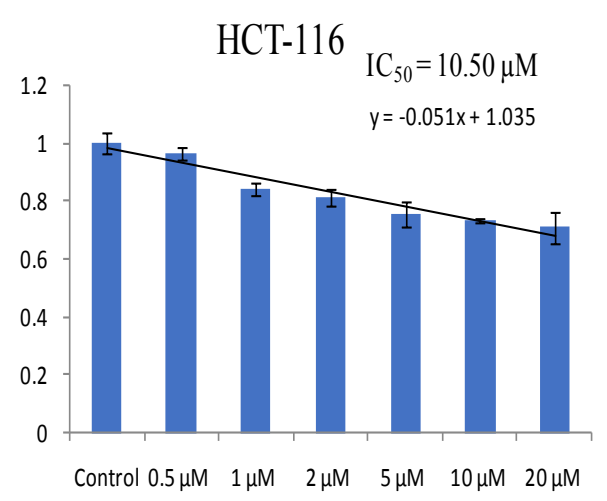

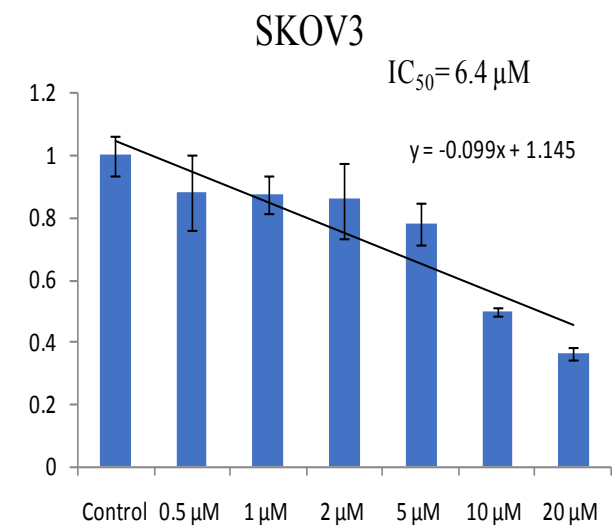




\section{Dose response curves for compound 22a}
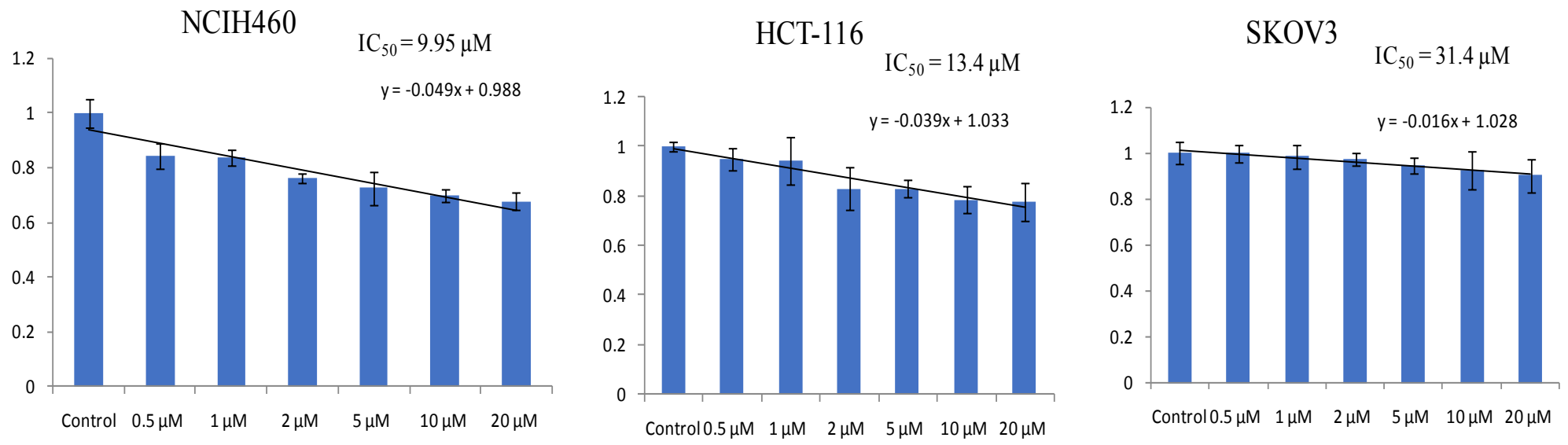

\section{Dose response curve for Capsaicin}

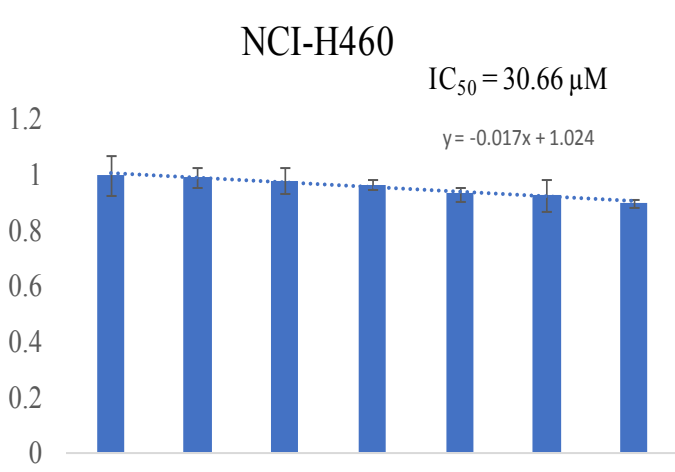

Control $0.5 \mu \mathrm{M} \quad 1 \mu \mathrm{M} \quad 2 \mu \mathrm{M} \quad 5 \mu \mathrm{M} \quad 10 \mu \mathrm{M} \quad 20 \mu \mathrm{M}$
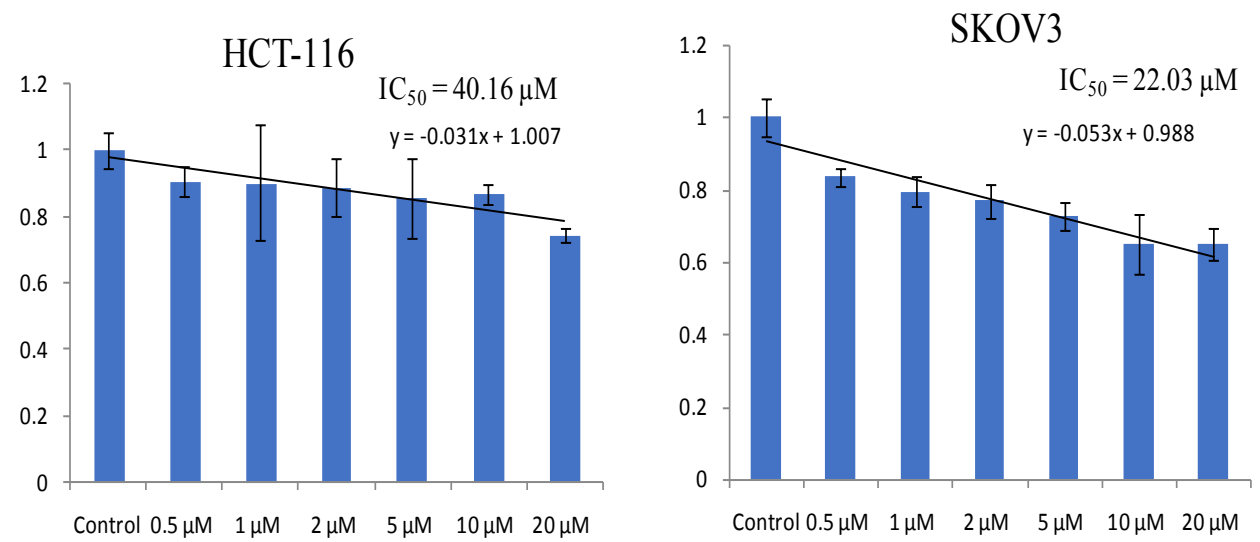

\section{Dose response curve for Combretastatin}
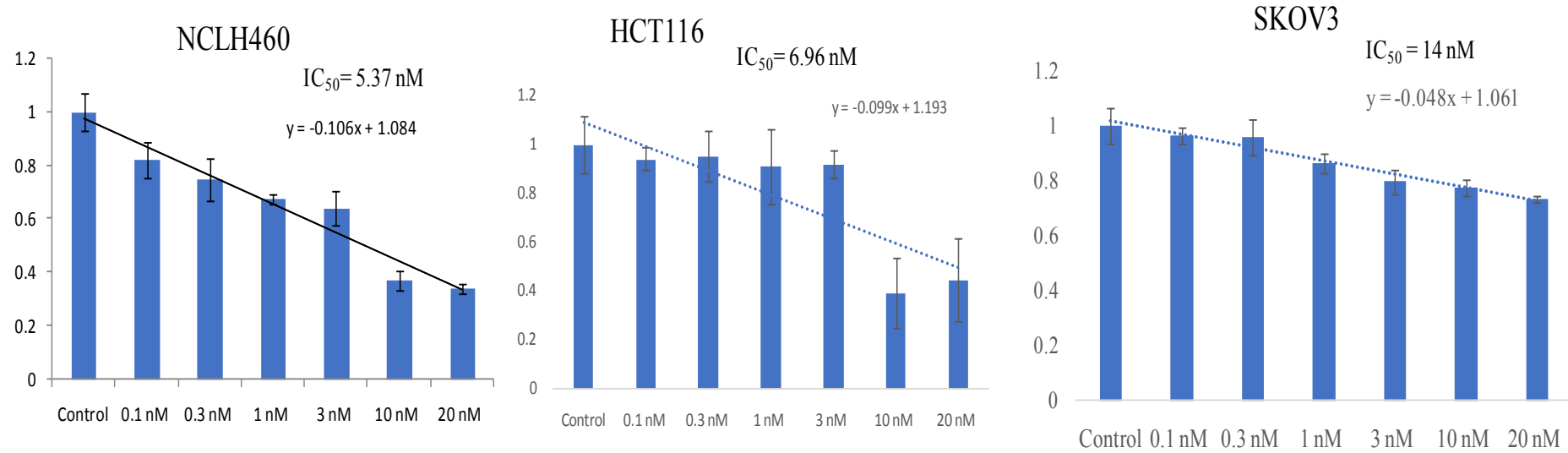


\section{Dose response curve for Doxorubicin}
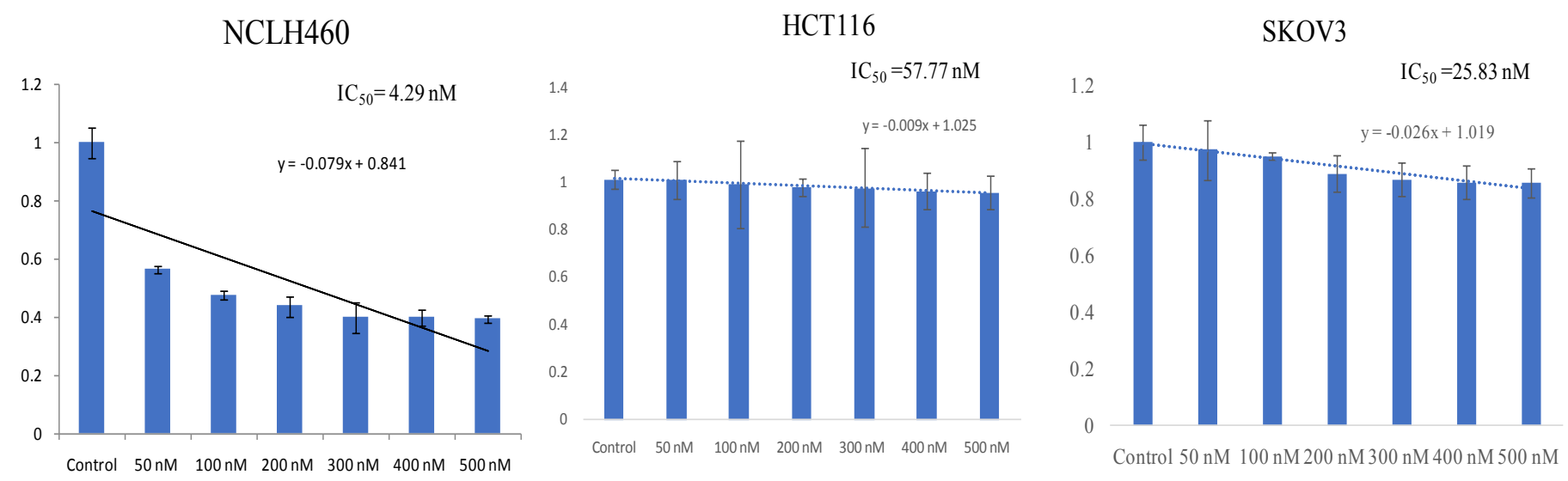

Dose response curve for Compound 20a against normal PNT2 cells (normal prostatic epithelial cells)

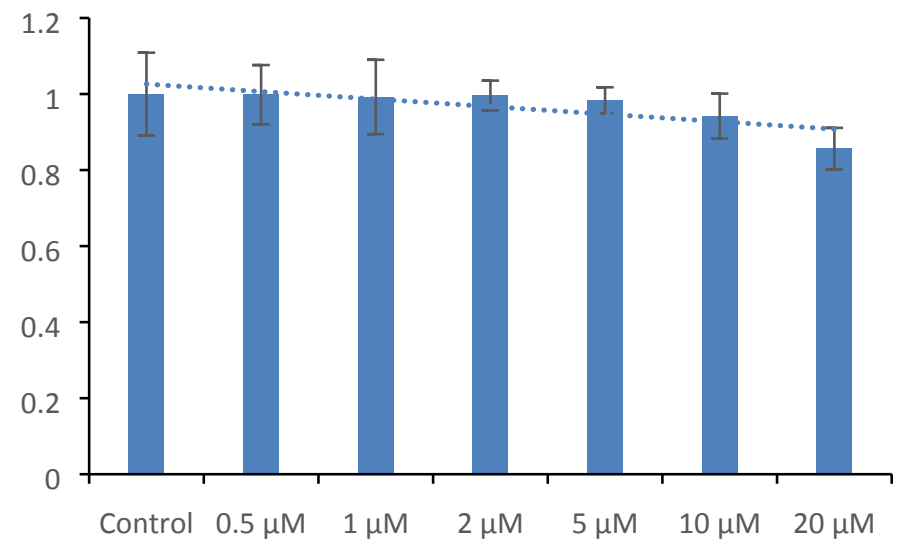

\subsubsection{Colony formation assay}

NCI-H460 cells were seeded in six-well plate at a density of 500 cells per well and caused adherence of the cells (left for overnight), these cells were treated with different concentration of 20a. After every $72 \mathrm{~h}$, the media was changed and the cells were treated with 20a and these experiments lasted for 15 days. After the development of colony, the wells were washed with PBS, fixed with 3.7\% formaldehyde for $20 \mathrm{~min}$, washed with PBS and then were stained using $0.4 \%$ crystal violet followed by rinsing the wells with PBS 4 to 5 times. The colonies were counted by using Image $\mathrm{J}$ software ${ }^{3}$.

\subsection{Evaluation of Mechanistic Studies}




\subsubsection{Flow cytometry for assessing intracellular ROS}

The levels of intracellular reactive oxygen species (ROS) were measured following 20a treatment. After treatment, the cells were incubated for $24 \mathrm{~h}$ followed by trypsinization of cells and re-suspension in pre-warmed PBS containing probe $\mathrm{CM}-\mathrm{H}_{2}$ DCFDA for 30 minutes in the dark at $37^{\circ} \mathrm{C}$. The fluorescence intensity was measured using flow cytometer ${ }^{4}$.

\subsubsection{Cell cycle analysis NCI-H460 cells}

Effect of 20a on the cell cycle of cell line was evaluated by using flow cytometry at $5 \mu \mathrm{M}, 10$ $\mu \mathrm{M}$, and $20 \mu \mathrm{M}$, concentrations. These cells were seeded into 6 well plates and placed for incubation at $37{ }^{\circ} \mathrm{C}$ for $24 \mathrm{~h}$ which lead to attachment of cells with $50-60 \%$ confluency. Further on it was treated with vehicle control $0.1 \%$ DMSO and 20a $(0.5,1,2,5$ and $10 \mu \mathrm{M})$ and incubated for $72 \mathrm{~h}$. The collected cells were harvested and fixed with $75 \%$ ice cold ethanol at $4^{\circ} \mathrm{C}$. Excess of ethanol was removed and cells were washed with PBS. Cells were treated and stained with RNase $(50 \mathrm{U} / \mathrm{mL})$ and Propidium Iodide $(20 \mu \mathrm{g} / \mathrm{mL})$ staining solution for $20 \mathrm{~min}$ at room temperature in dark and was further subjected for flow cytometry (Bectone Dickinson, FACS Verse) ${ }^{5}$.

\subsubsection{Cell apoptosis assay}

To assess the effect of compound 20a treatment on apoptosis, Annexin V-FITC and Propidium iodide staining was performed and the cells were analyzed using FACS verse (BD). Briefly, NCI-H460 cells were treated with compound 20a at $5 \mu \mathrm{M}, 10 \mu \mathrm{M}$ and $20 \mu \mathrm{M}$ and the cells were incubated for $72 \mathrm{~h}$ at $37^{\circ} \mathrm{C}$ and $5 \% \mathrm{CO}_{2}$. Next, the cells were harvested and incubated with $1 \mathrm{X}$ binding buffer containing Annexin-V FITC and propidium for 30 minutes. The samples were acquired for cell death analysis using FACS verse (BD) ${ }^{6}$.

\subsubsection{Wound healing assay}

NCI-H460 cells $\left(3 \times 10^{5}\right)$ were seeded and grown to each well of 6 well plates until mono-layer was formed. Then by using $200 \mu \mathrm{L}$ pipette tip, a scratch was given in confluent mono layer. Cells were washed, to remove non-adherent cell debris. Cells were further treated with $5 \mu \mathrm{M}, 10$ $\mu \mathrm{M}$ and $20 \mu \mathrm{M}$ of compound 20a. Cell migration across the wound area were captured with an inverted microscope and photographed for indicated time $(0$, and $24 \mathrm{~h})$. The percentage wound healed area was calculated after normalizing the wound area ${ }^{7}$. 


\subsubsection{Western blotting}

NCI-H460 Cells treated with compound 20a were lysed after $72 \mathrm{~h}$ of incubation period with $2 \mathrm{X}$ SDS lysis buffer containing $0.5 \mathrm{M}$ Tris-HCl, $\mathrm{pH}$ 6.8, glycerol, $10 \%(\mathrm{w} / \mathrm{v})$ SDS, protease inhibitor cocktail. The lysates were sonicated and centrifuged at $16000 \mathrm{~g}$ for $20 \mathrm{~min}$ following which supernatant was collected and subjected to protein estimation by Pierce ${ }^{\mathrm{TM}} \mathrm{BCA}$ assay kit (ThermoFisher). 30-40 $\mu \mathrm{g}$ of proteins were separated on SDS gel and transferred to PVDF membranes. Membranes were exposed to blocking buffer containing $5 \%$ skim milk and probed with specific primary antibodies at $4{ }^{\circ} \mathrm{C}$ overnight. Next, the blots were washed three times for 5 minutes with Tris buffer solution with tween-20 (TBST) and incubated with HRP-conjugated secondary antibody for $1 \mathrm{~h}$. The blots were washed three times with 1x TBST and the bands were detected by ECL Elistar ETA ultra 20 (Cyanagen) ${ }^{8}$.

\subsection{RNA isolation and quantitative PCR}

TRIzol reagent was used to isolate total RNA from the control and drug treated NCI-H460 cells. Following that, cDNA was synthesized from $2 \mathrm{~g}$ of total RNA using a cDNA synthesis kit (Takara), according to the manufacturer's instructions. Table S4 lists below the primers used against the genes under investigation.

Table S2: Lists the primers used against the genes under investigation.

\begin{tabular}{|l|l|l|}
\hline GENE & FORWARD PRIMER SEQUENCE & REVERSE PRIMER SEQUENCE \\
\hline GAPDH & 5'-GTCAAGGCTGAGAACGGGAA-3' $^{\prime}$ & 5'-AGTGGCTCCATTCACCGC-3' \\
\hline VEGFR2 & 5'-GGAACCTCACTATCCGCAGA-3' $^{\prime}$ & 5'-CCGCCGTGCCTACTAGAATA-3' \\
& & \\
\hline
\end{tabular}

The PCR cycling schedule was 10 minutes at $95^{\circ} \mathrm{C}$, followed by 40 cycles of 15 seconds at $95^{\circ} \mathrm{C}$, 30 seconds at $60^{\circ} \mathrm{C}$, and a melt curve with a single reaction cycle at $95^{\circ} \mathrm{C}$ for 15 seconds, $60^{\circ} \mathrm{C}$ for 1 minute, and dissociation at $95^{\circ} \mathrm{C}$ for 15 seconds. The resulting $\mathrm{Ct}$ values were then adjusted to the housekeeping gene actin. The relative expression of genes was determined using the $2^{-\Delta \Delta \mathrm{ct}}$ method. 


\subsection{Molecular docking}

To view binding pattern of all the synthesized compounds for their anti-proliferative activity, molecular docking was carried out at the VEGFR2 kinase receptor catalytic ligand binding site (PDBID: 2QU5). Docking simulations of Compounds20a-k, 21, 22a-b were performed using Maestro, version 9.6 implemented from Schrodinger software suite. The ligands were sketched in $3 \mathrm{D}$ format using build panel and were prepared for docking using ligprep application. The protein for docking study was obtained from Protein data bank (PDB ID: 2QU5) and prepared by removing solvent, adding hydrogen and further minimization in the presence of bound ligand (276) using protein preparation wizard. Grids for molecular docking were generated with bound co-crystallized ligand. For the validation of docking parameters, the co-crystal ligand (276) was re-docked at the catalytic site of protein and the RMSD between co-crystal and re-docked pose was found to be $0.405 \AA$. All the synthesized compounds were docked using Glide extraprecision (XP) mode, with up to three poses saved per molecule ${ }^{9}$. 


\section{References}

(1) Janganati, V.; Ponder, J.; Thakkar, S.; Jordan, C. T.; Crooks, P. A. Succinamide derivatives of melampomagnolide B and their anti-cancer activities. Bioorg Med Chem 2017, 25, 2017.

(2) Feoktistova, M.; Geserick, P.; Leverkus, M. Crystal Violet Assay for Determining Viability of Cultured Cells. Cold Spring Harbor protocols 2016, 2016, 2016.

(3) Franken, N. A. P.; Rodermond, H. M.; Stap, J.; Haveman, J.; van Bree, C. Clonogenic assay of cells in vitro. Nature Protocols 2006, 1, 2006.

(4) Wu, D.; Yotnda, P. Production and detection of reactive oxygen species (ROS) in cancers. J Vis Exp 2011, 2011.

(5) Mustafa, M.; Abdelhamid, D.; Abdelhafez, E. M. N.; Ibrahim, M. A. A.; Gamal-Eldeen, A. M.; Aly, O. M. Synthesis, antiproliferative, anti-tubulin activity, and docking study of new 1,2,4-triazoles as potential combretastatin analogues. European journal of medicinal chemistry 2017, 141, 2017.

(6) Ma, L.; Peng, H.; Li, K.; Zhao, R.; Li, L.; Yu, Y.; Wang, X.; Han, Z. Luteolin exerts an anticancer effect on NCI-H460 human non-small cell lung cancer cells through the induction of Sirt1-mediated apoptosis. Molecular medicine reports 2015, 12, 2015.

(7) Li, W.; Yin, Y.; Shuai, W.; Xu, F.; Yao, H.; Liu, J.; Cheng, K.; Xu, J.; Zhu, Z.; Xu, S. Discovery of novel quinazolines as potential anti-tubulin agents occupying three zones of colchicine domain. Bioorganic chemistry 2018, 83, 2018.

(8) Gour, R.; Ahmad, F.; Prajapati, S. K.; Giri, S. K.; Lal Karna, S. K.; Kartha, K. P. R.; Pokharel, Y. R. Synthesis of novel S-linked dihydroartemisinin derivatives and evaluation of their anticancer activity. European journal of medicinal chemistry 2019, 178, 2019.

(9) Potashman, M. H.; Bready, J.; Coxon, A.; DeMelfi, T. M., Jr.; DiPietro, L.; Doerr, N.; Elbaum, D.; Estrada, J.; Gallant, P.; Germain, J.; Gu, Y.; Harmange, J. C.; Kaufman, S. A.; Kendall, R.; Kim, J. L.; Kumar, G. N.; Long, A. M.; Neervannan, S.; Patel, V. F.; Polverino, A.; Rose, P.; Plas, S.; Whittington, D.; Zanon, R.; Zhao, H. Design, synthesis, and evaluation of orally active benzimidazoles and benzoxazoles as vascular endothelial growth factor-2 receptor tyrosine kinase inhibitors. J Med Chem 2007, 50, 2007. 
4. Scanned copies of ${ }^{1} \mathrm{H},{ }^{13} \mathrm{C}$ NMR and Mass spectra's of the representative compounds:

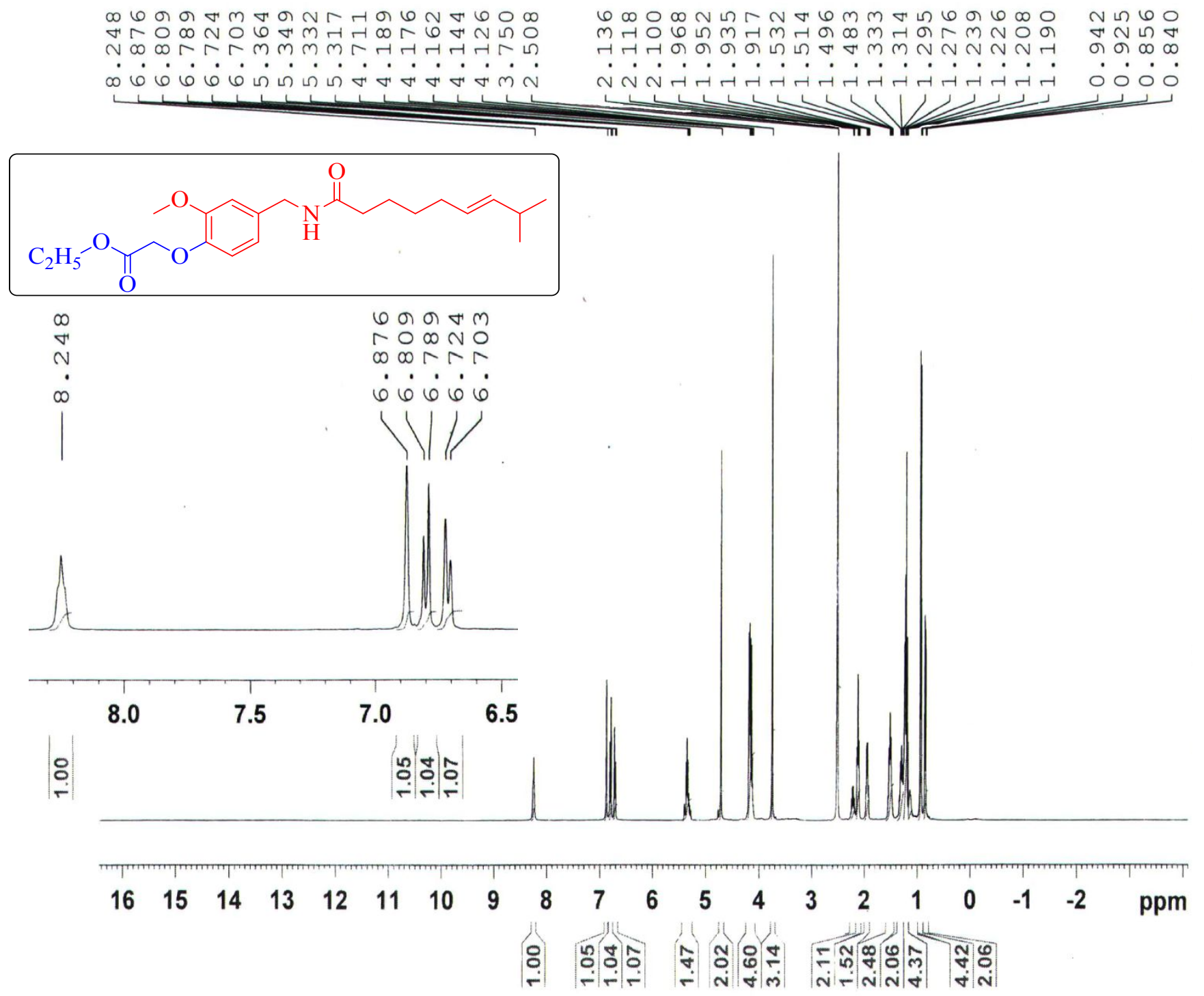

${ }^{1}$ H NMR of Compound 16 

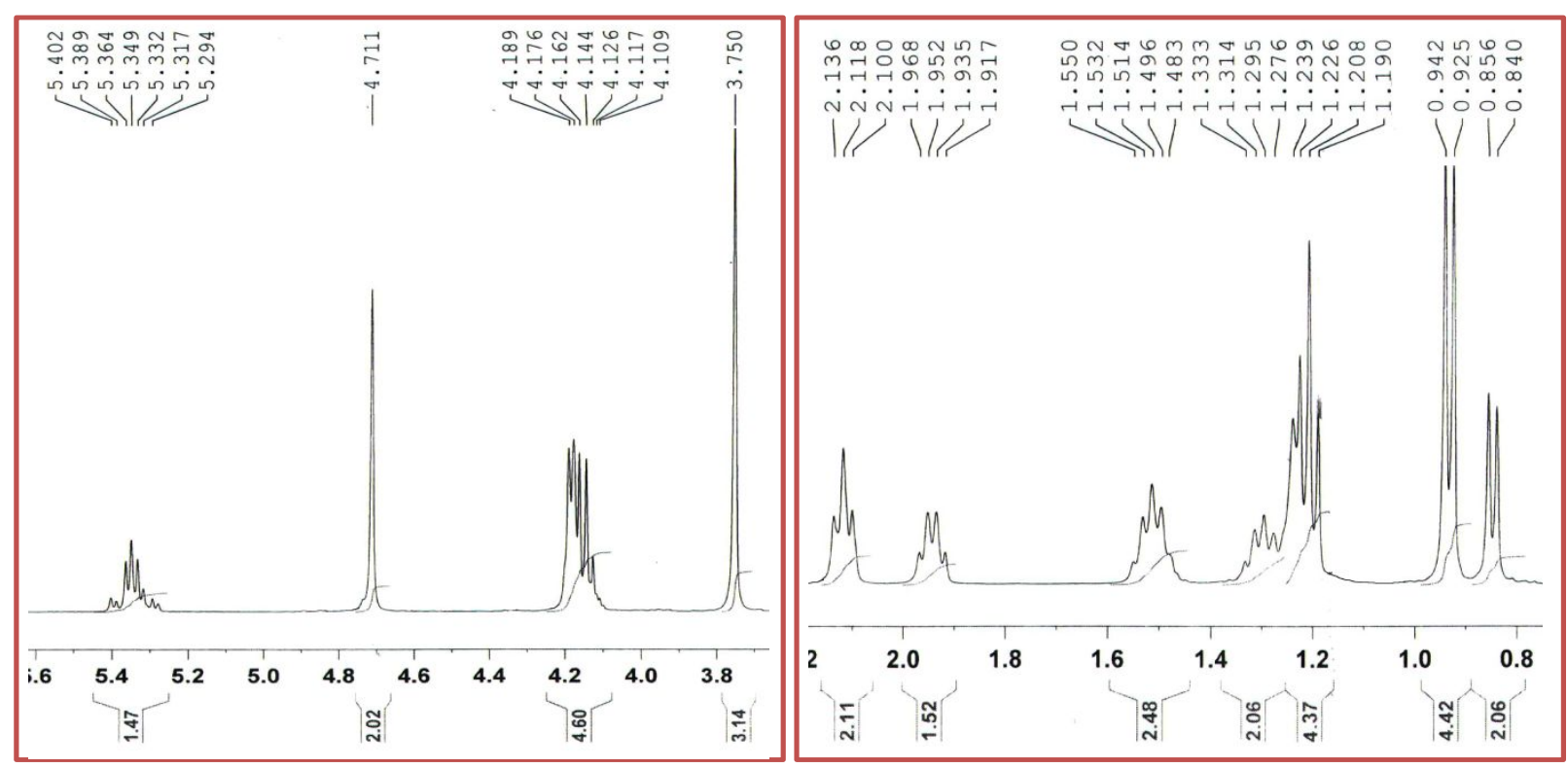

${ }^{1} \mathrm{H}$ NMR of Compound 16
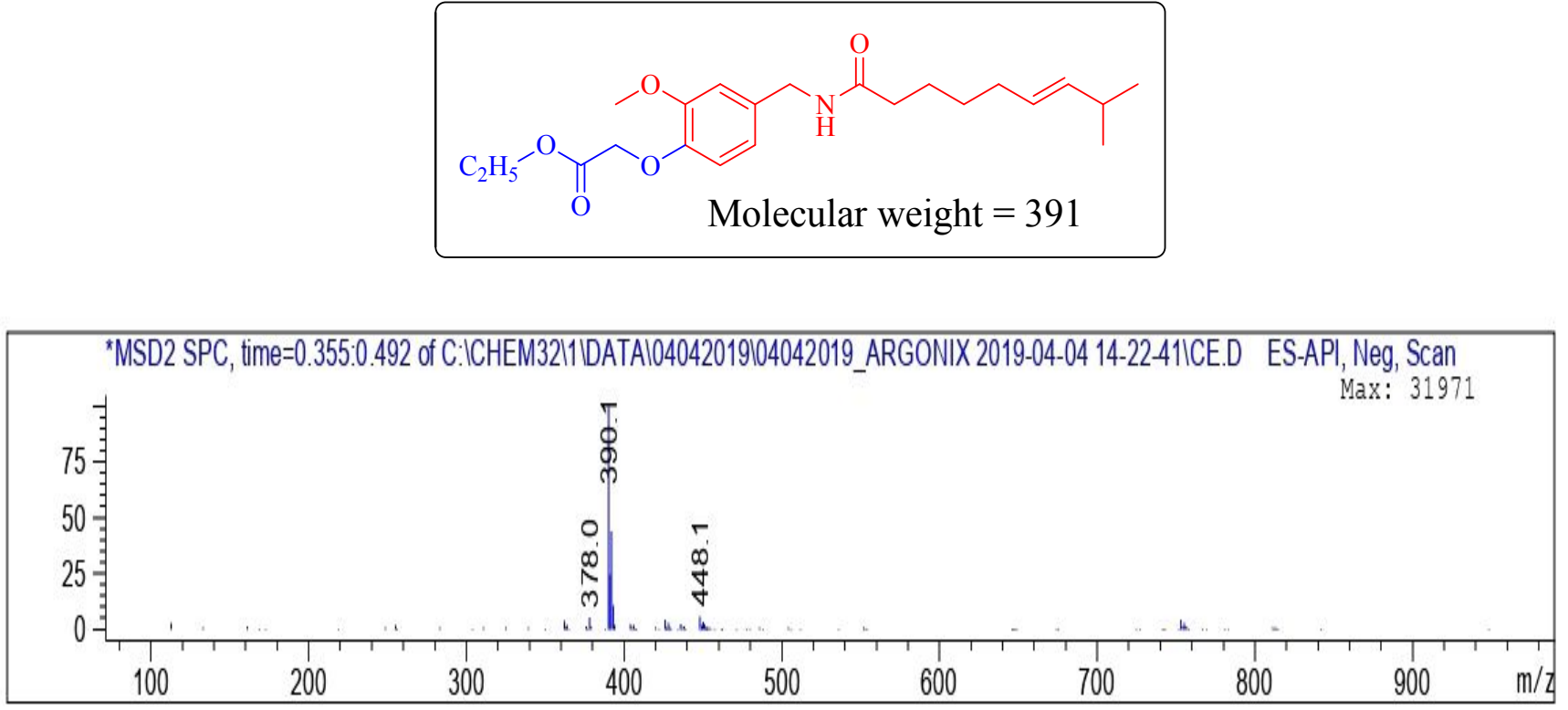

\section{ESI-MS of compound 16}




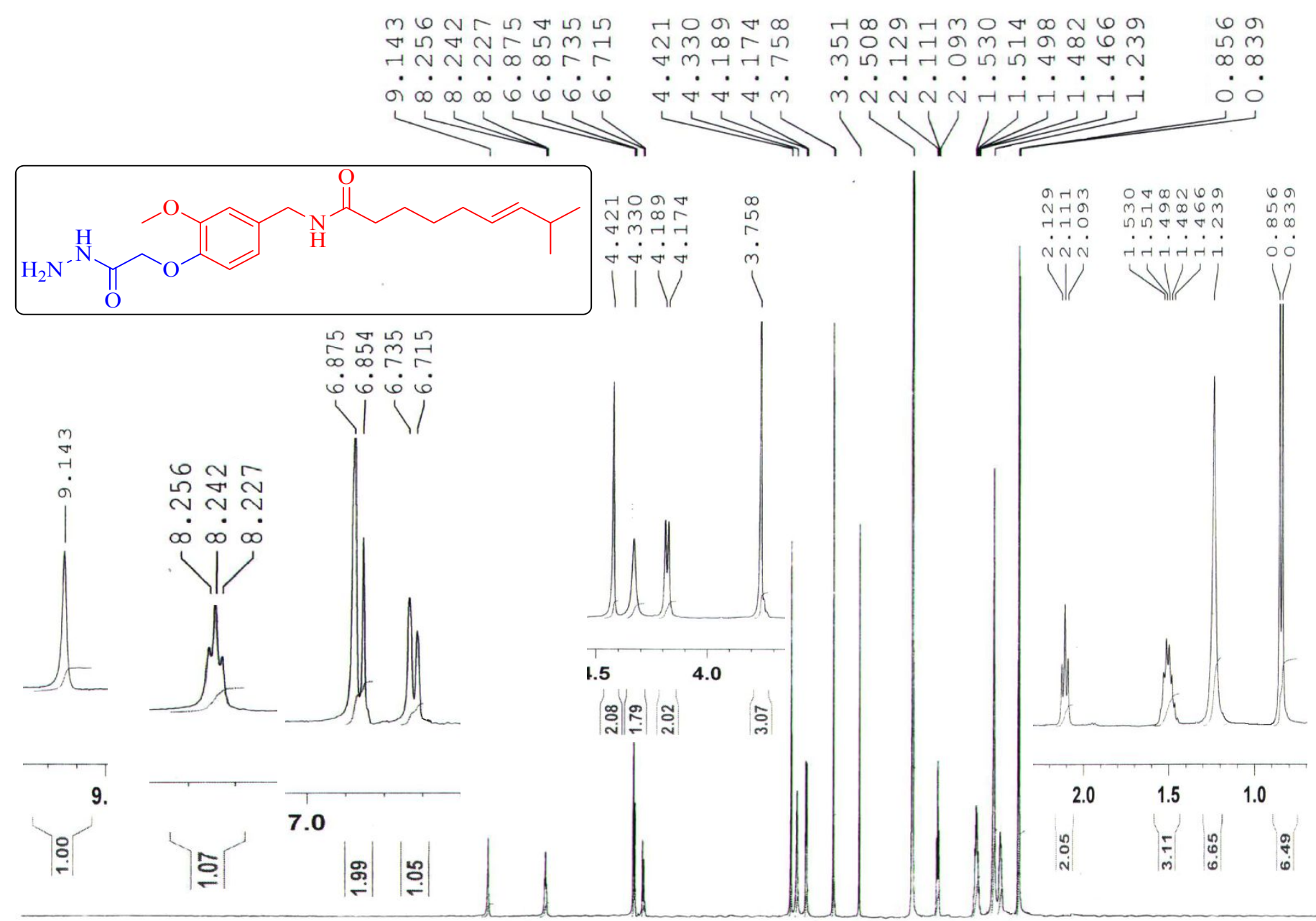

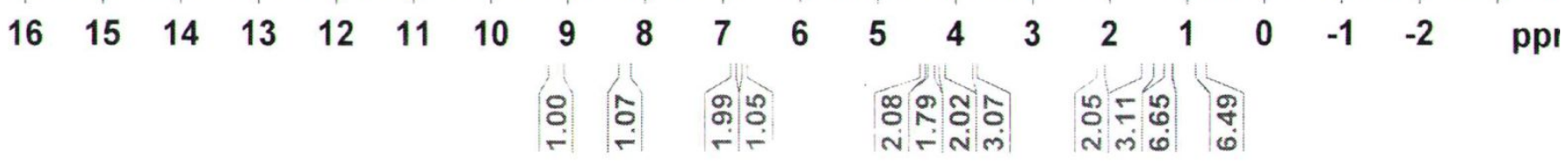

${ }^{1}$ H NMR of Compound 17 


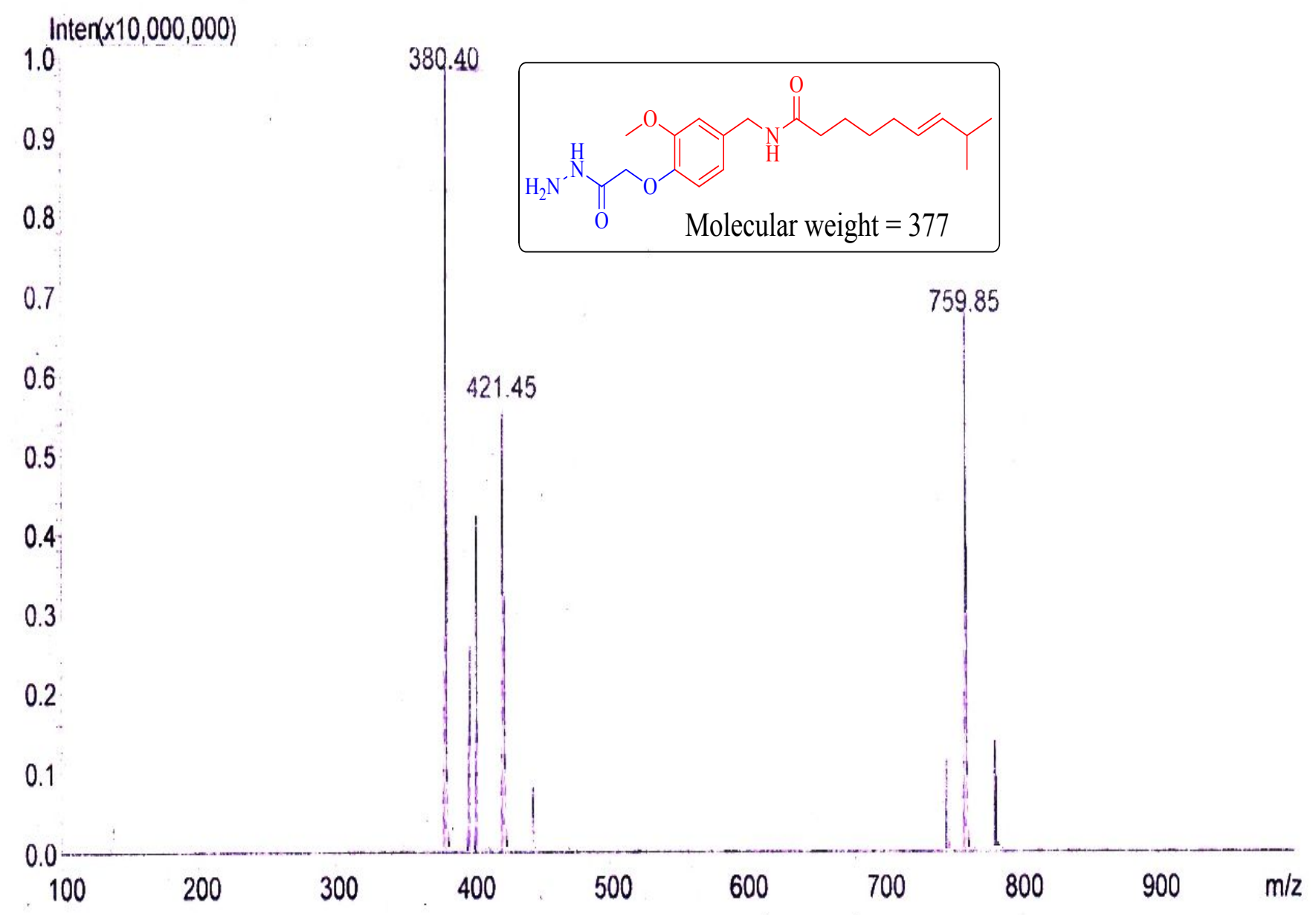

ESI-MS of compound 17 

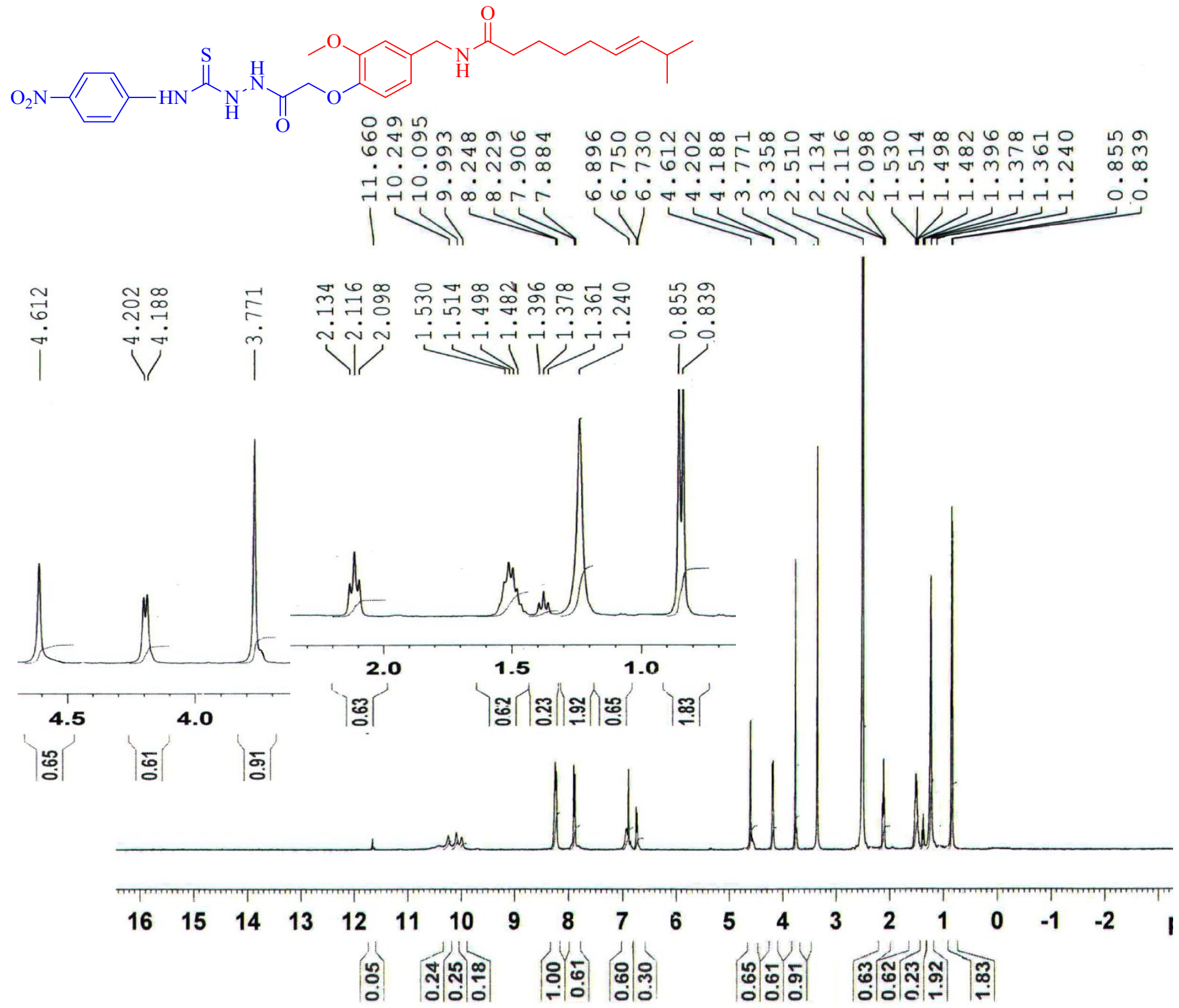

\section{${ }^{1} \mathrm{H}$ NMR of Compound 19a}




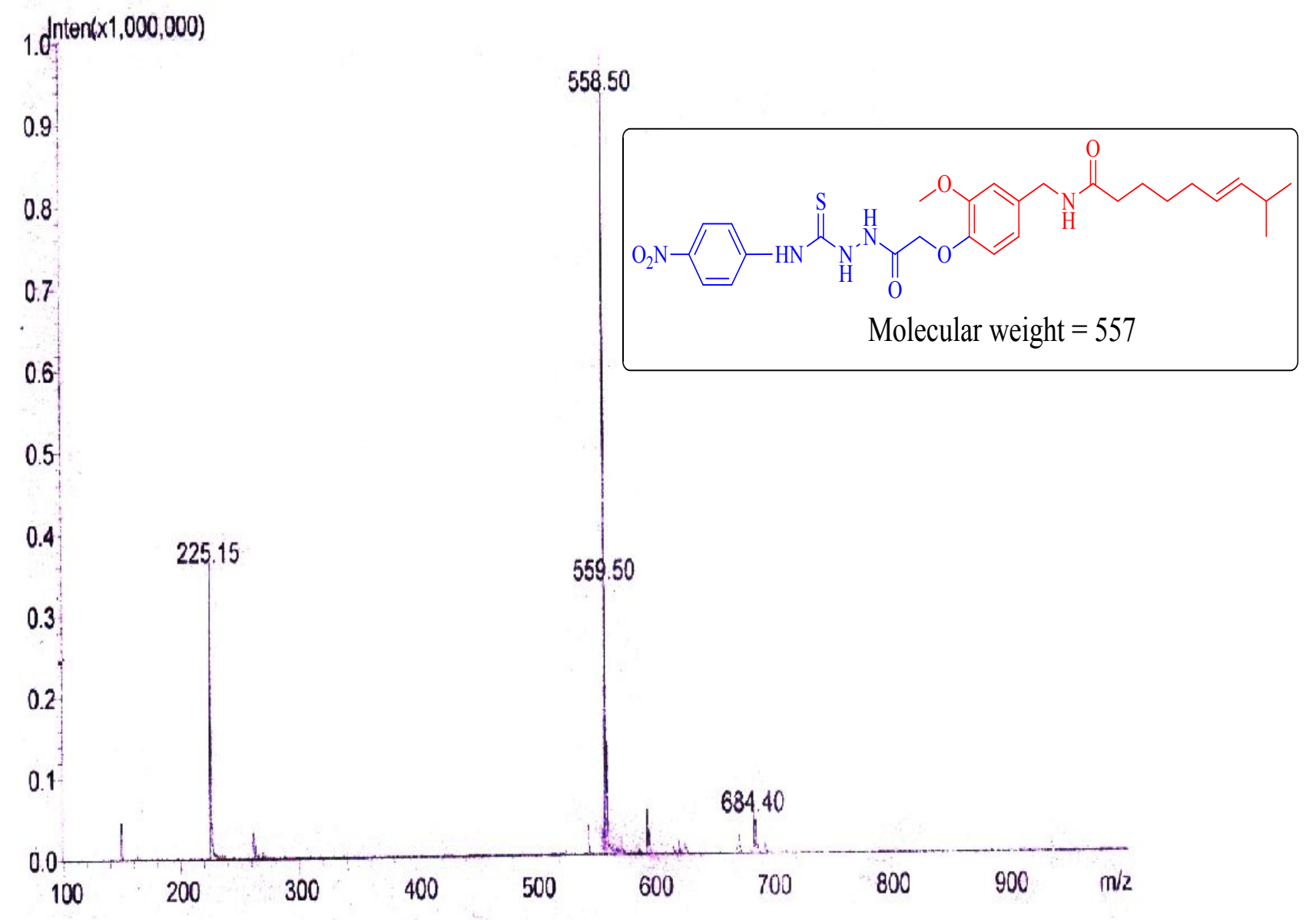

ESI-MS of compound 19a 


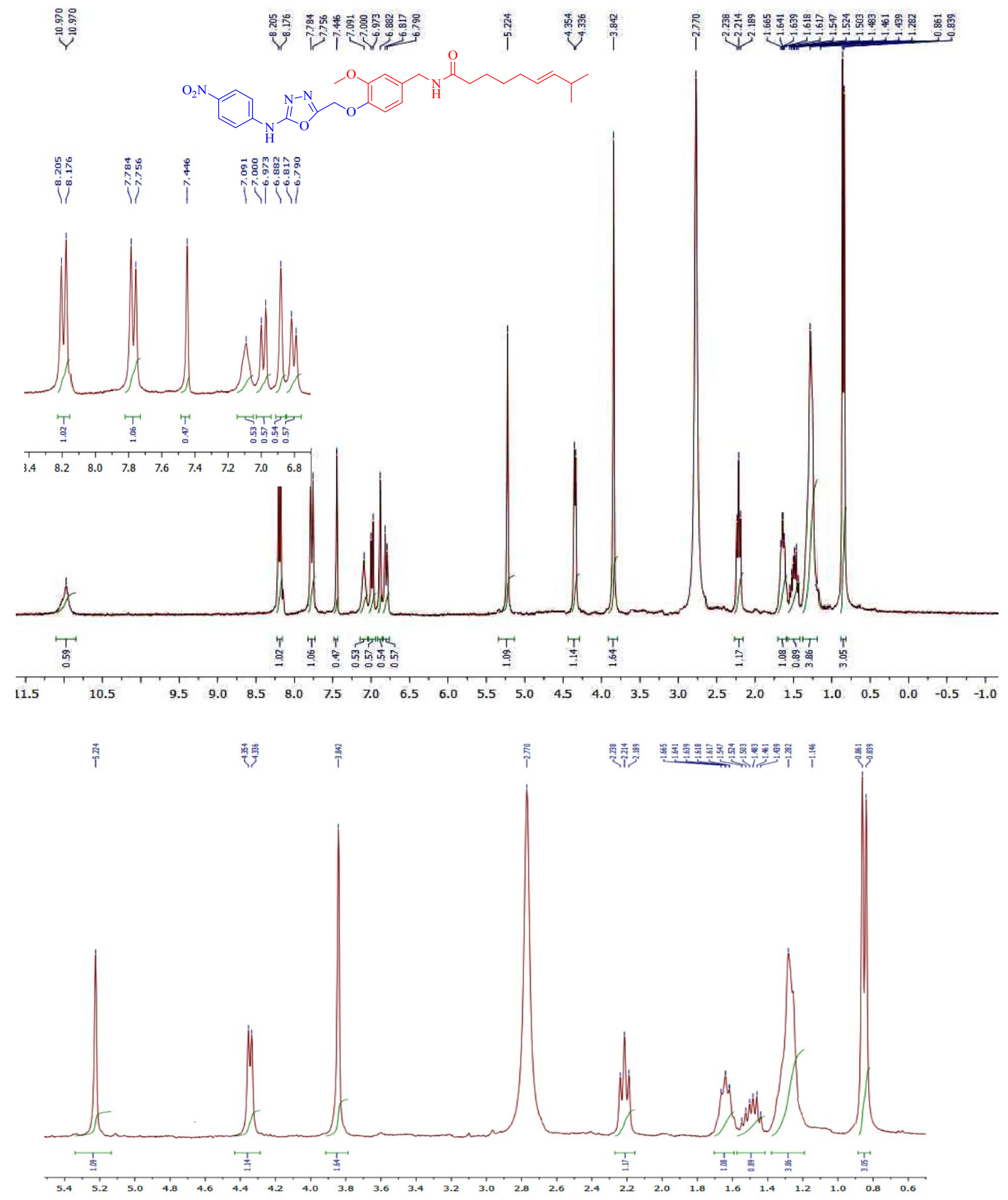

${ }^{1}$ H NMR of Compound 20a 
$\mathrm{D}_{2} \mathrm{O}$ exchange

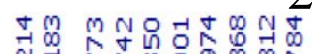

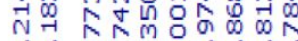

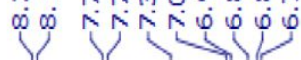

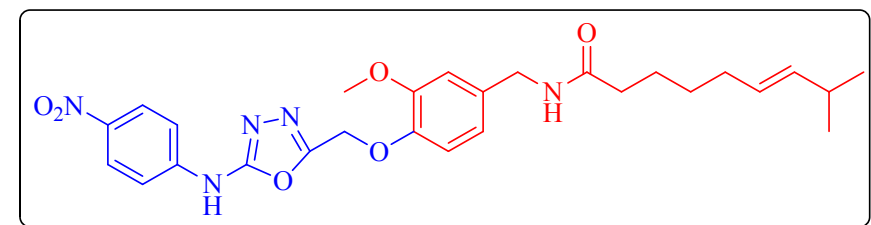

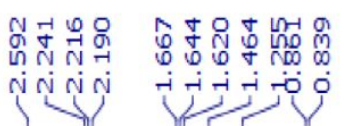

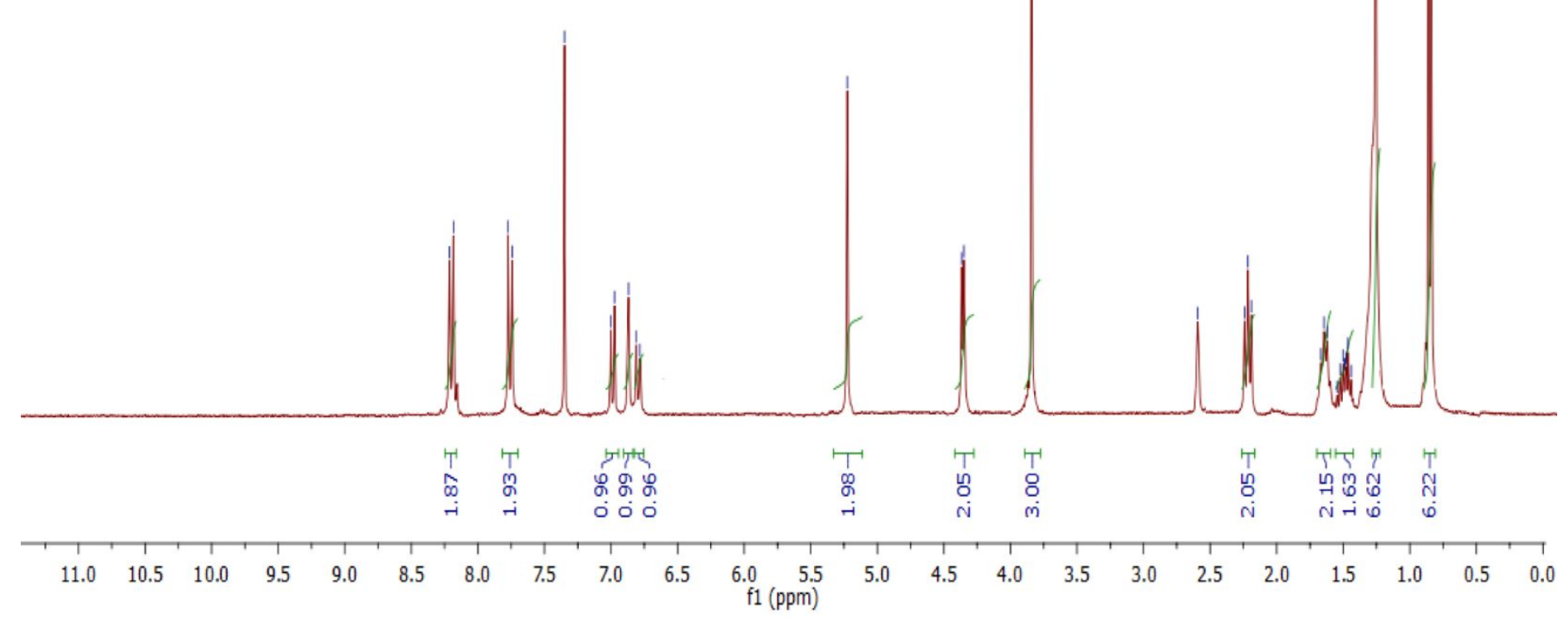

${ }^{1} \mathrm{H}$ NMR of Compound 20a 


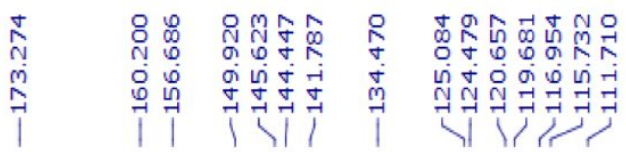
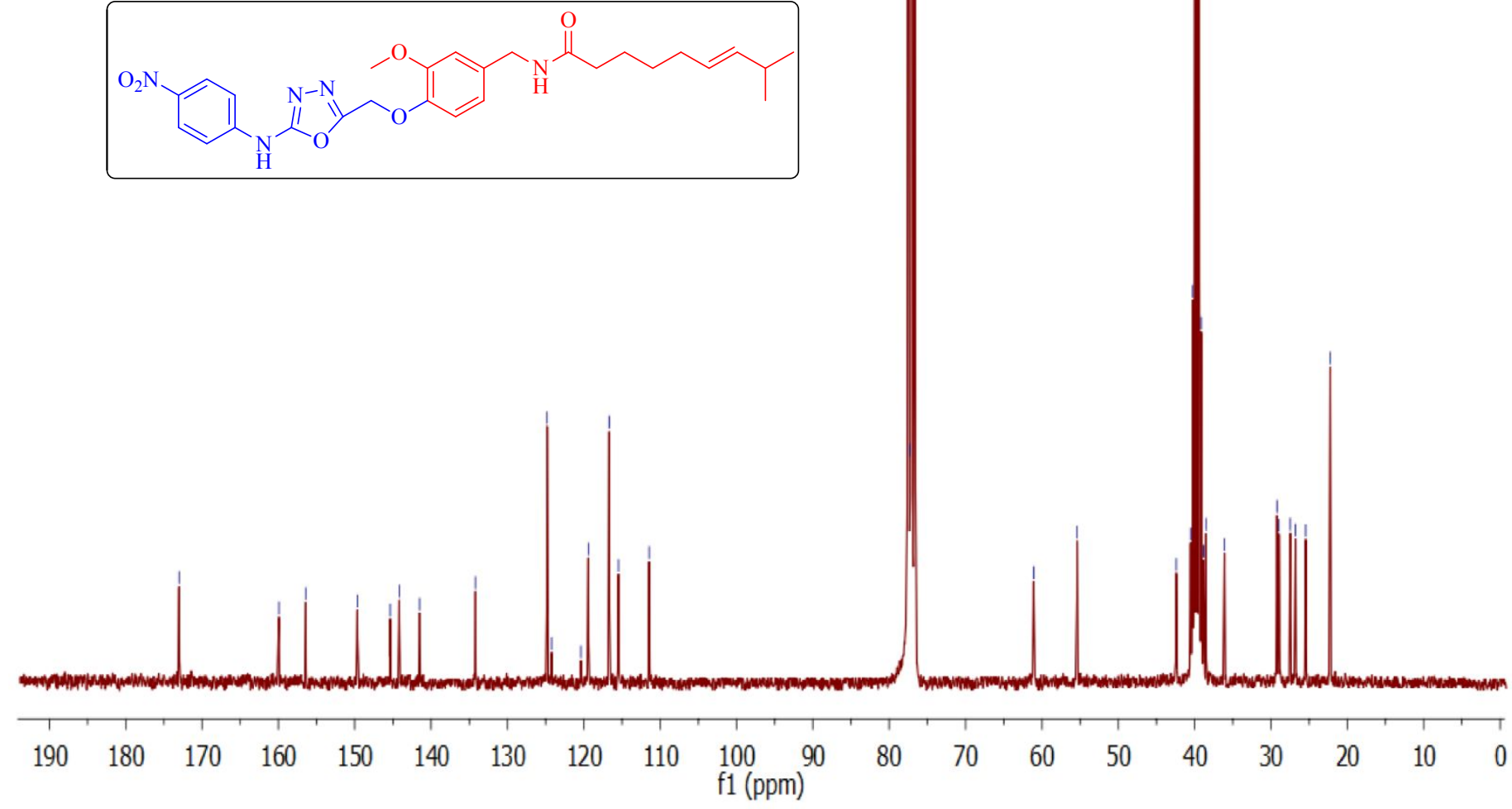

${ }^{13}$ C NMR of Compound 20a 


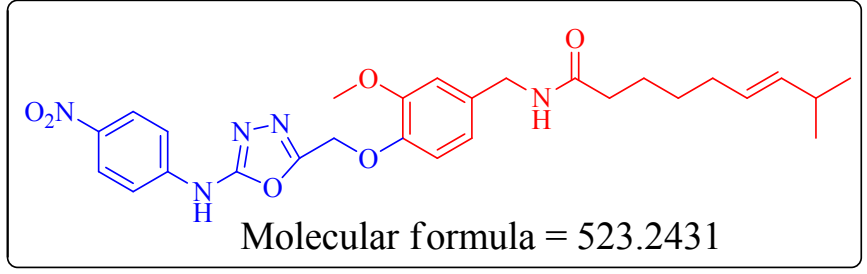

240821_05 $12(0.259)$ Cm (12:13)

Xevo G2-XS QTOF YFC2015

24-Aug-2021

13:01:33

1: TOF MS ES+

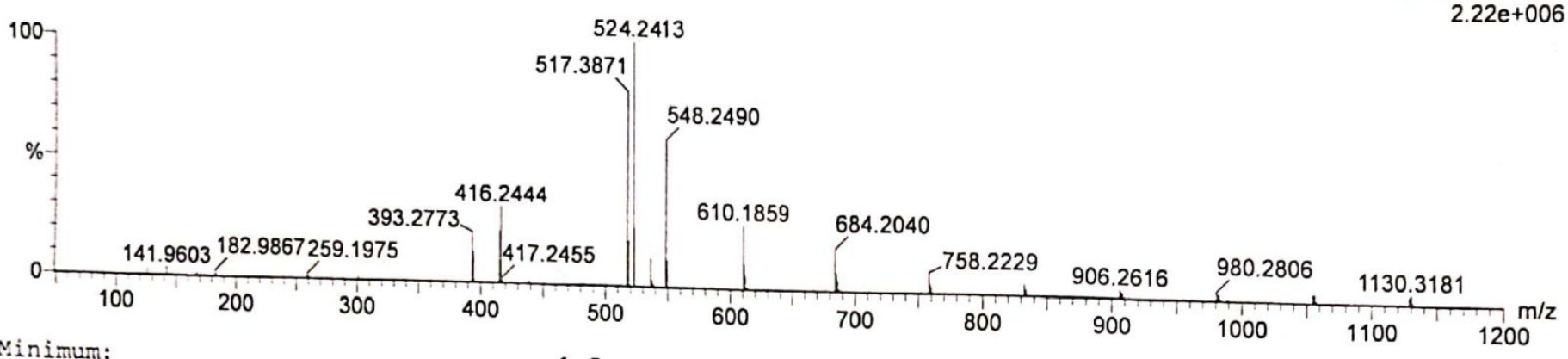

Ninimum:

Maximum:

$$
\begin{array}{lll}
2.0 & 3.0 & -1.5 \\
& & 50.0
\end{array}
$$

HRMS of compound 20a 


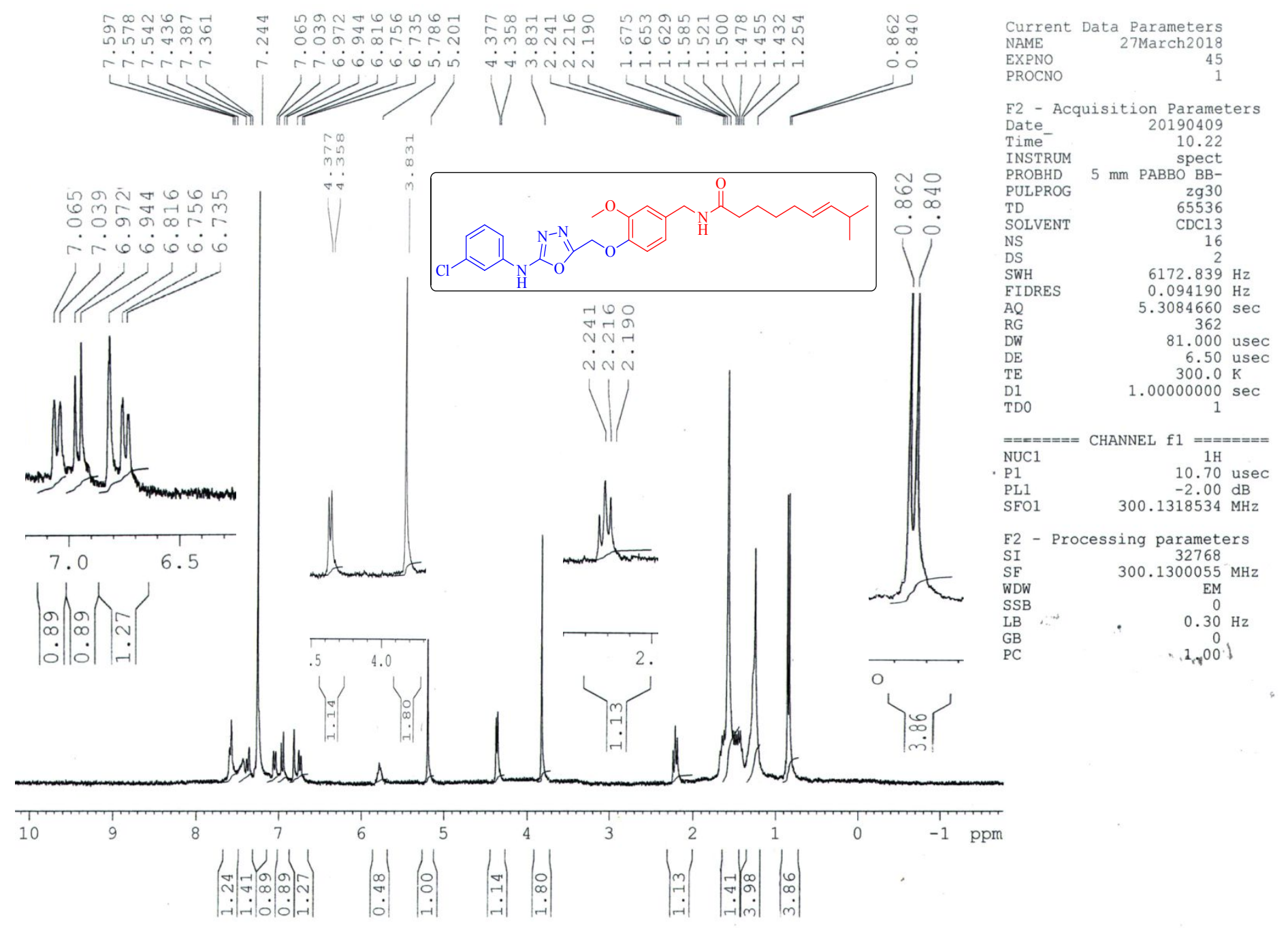

${ }^{1} \mathrm{H}$ NMR of Compound 20b 


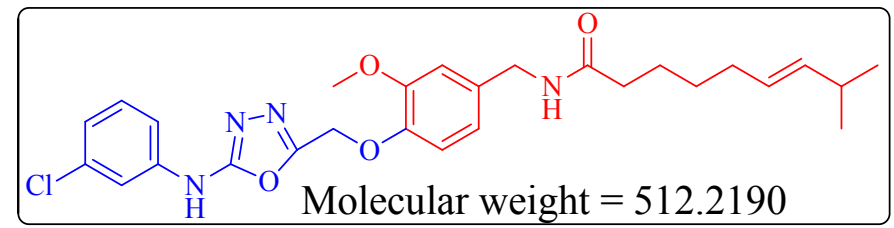

170921_05 $10(0.225) \mathrm{Cm}(10)$

Xevo G2-XS QTOF YFC2015

11:51:21

1: TOF MS ES+

$1.15 e+006$

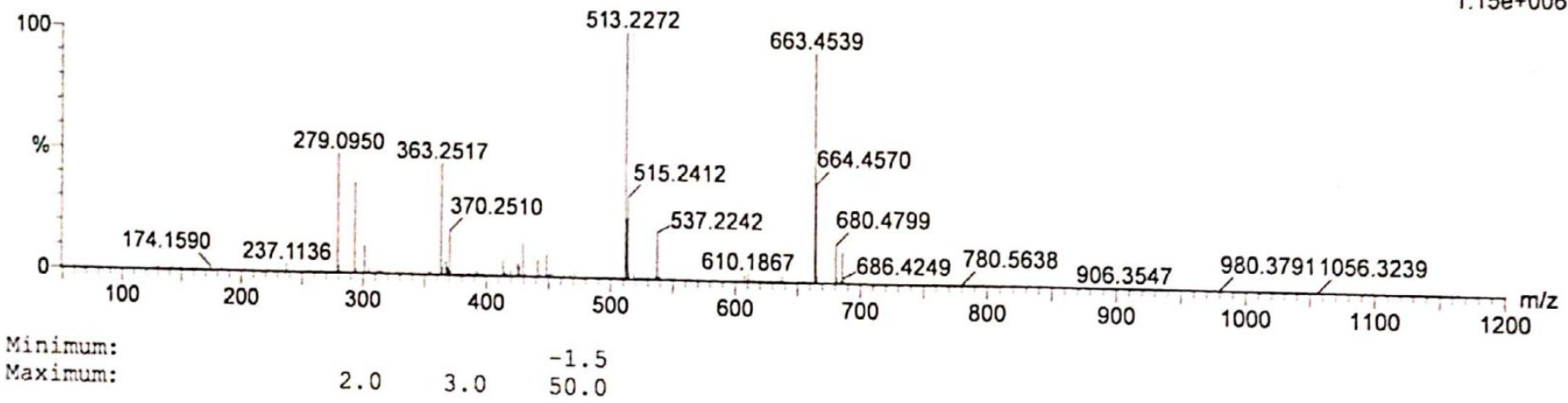

HRMS of compound 20b 


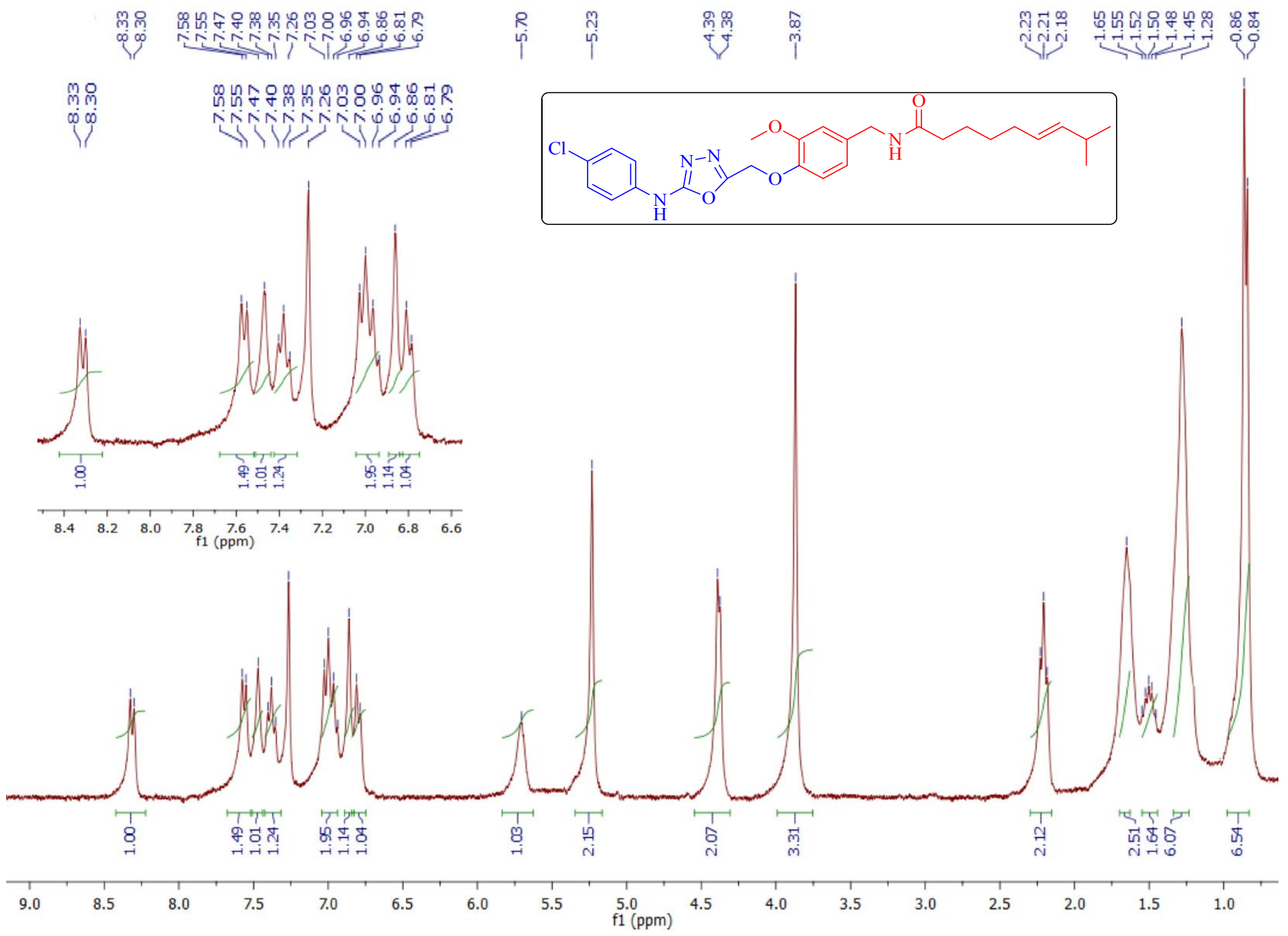

${ }^{1} \mathrm{H}$ NMR of Compound 20c 


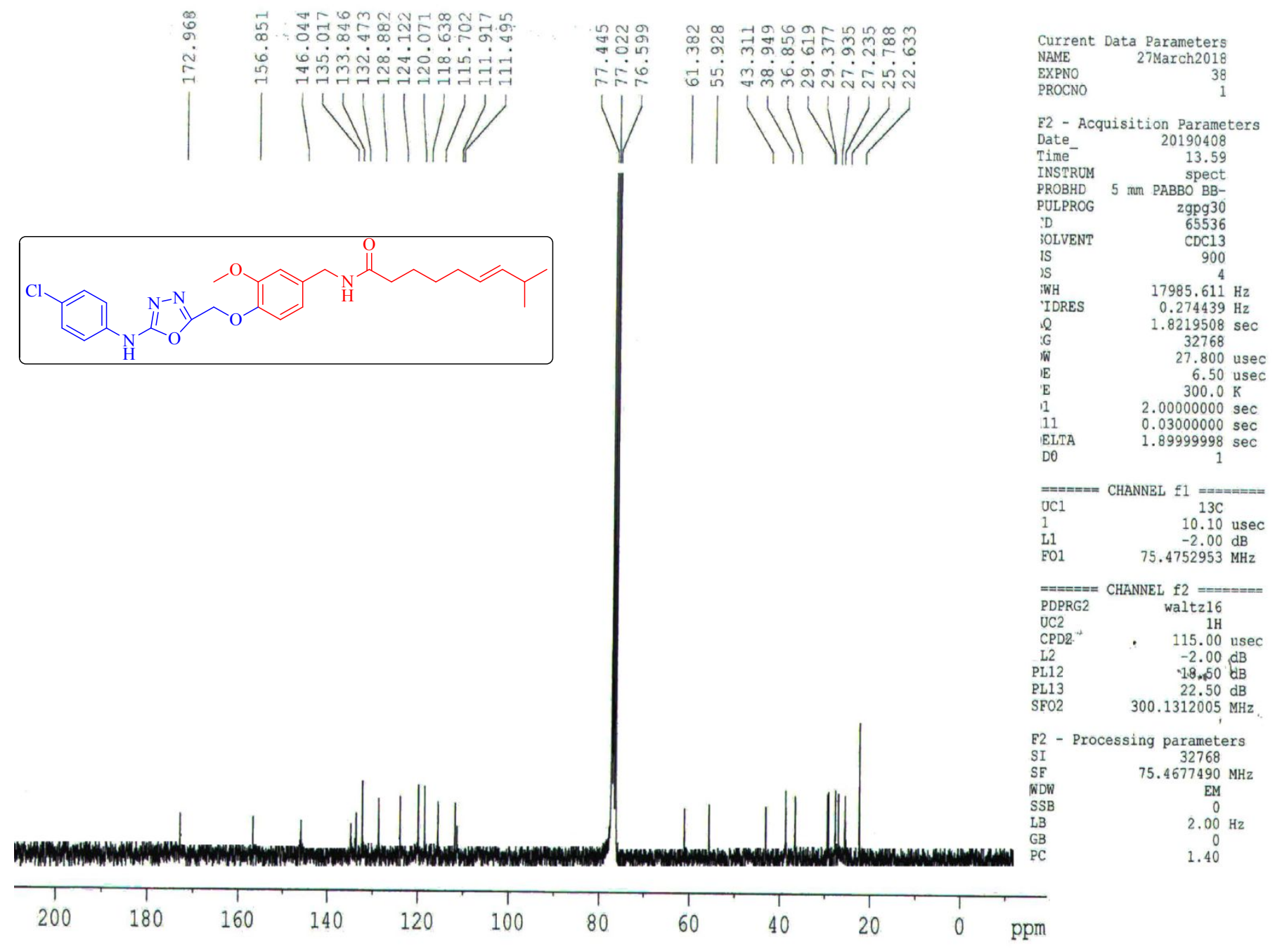

${ }^{13} \mathrm{C}$ NMR of Compound 20c 


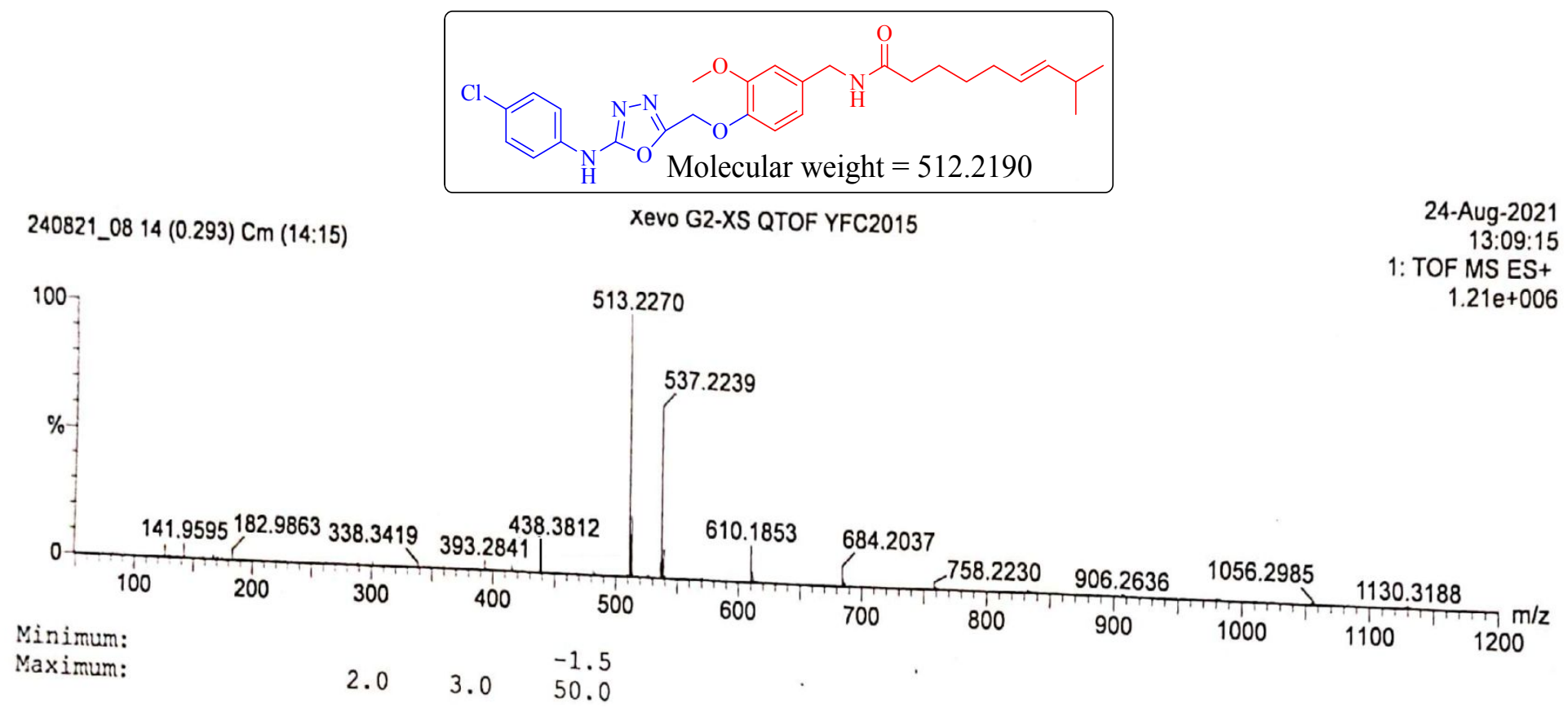

HRMS of Compound 20c 

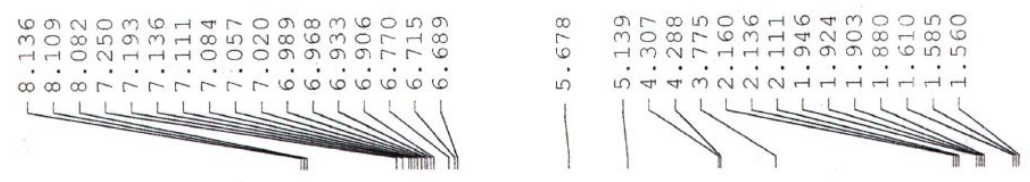

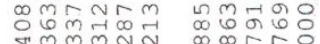

निनंनंन 00000

1110
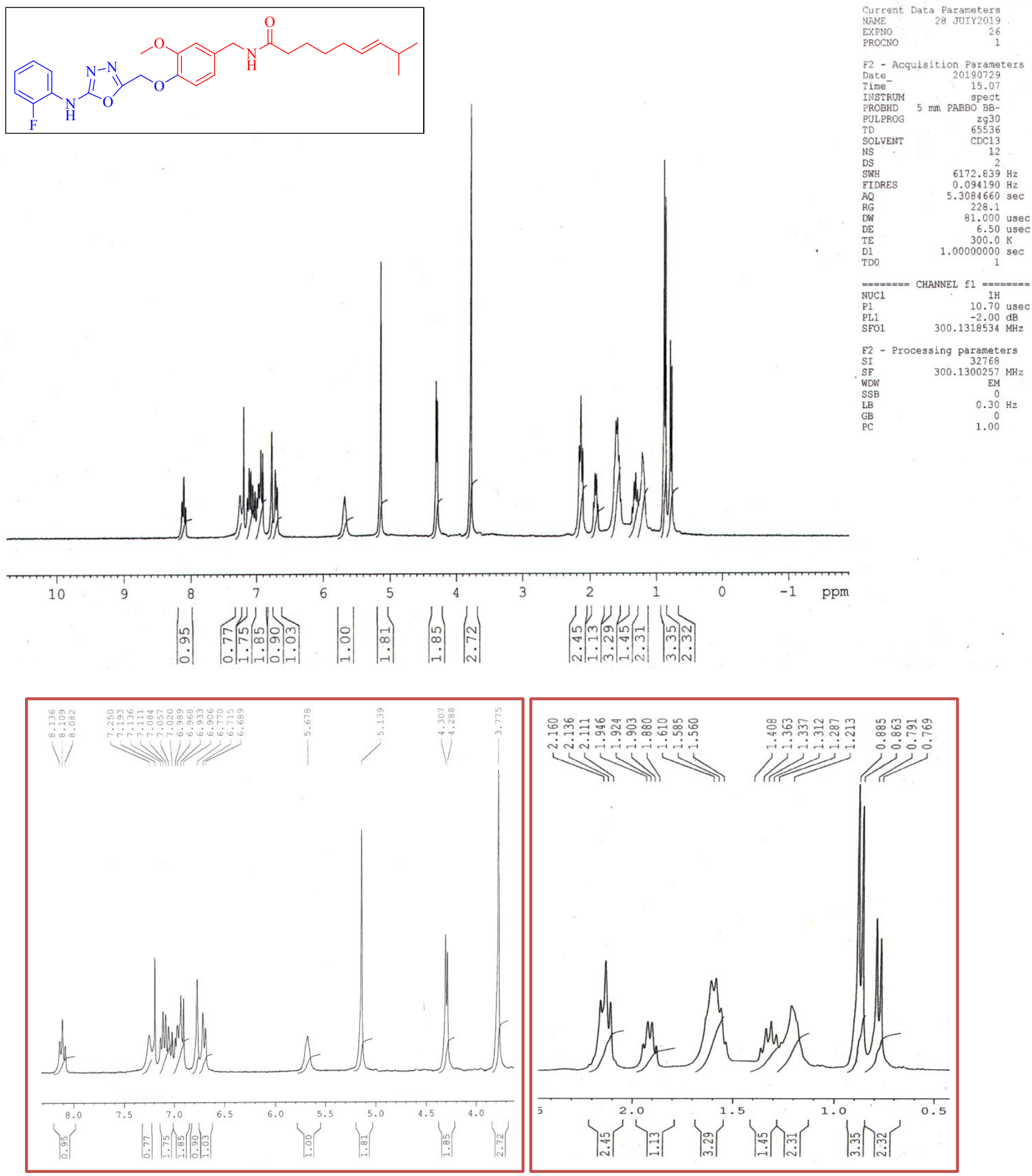

${ }^{1}$ H NMR of Compound 20d 


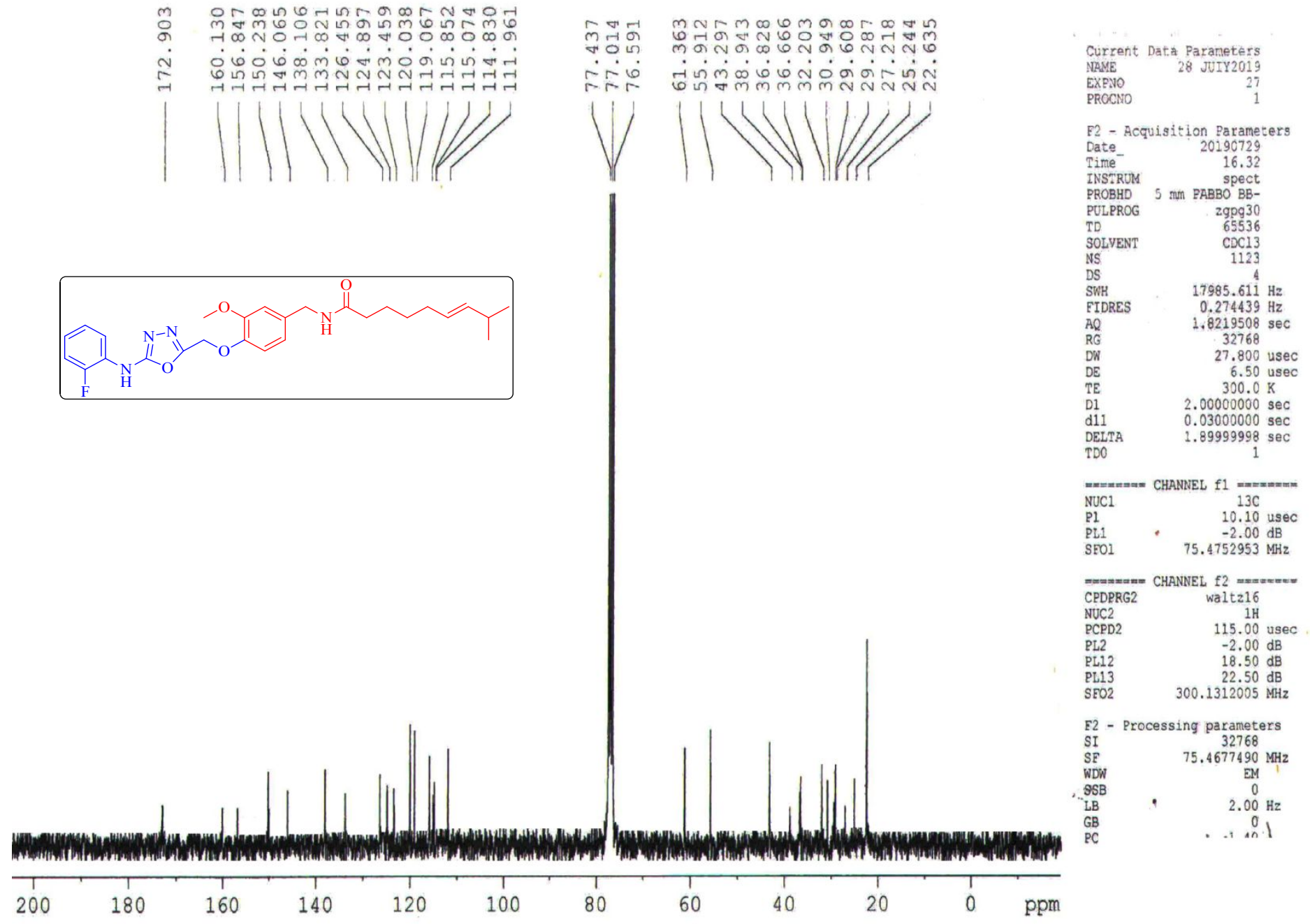

${ }^{13}$ C NMR of Compound 20d 


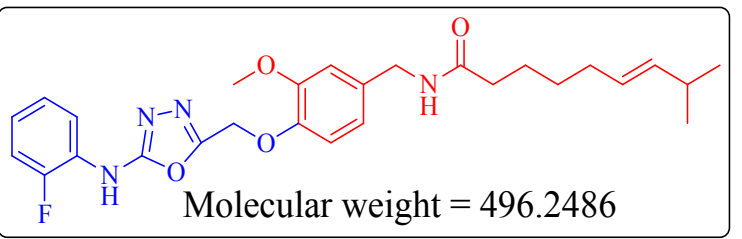

170921_04 18 (0.380) Cm (18)

Xevo G2-XS QTOF YFC2015

11:48:46

1: TOF MS ES+

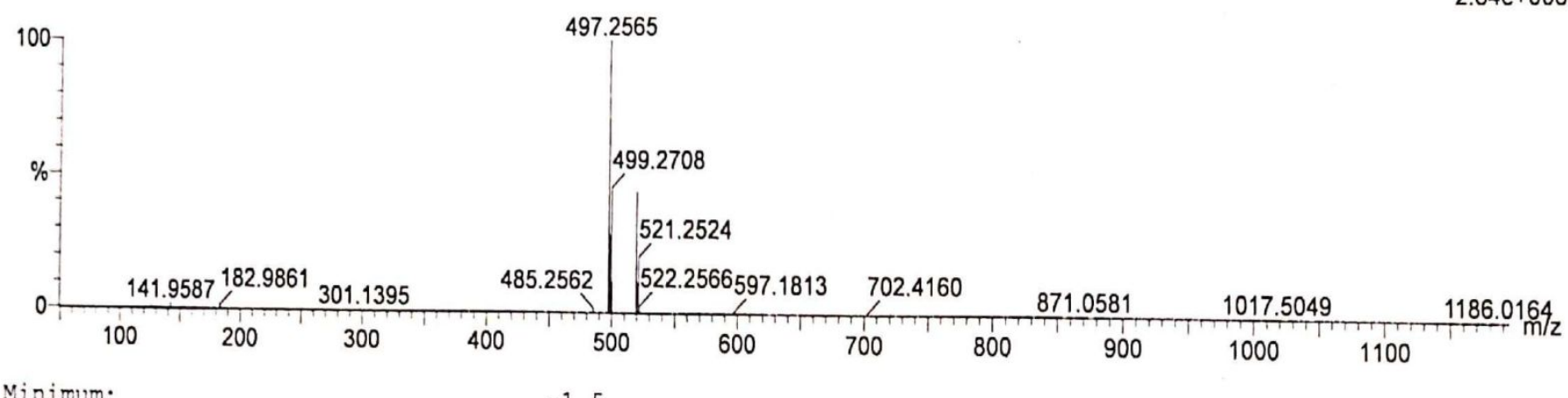

$\begin{array}{llll}\text { Maximum: } & 2.0 & 3.0 & -1.5\end{array}$

\section{HRMS of Compound 20d}



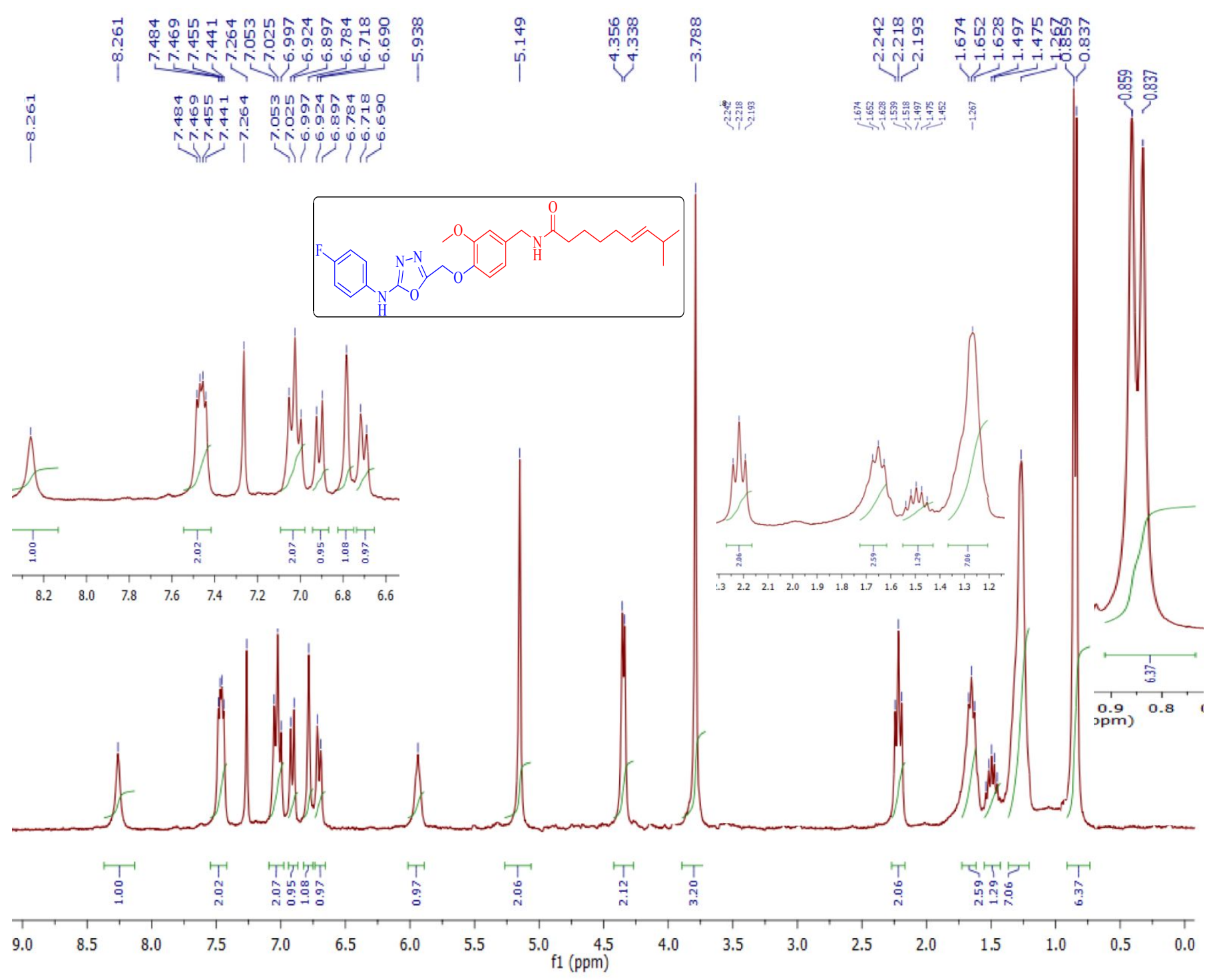

\section{${ }^{1} \mathrm{H}$ NMR of Compound 20e}




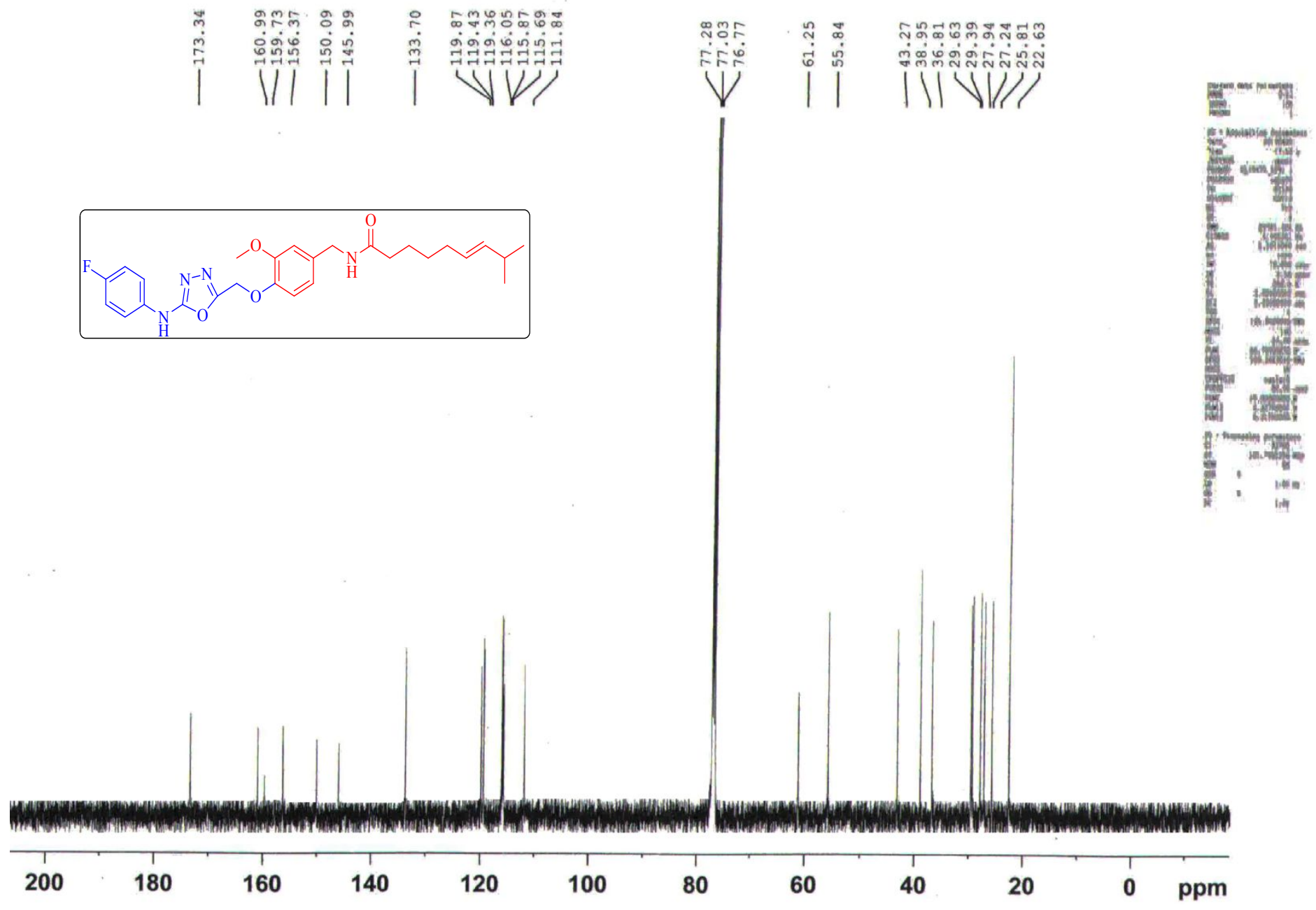

${ }^{13} \mathrm{C}$ NMR of Compound 20e 


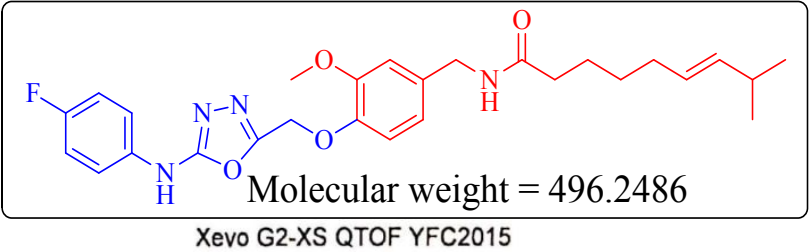

170921_04 18 (0.380) Cm (18)

Xevo G2-XS QTOF YFC2015

11:48:46 1: TOF MS ES+

$2.84 e+006$

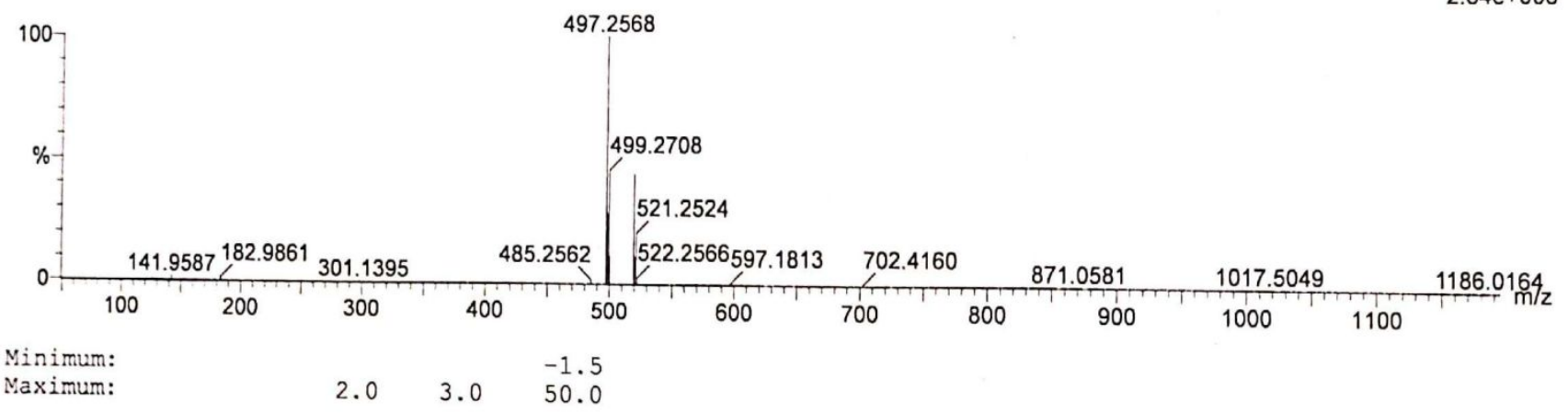

HRMS of Cmpound 20e 


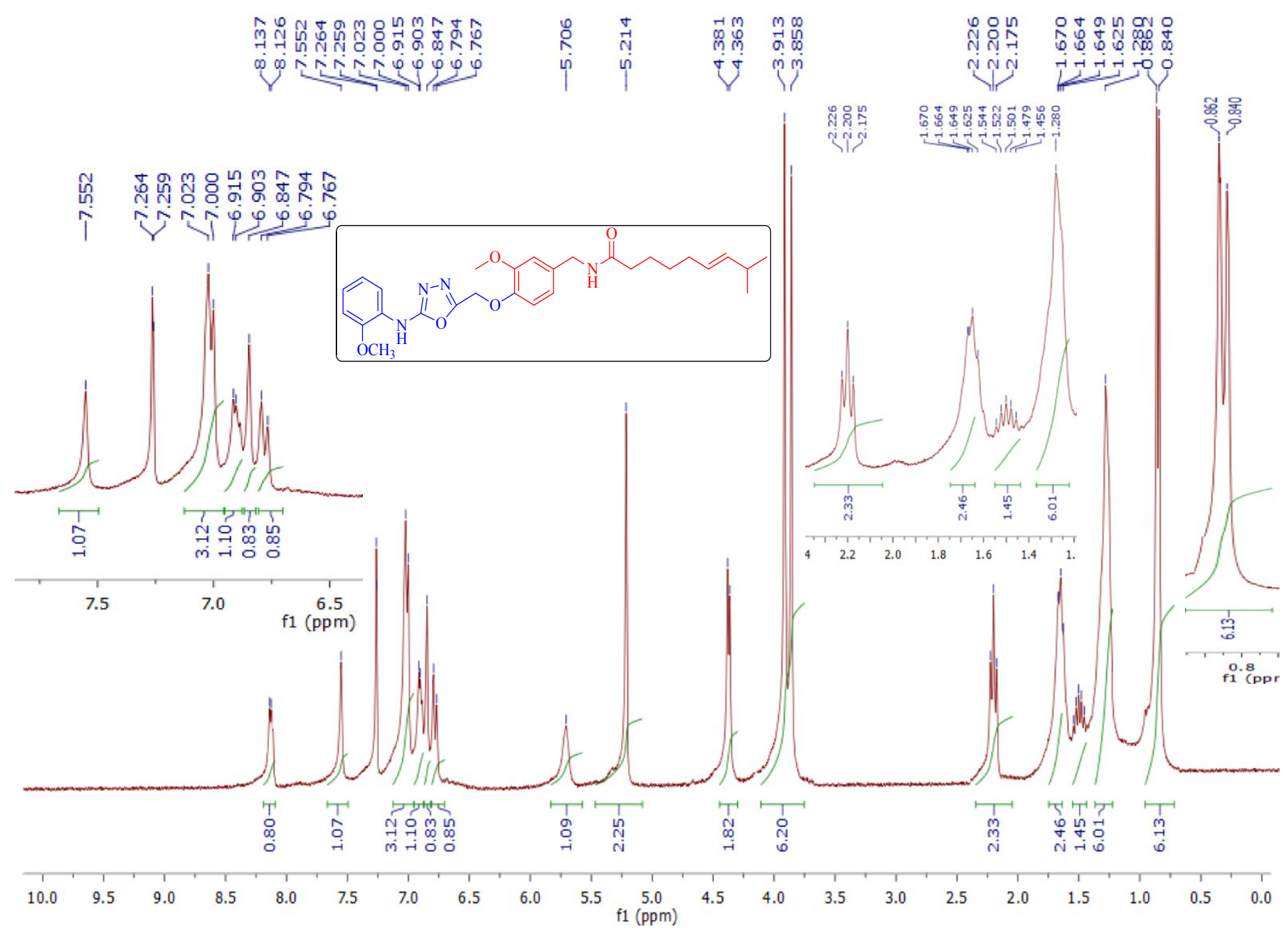

${ }^{1}$ H NMR of Compound $20 f$ 


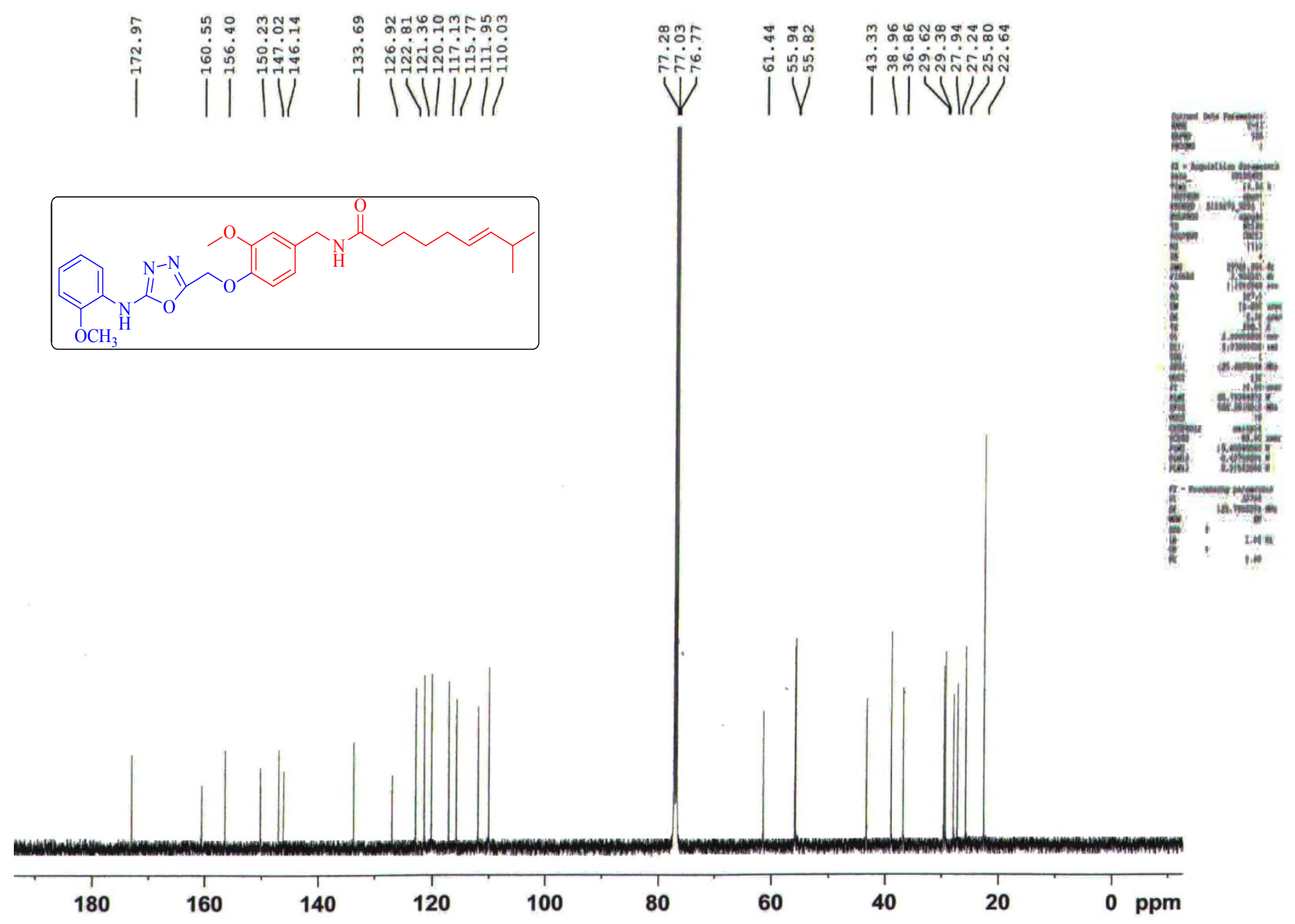

${ }^{13} \mathrm{C}$ NMR of Compound $20 \mathrm{f}$ 

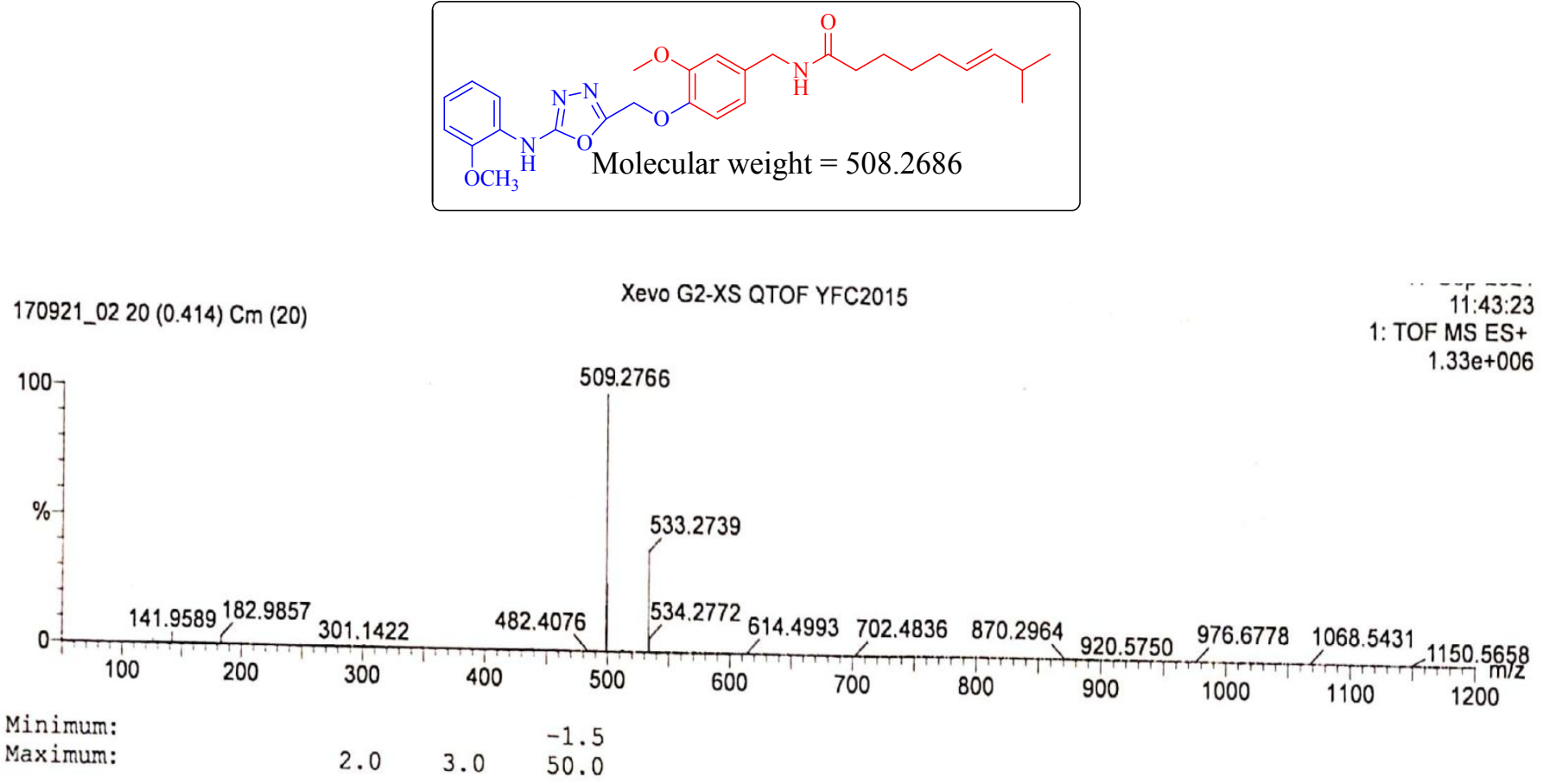

HRMS of compound $20 \mathrm{f}$ 


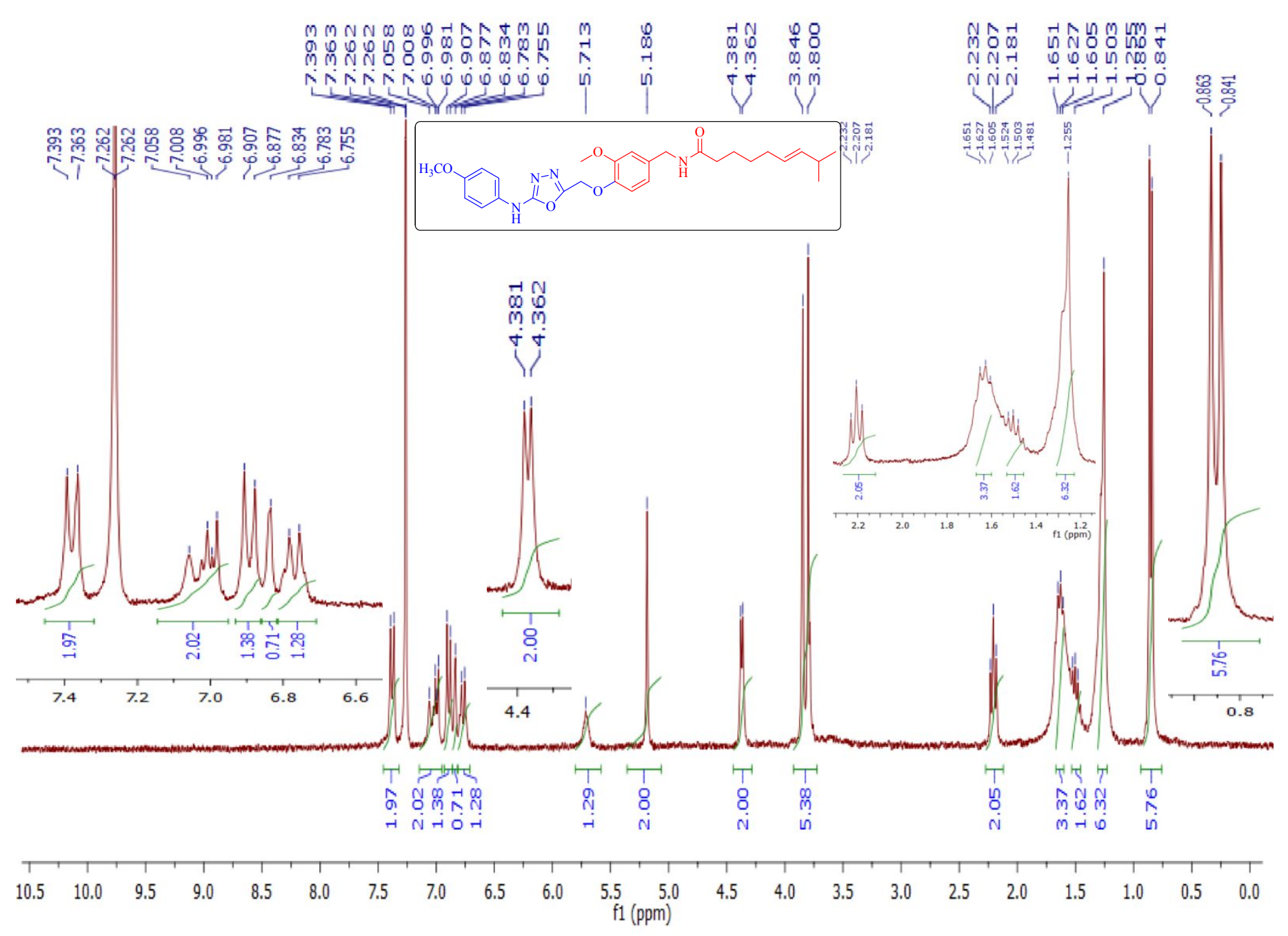

${ }^{1} \mathrm{H}$ NMR of Compound $20 \mathrm{~g}$ 


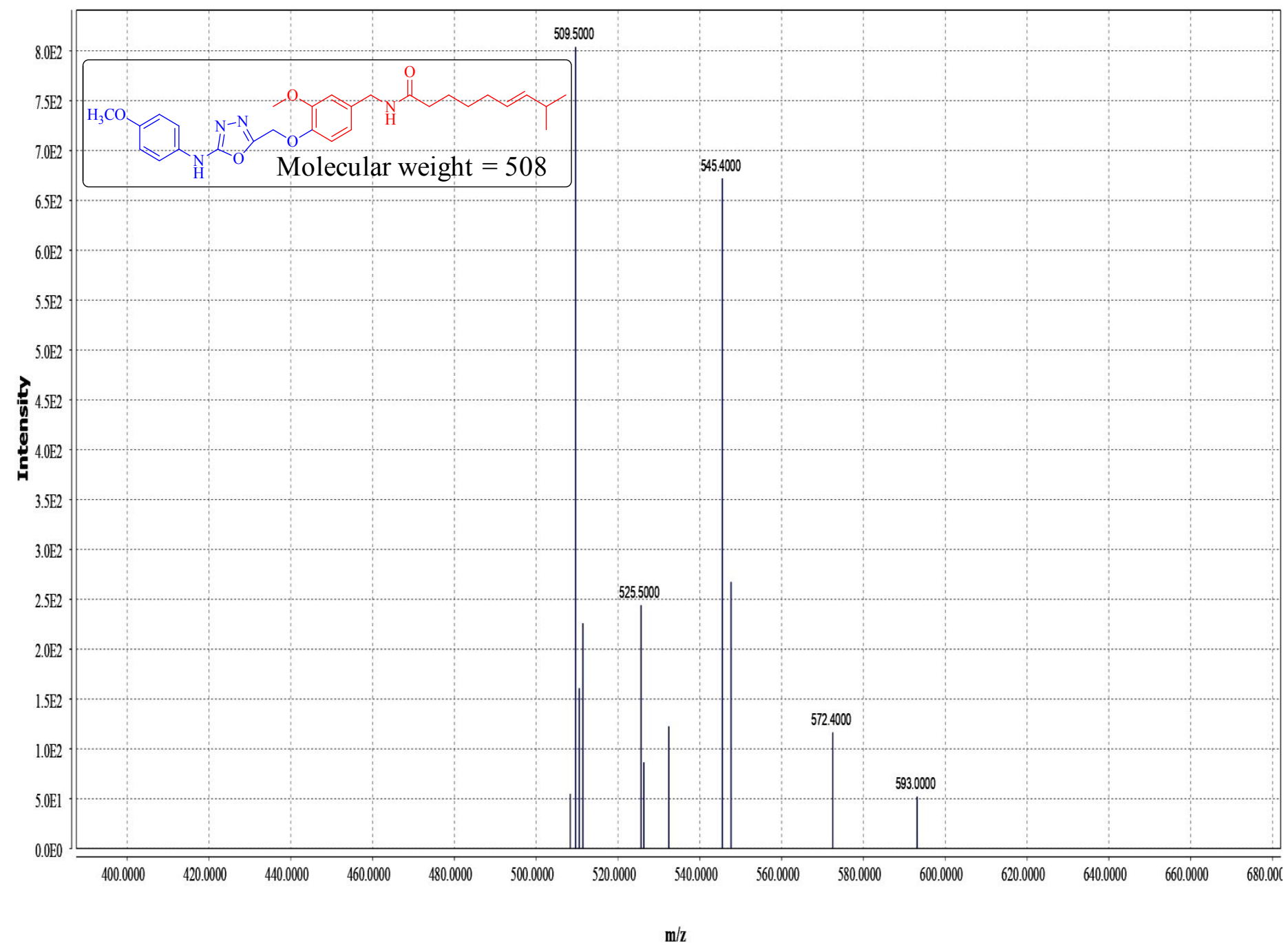

ESI-MS of compound $20 \mathrm{~g}$ 

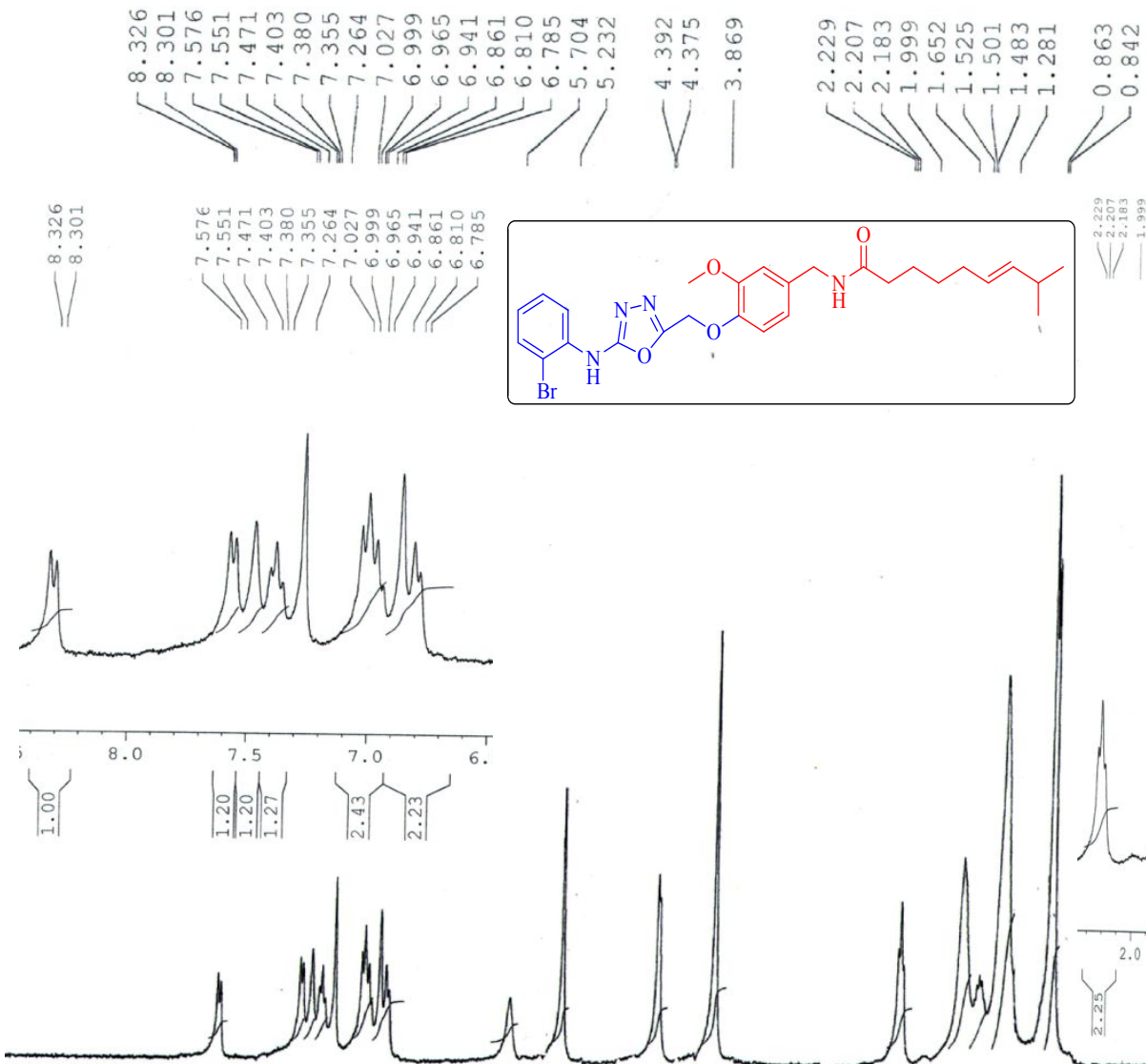

\section{คิ5}
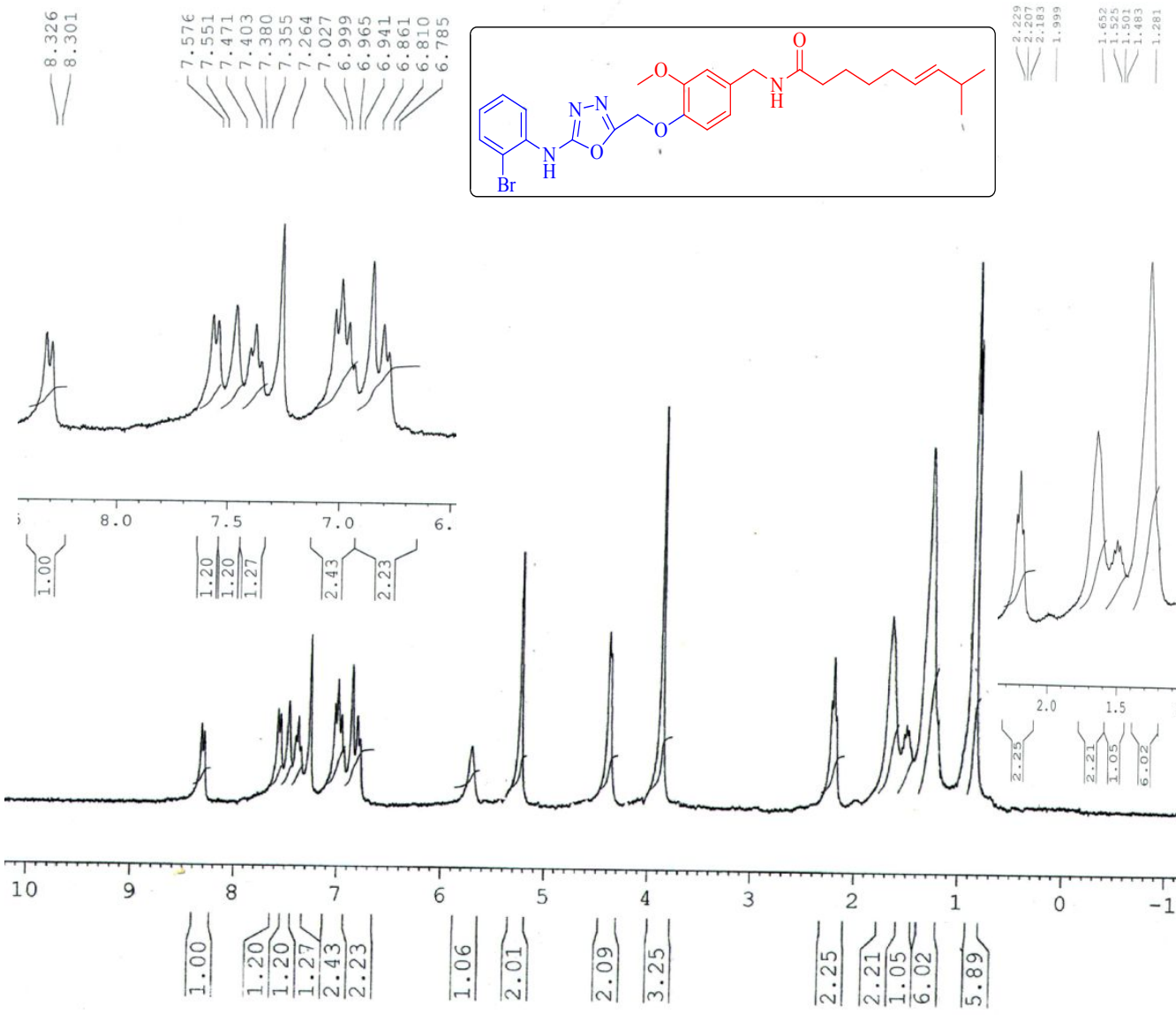

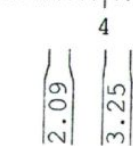

Current Data Parameters

27 March 2018

EXPNO

PROCNO

F2 - Acquisition Parameters

20190408

$\begin{array}{ll}\text { TIme } & 10.18 \\ \text { INSTRUM } & \text { spect }\end{array}$

PROBHD $5 \mathrm{~mm}$ PABBO BB-
PULPROG

$\begin{array}{lr}\text { PULPROG } & \text { zg30 } \\ \text { TD } & 65536\end{array}$

TD

SOLVENT

NS
DS
SWH

$\begin{array}{ll}2 \\ \text { SWH } & 6172.839 \mathrm{~Hz}\end{array}$

IDRES $\quad 0.094190 \mathrm{~Hz}$

$5.3084660 \mathrm{sec}$ 322.5 81.000 usec
6.50 usec $1.00000000 \mathrm{sec}$

TE

TDO

$00 \mathrm{sec}$

$=======0$ CHANNEL $\mathrm{f}]$

NUC1

P1

SFO1

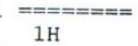

10.70 usec

$-2.00 \mathrm{~dB}$

$300.1318534 \mathrm{MHz}$

F2 - Processing parameters

$\begin{array}{rr}\mathrm{SI} & 32768 \\ \mathrm{SF} & 300.1300033\end{array}$

$300.1300033 \mathrm{MHz}$

EM

$0.30 \mathrm{~Hz}$

i.:bo

\section{${ }^{1} \mathrm{H}$ NMR of Compound 20h}




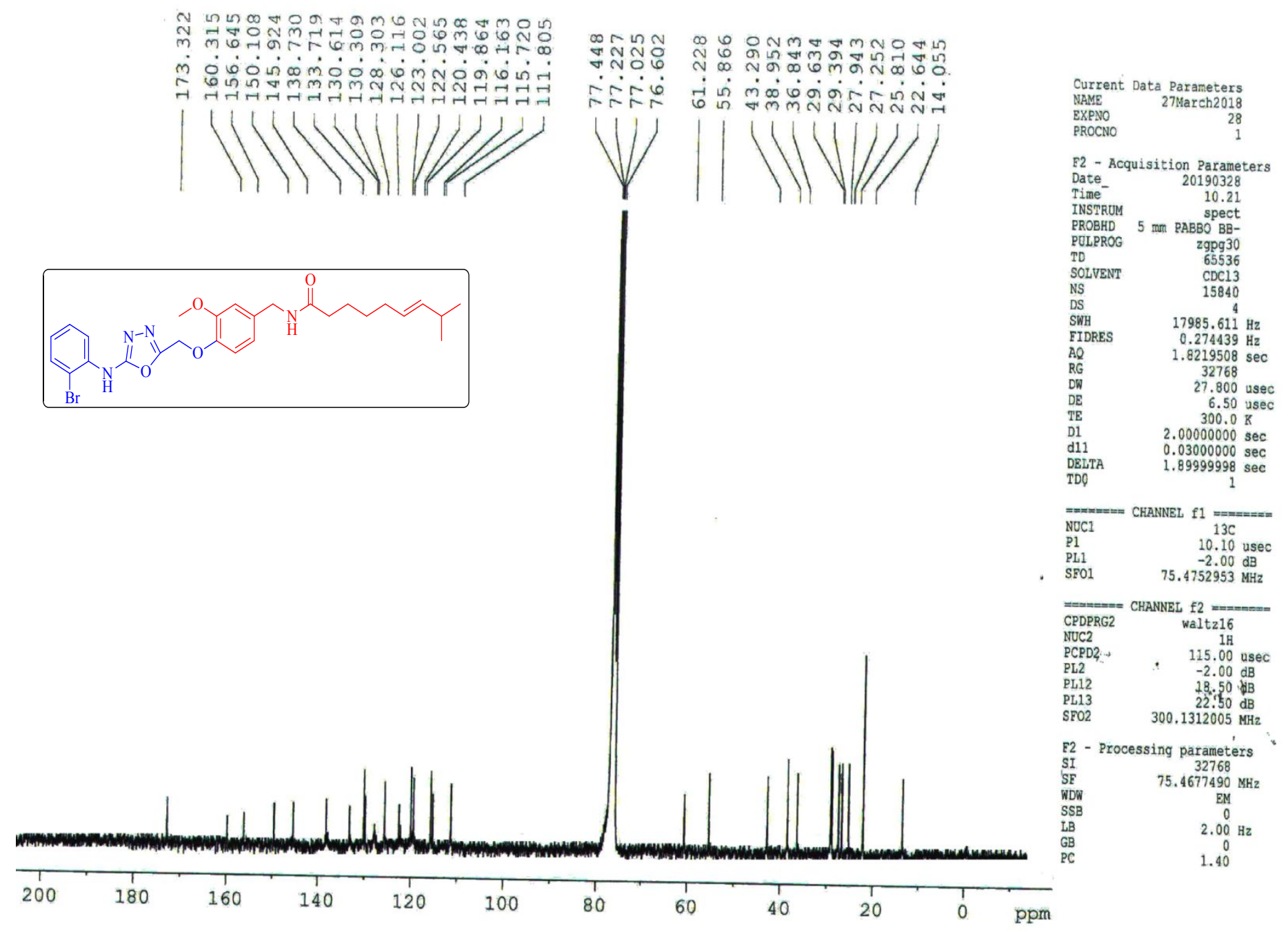

${ }^{13} \mathrm{C}$ NMR of Compound 20h 


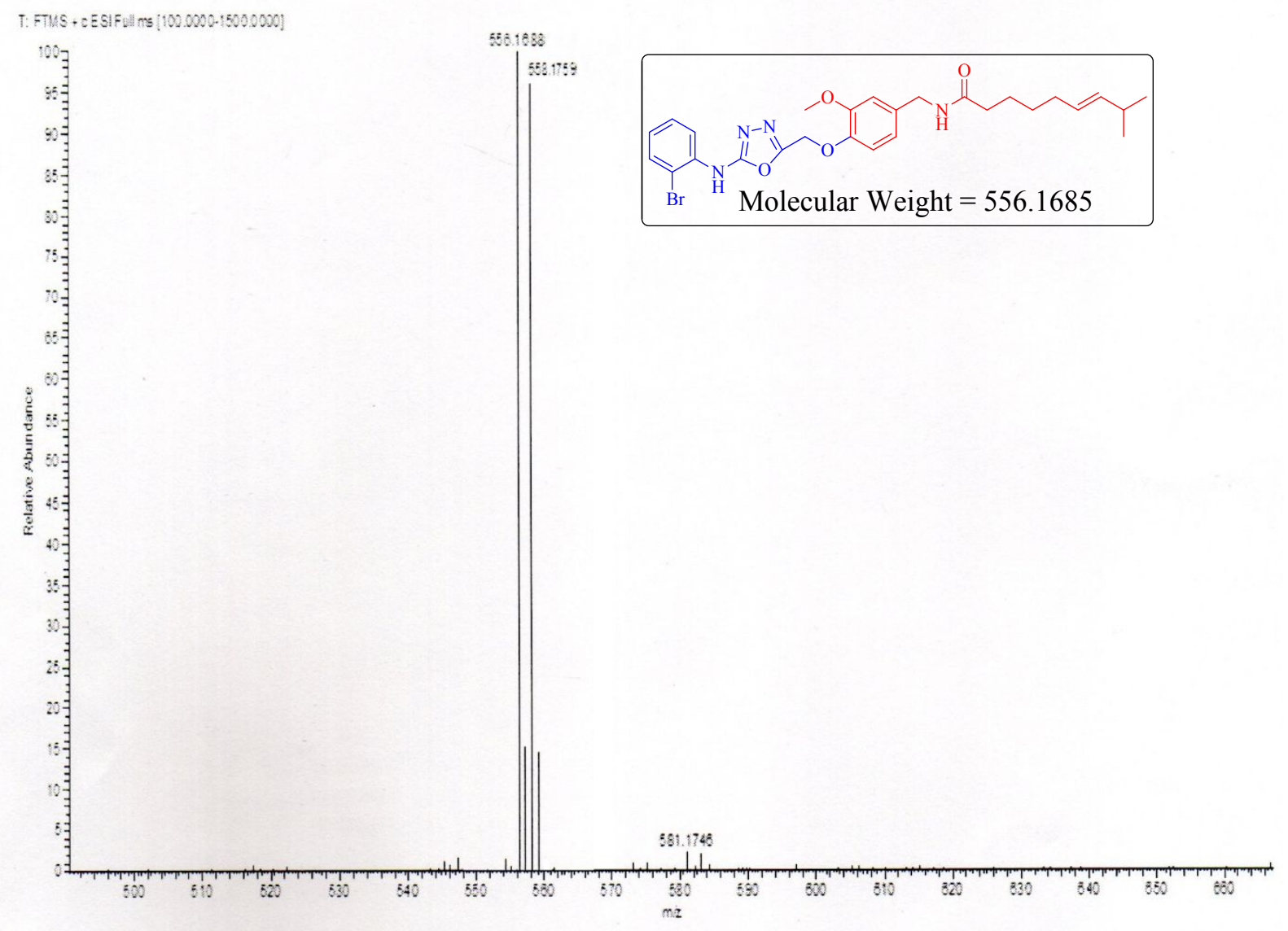

HRMS of compound 20h 


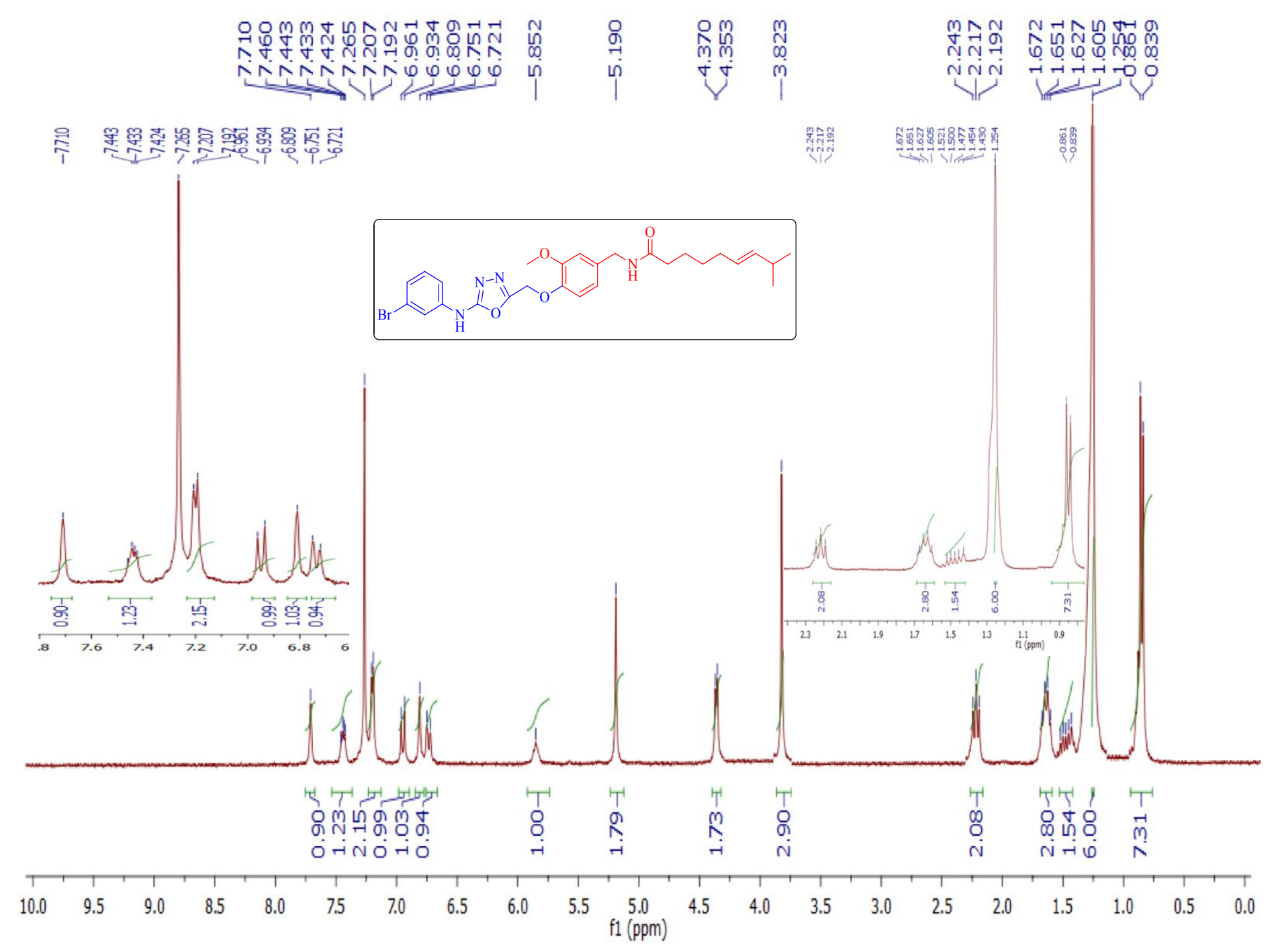

${ }^{1} \mathrm{H}$ NMR of Compound 20i 


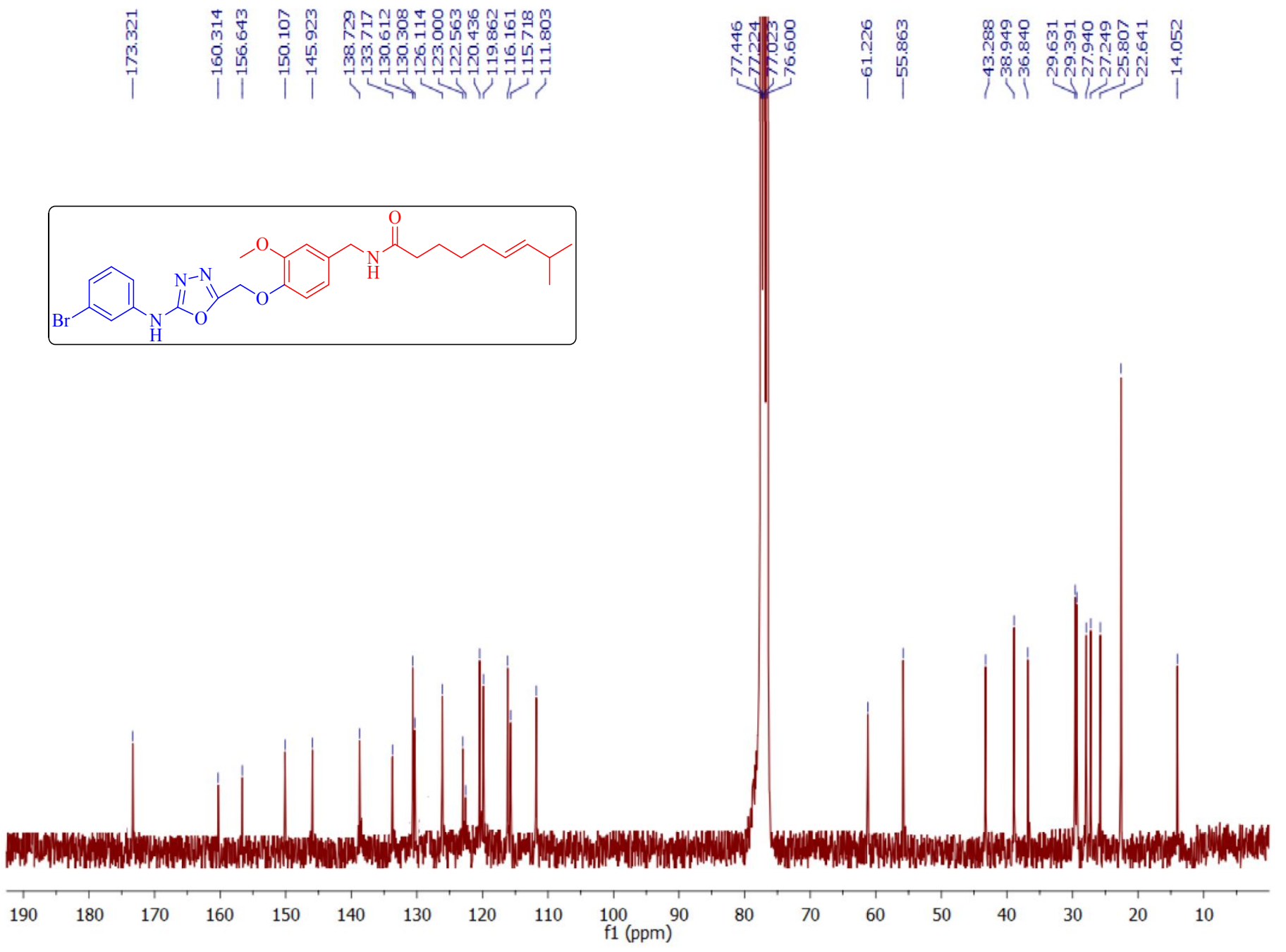

${ }^{13}$ C NMR of Compound 20i 


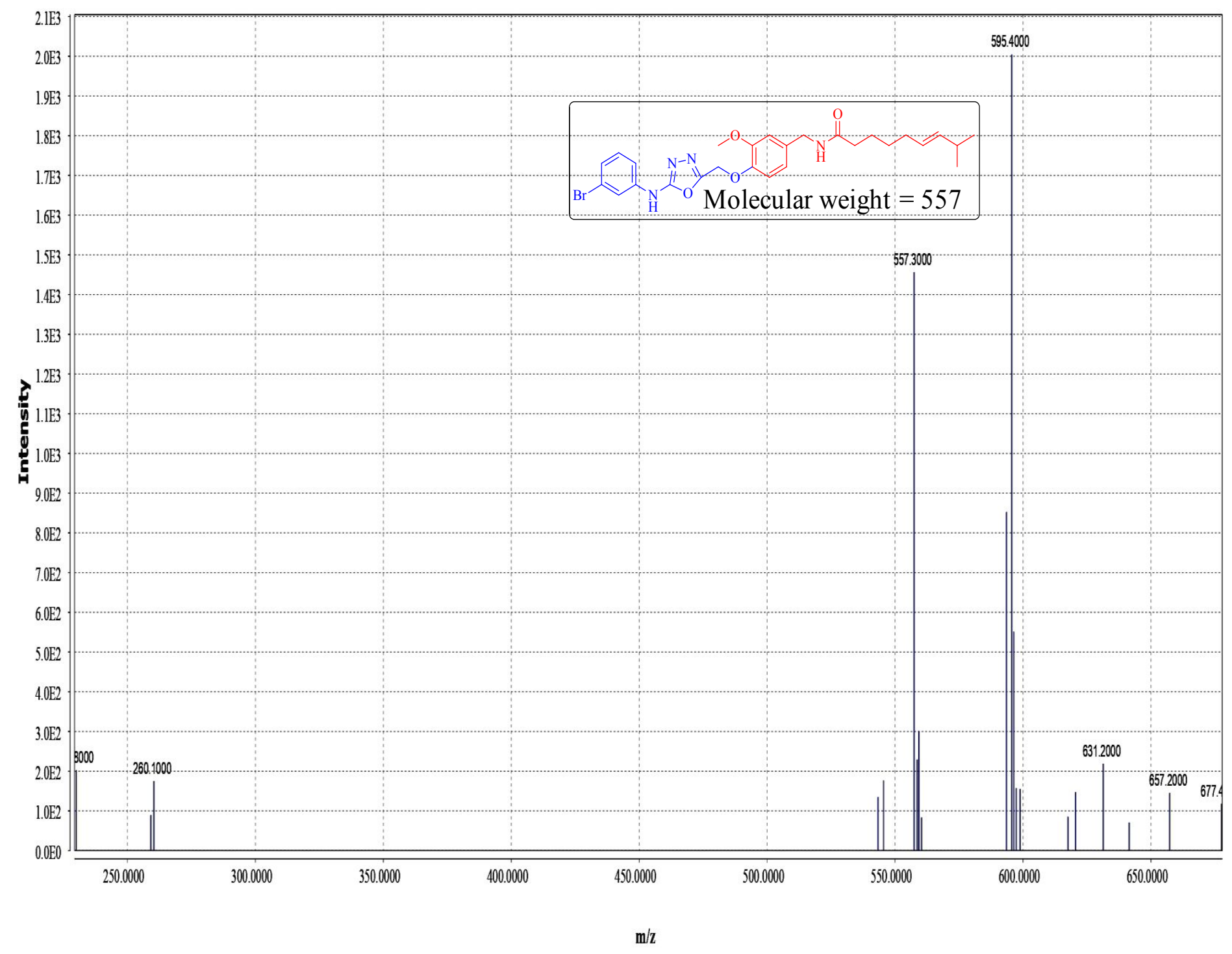

ESI-MS of compound 20i 


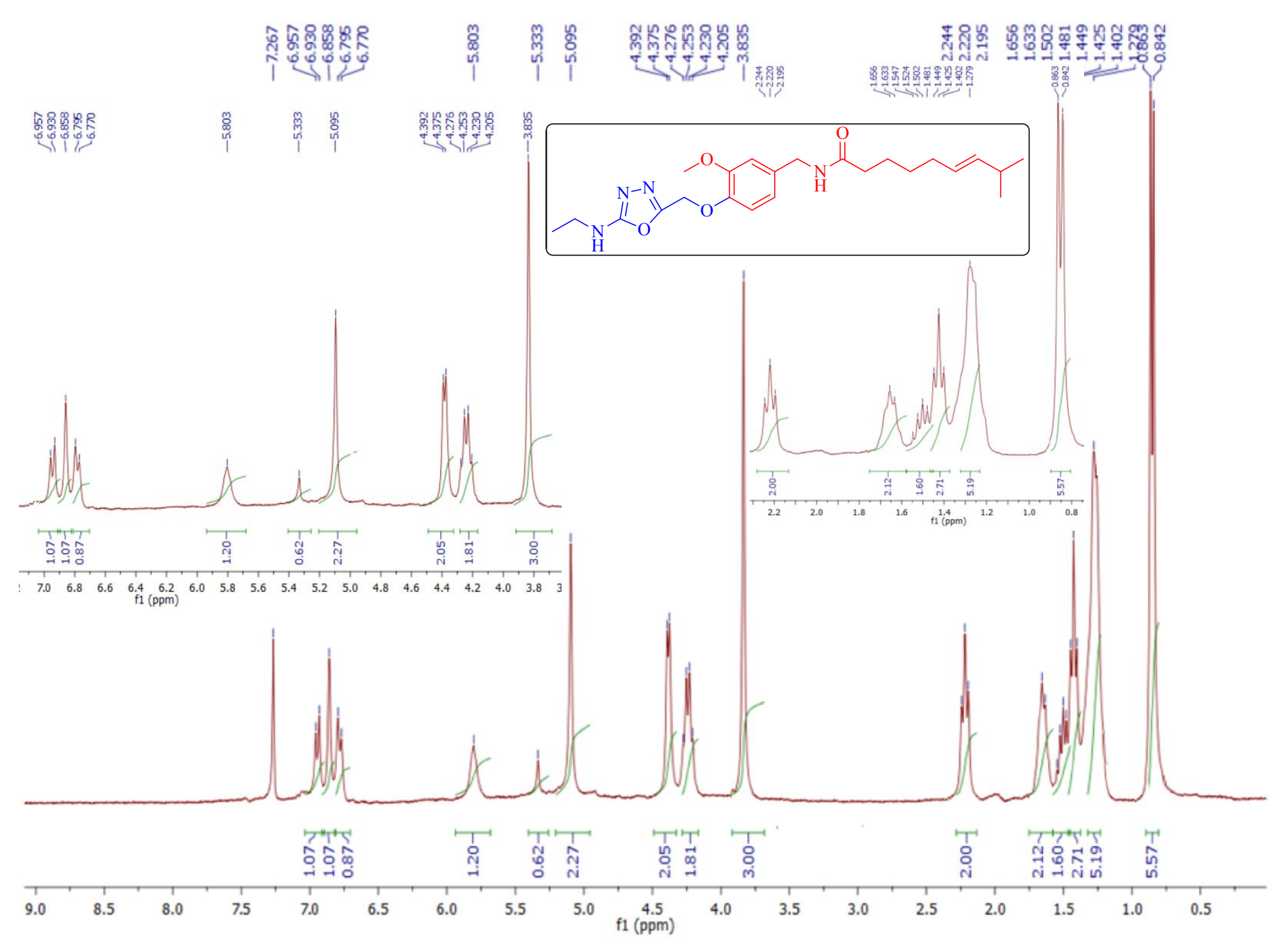

${ }^{13} \mathrm{H}$ NMR of Compound 20j 

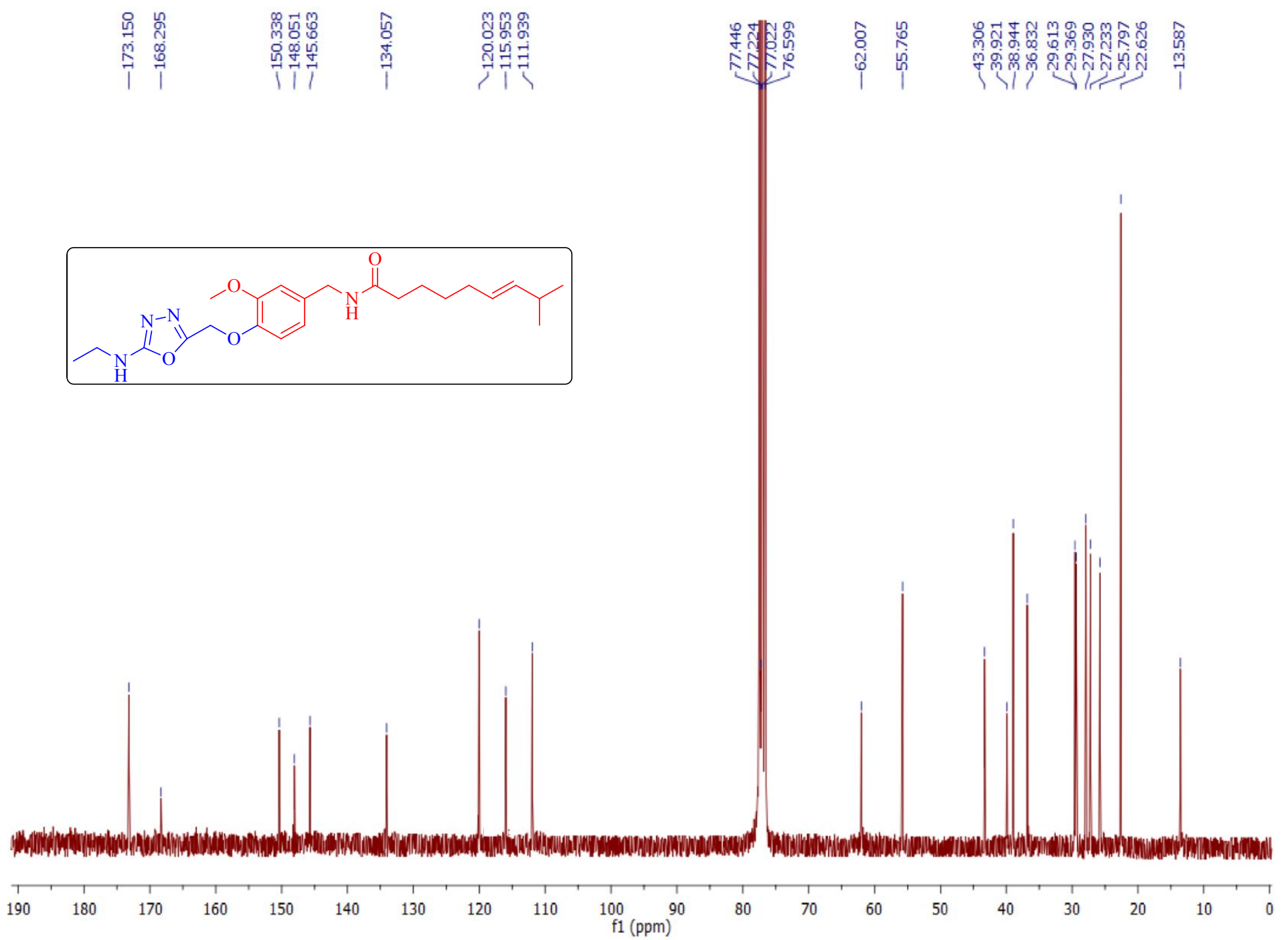

${ }^{13}$ C NMR of Compound 20j 


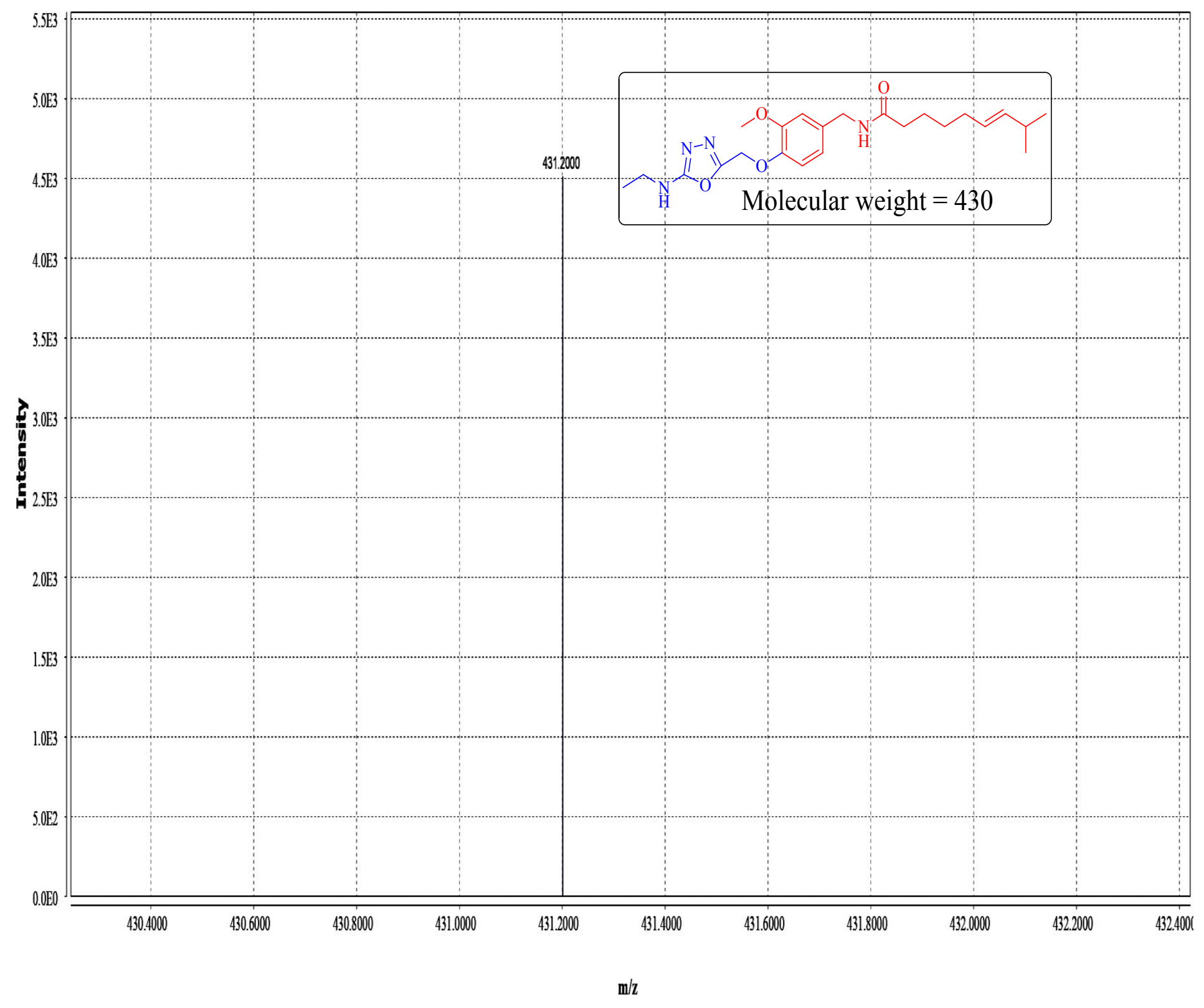

ESI-MS of compound 20j 


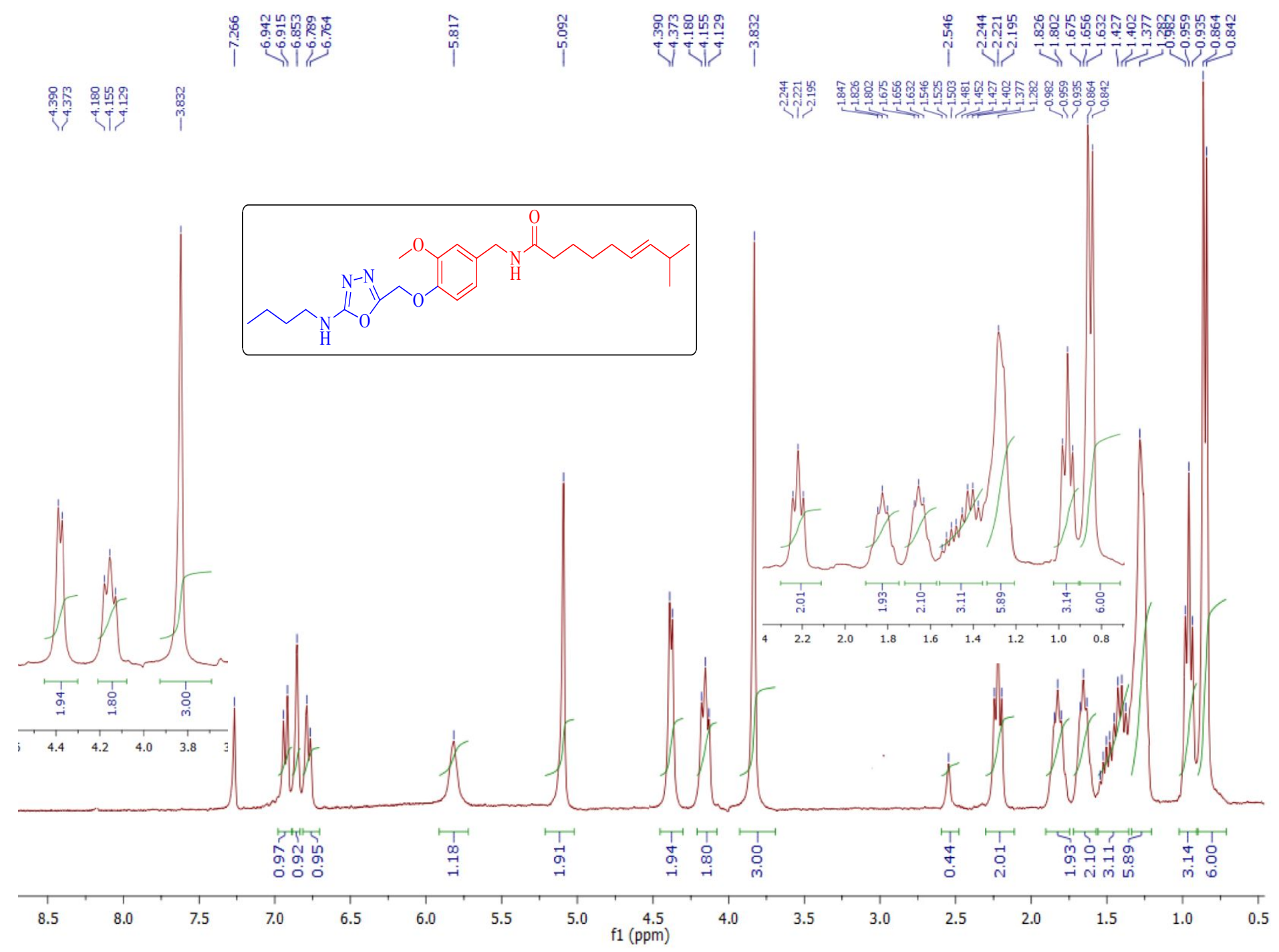

${ }^{1} \mathrm{H}$ NMR of Compound 20k 


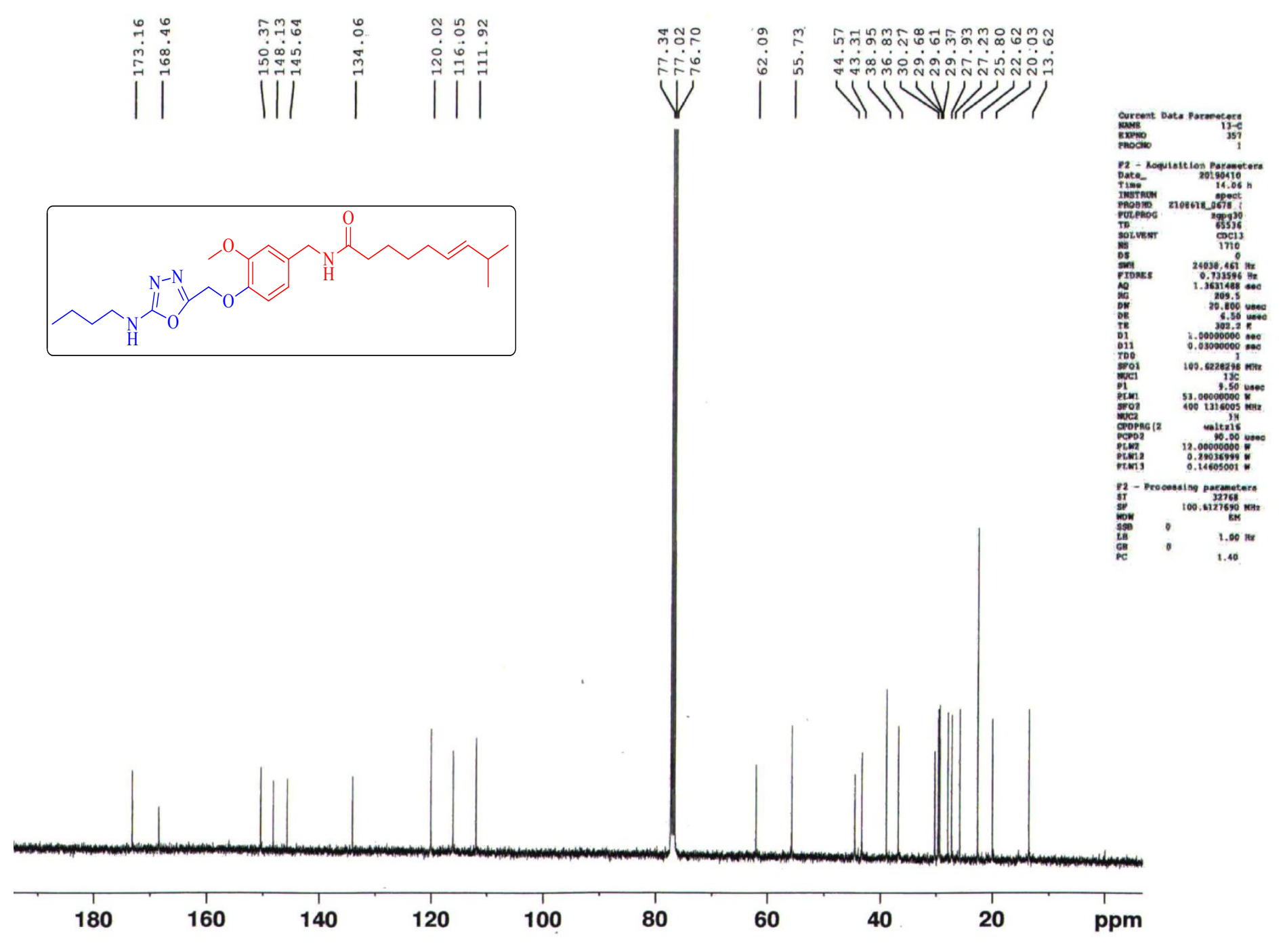

${ }^{13}$ C NMR of Compound 20k 


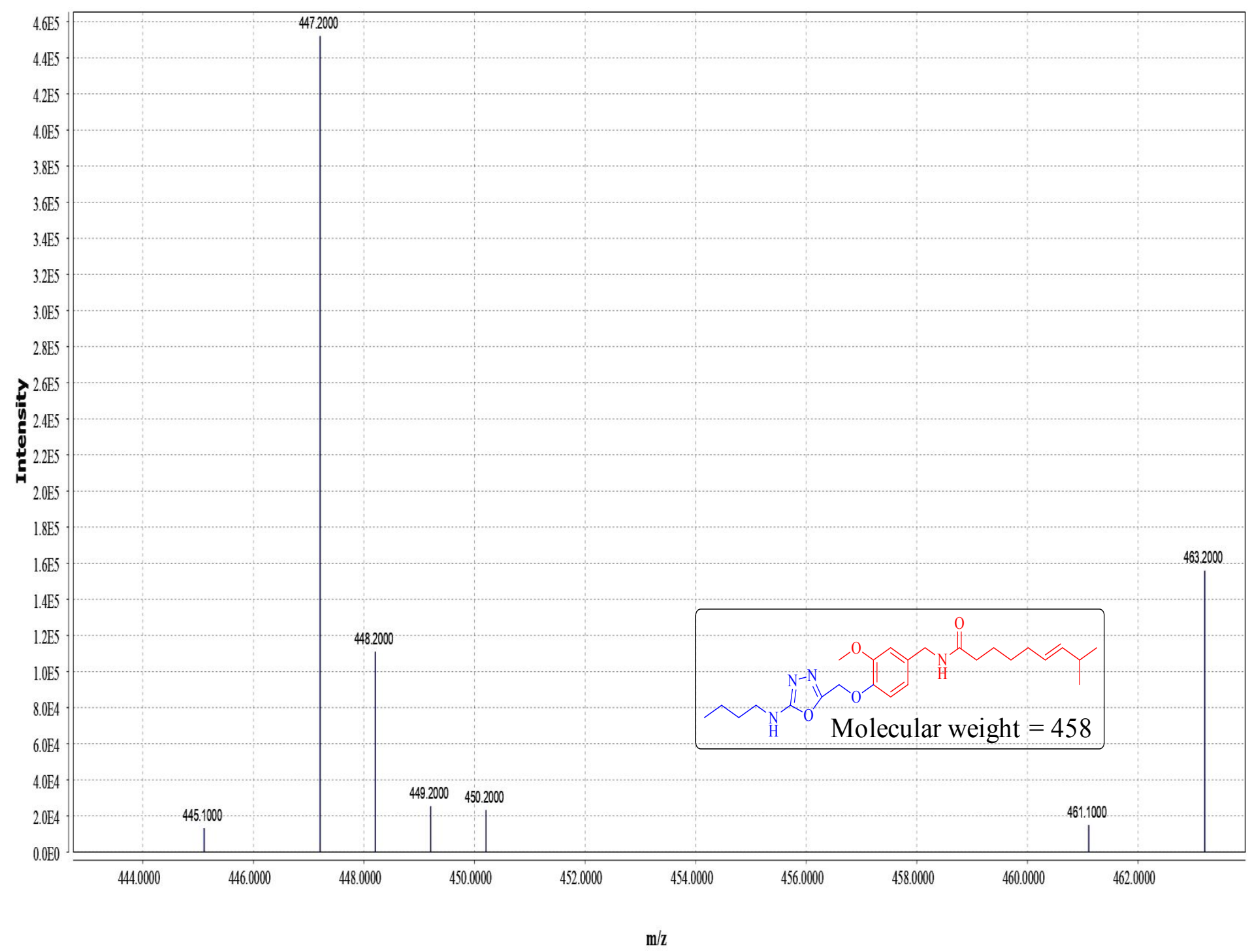

\section{ESI-MS of compound $20 \mathrm{k}$}



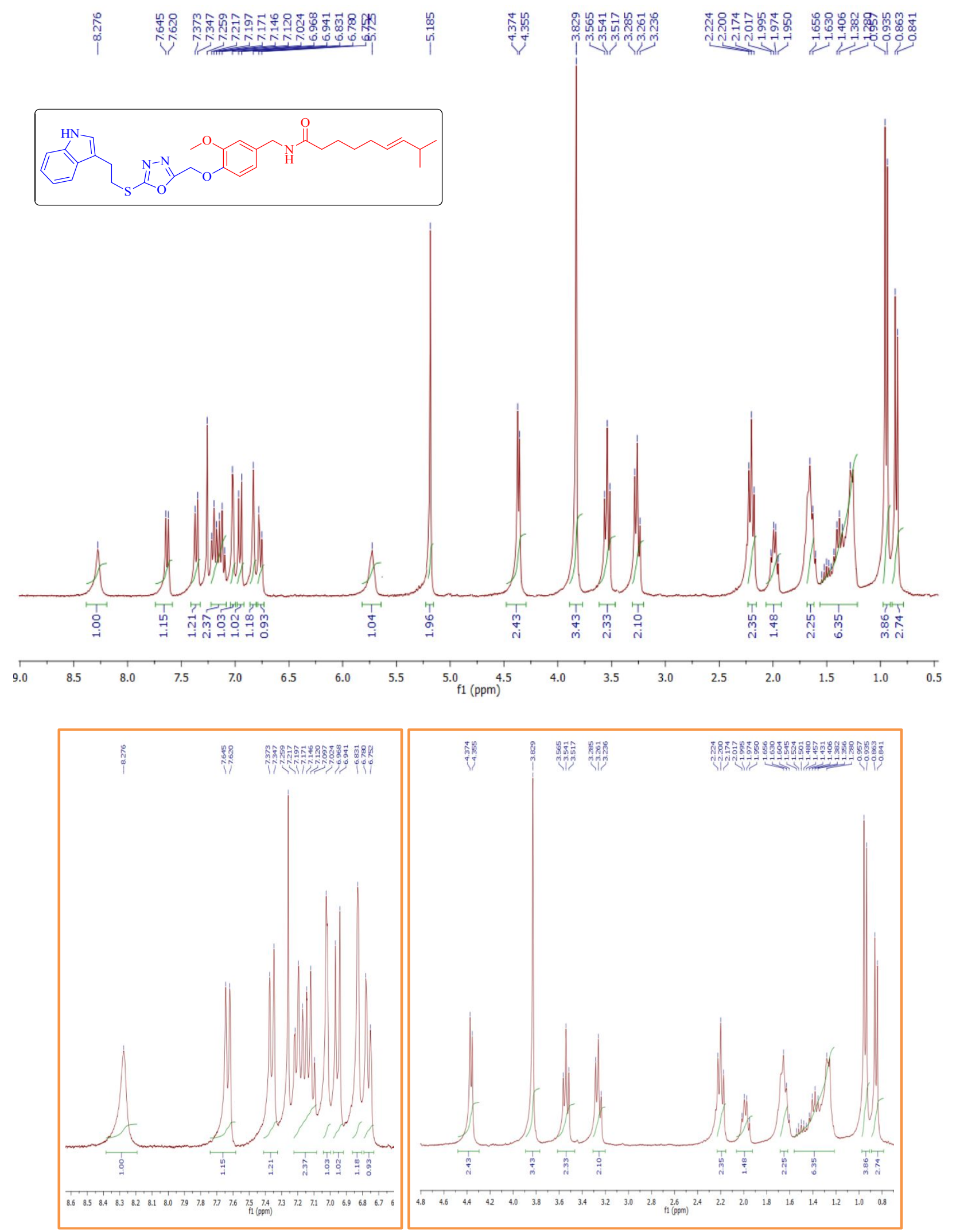

${ }^{1} \mathrm{H}$ NMR of Compound 22a 


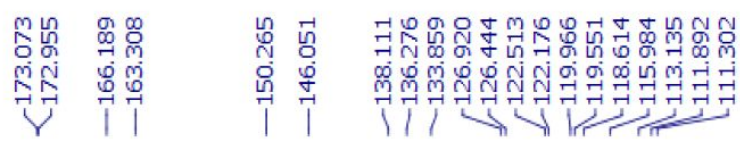
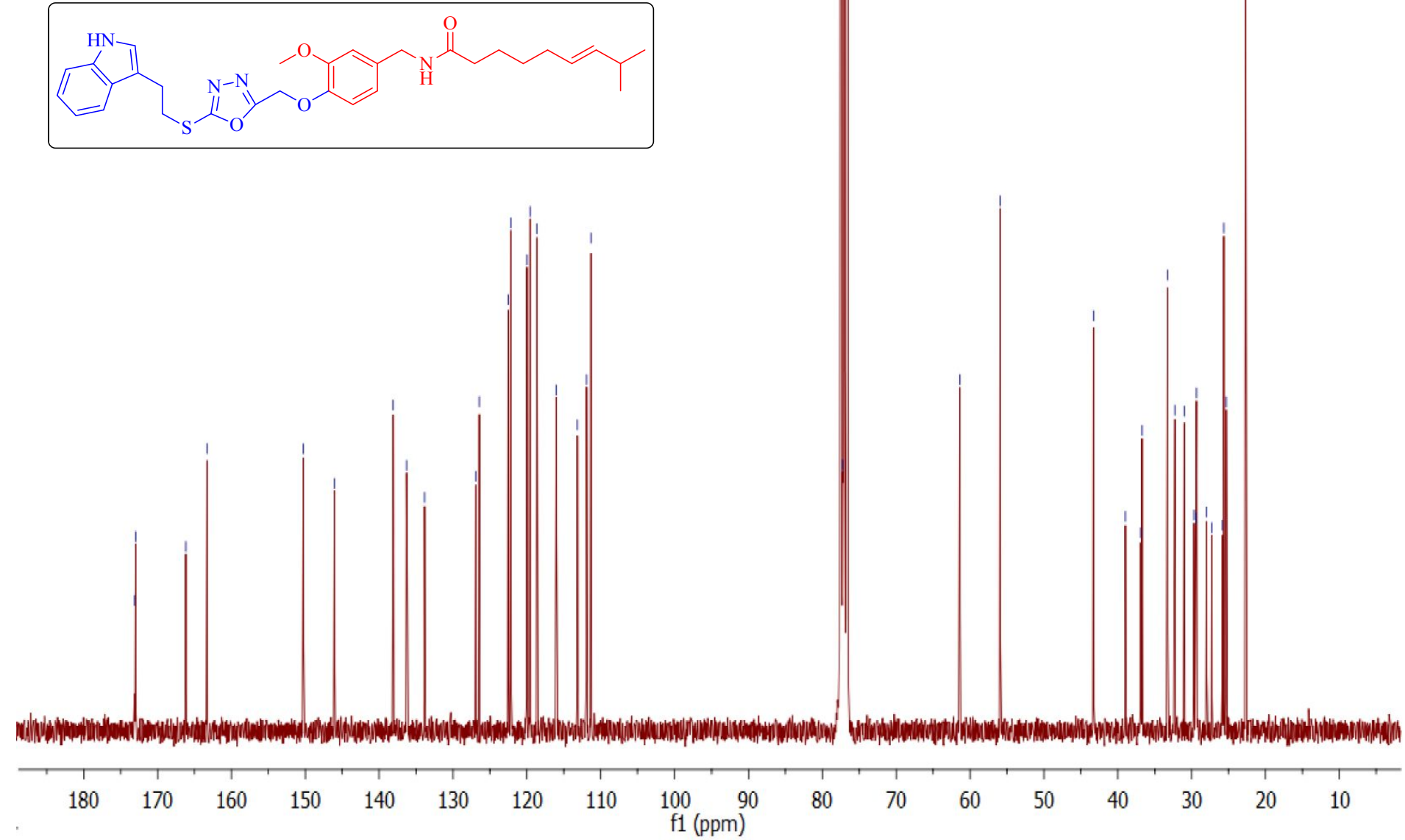

${ }^{13}$ C NMR of Compound 22a 


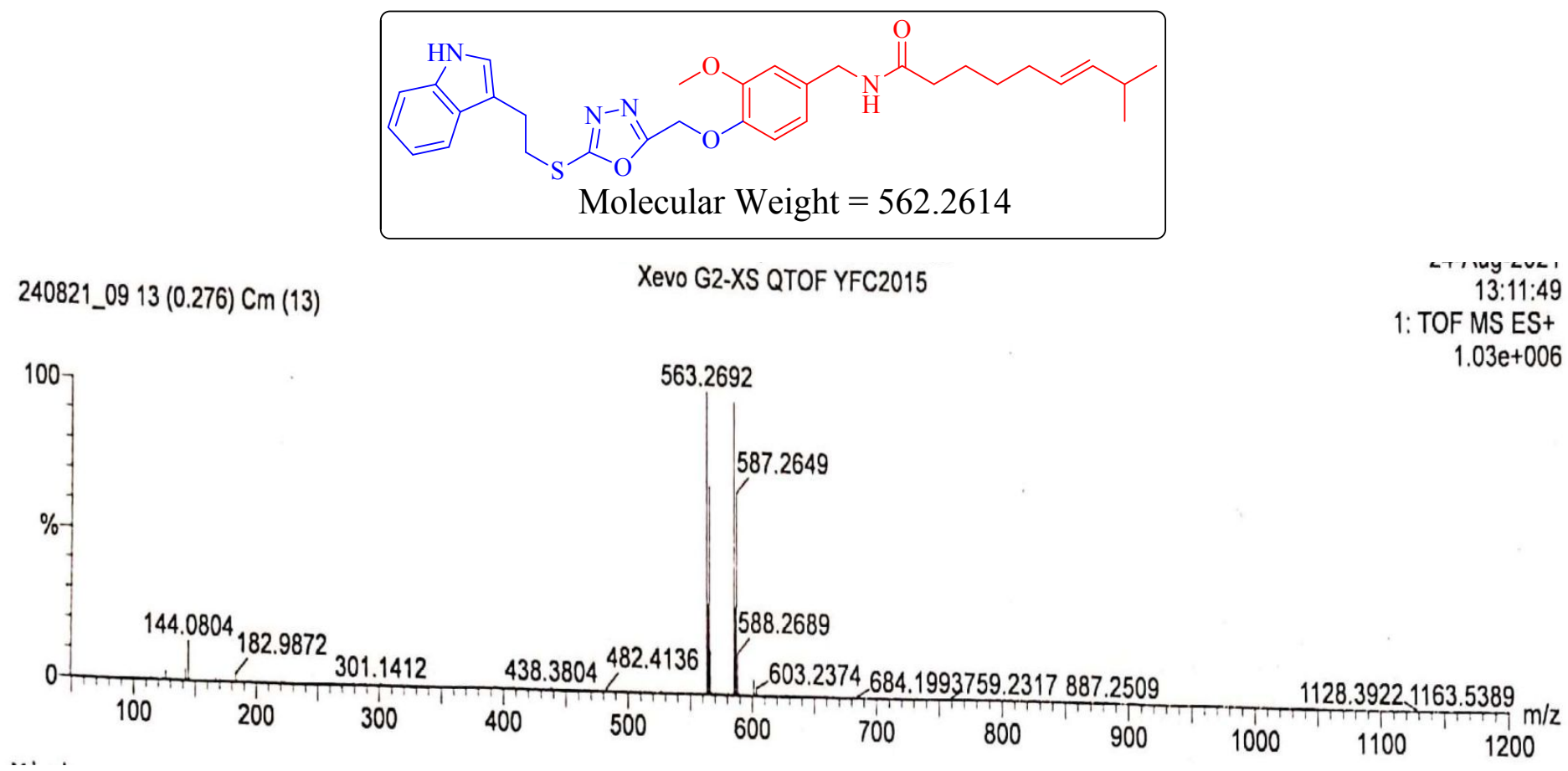

HRMS of compound 22a 


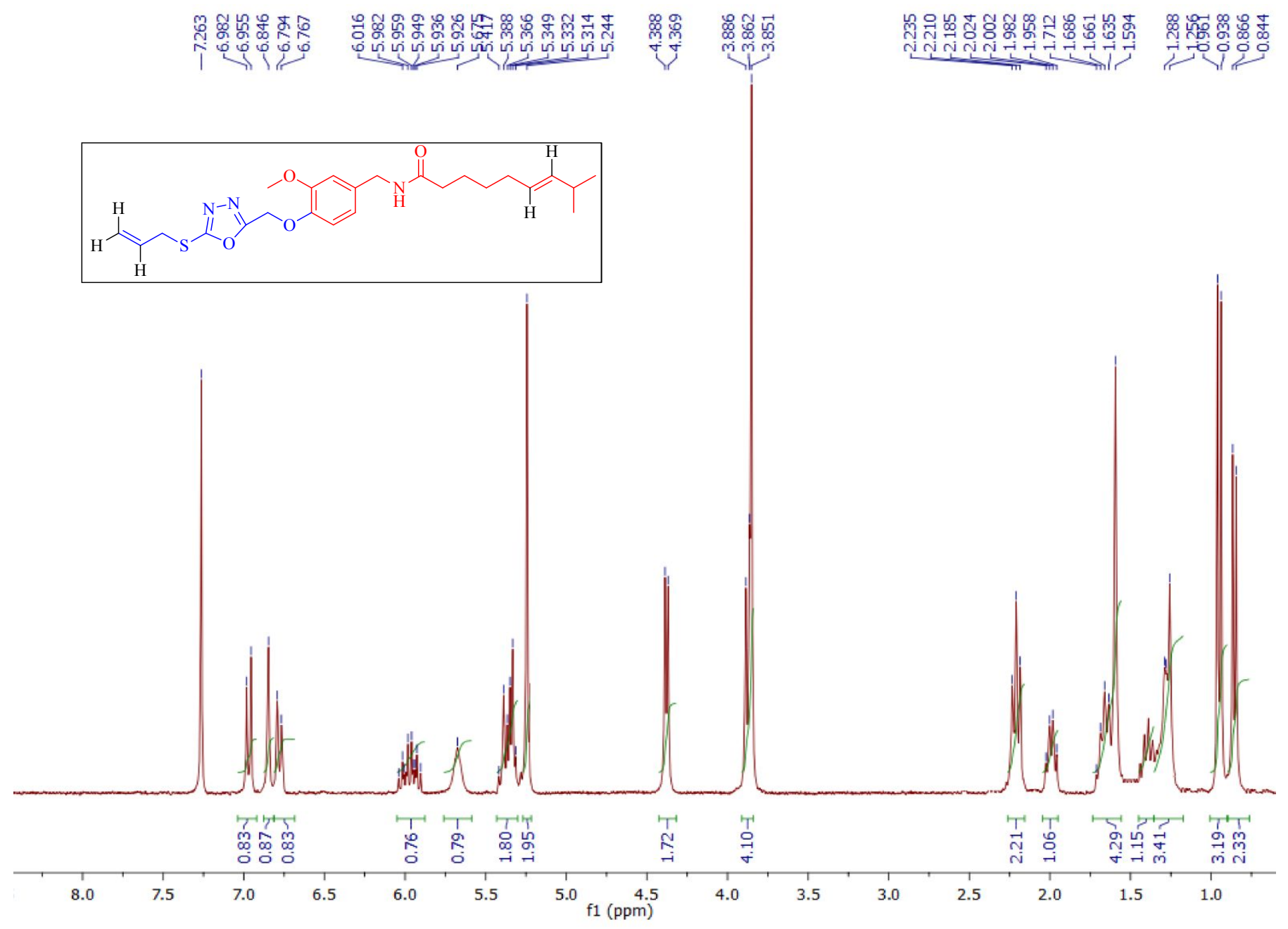

${ }^{1} \mathrm{H}$ NMR of Compound $22 \mathrm{~b}$ 

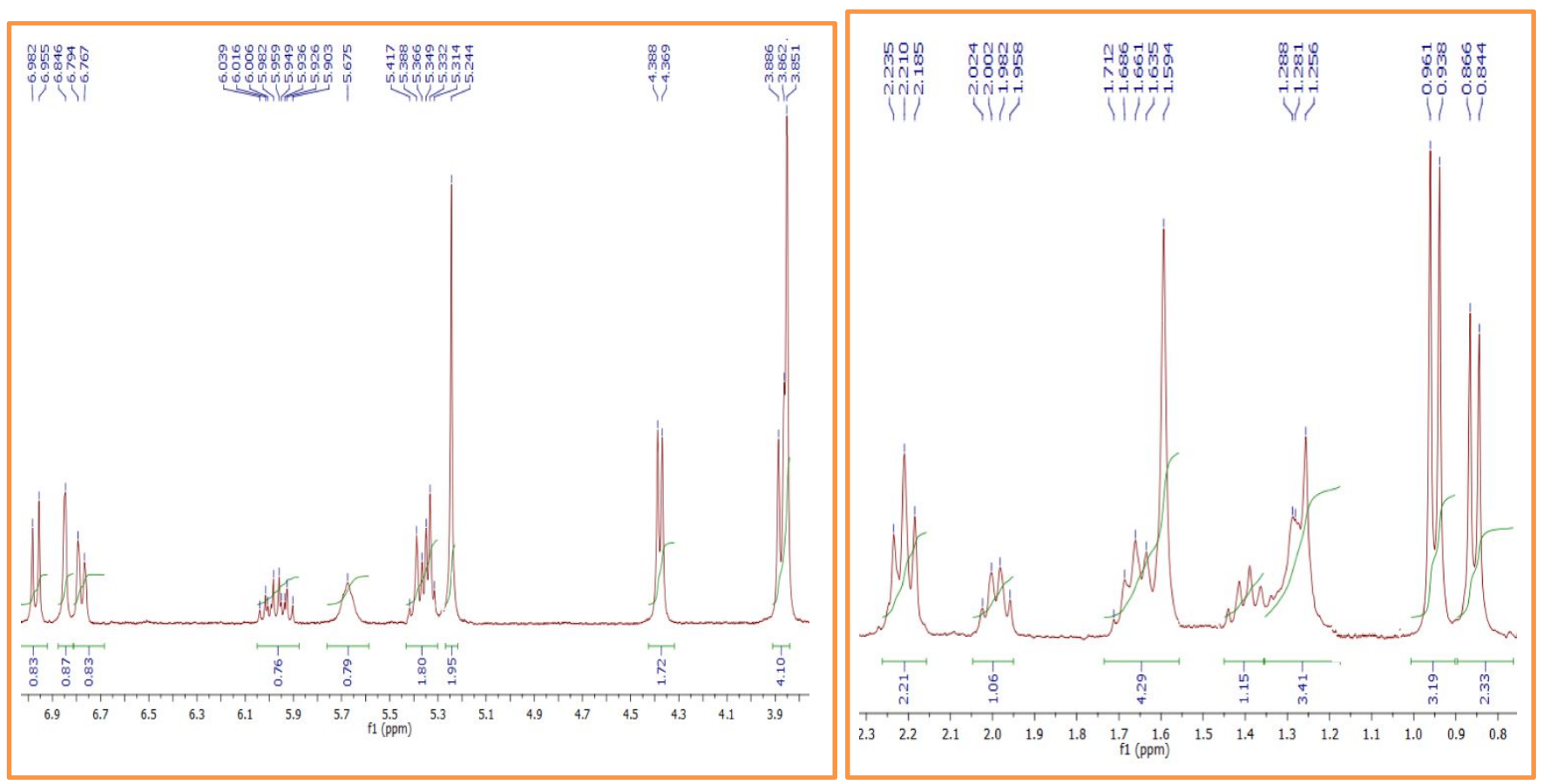

${ }^{1} \mathrm{H}$ NMR of Compound $22 \mathrm{~b}$ 


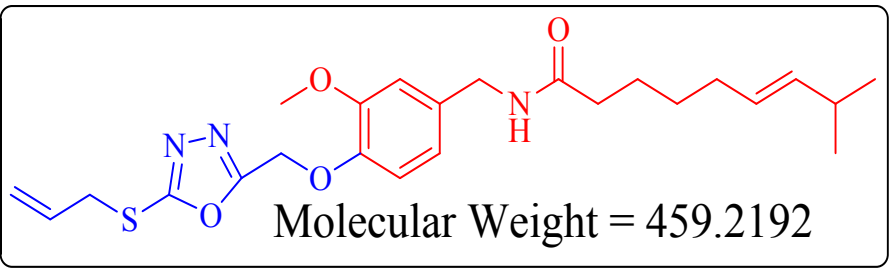

240821_06 14 (0.293) Cm (14)

Xevo G2-XS QTOF YFC2015

¿4-muy-<U<1

13:04:07

1: TOF MS ES+

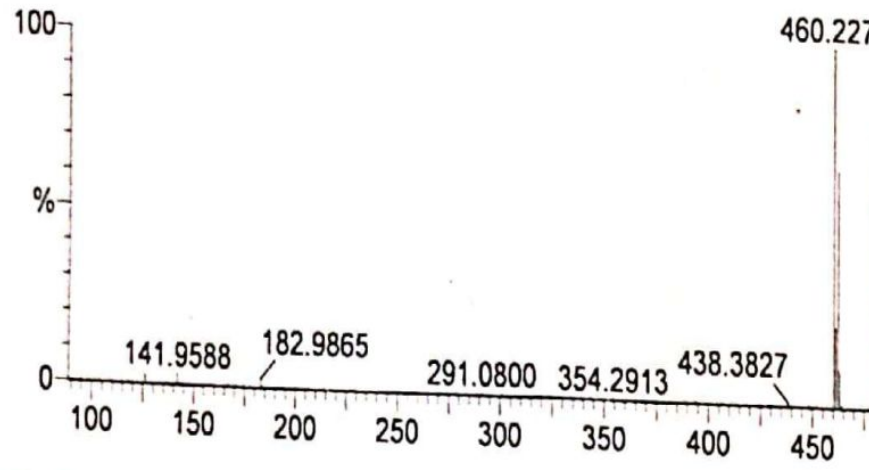

60.2279

$1.17 \mathrm{e}+006$

Minimum:

Maximum:

$\begin{array}{lll}2.0 & 3.0 \quad-1.5 \\ & 50.0\end{array}$

482.2122

484.2241

485.2279

$\int_{500}^{570.4641,614.4852684 .2106 \quad 758.2324} \frac{832.2813}{650} \mathrm{~m} / \mathrm{z}$

\section{HRMS of compound 22b}

